\title{
Body-Centered Cubic Ion Correlation Experiment
}

Compiled by

J. L. Brimhall

April 1977

Prepared for the Energy Research and Development Administration under Contract EY-76-C-06-1830 


\section{NOTICE}

This report was prepared as an account of work sponsored by the United States Government. Neither the United States nor the Energy Research and Development Administration, nor any of their employees, nor any of their contractors, subcontractors, or their employees, makes any warranty, express or implied, or assumes any legal liability or responsibility for the accuracy, completeness or usefulness of any information, apparatus, product or process disclosed, or represents that its use would not infringe privately owned rights.

PACIFIC NORTHWEST LABORATORY

operated by

BATTELLE

for the

ENERGY RESEARCH AND DEVELOPMENT ADMINISTRATION

Under Contract EY-76-C-06-1830

Printed in the United States of America

Availabie from

National Technical Information Service

U.S. Department of Commerce

5285 Port Royal Road

Springrield, Virginia 22151

Price: Printed Copy 5

$\because$ Microfiche $\$ 3.00$

NTIS

Selling Price

$001-025=\$ 4.50$

$026-050 \quad \$ 5.00$

$051-075 \quad \$ 5.50$

$076.100=\$ 6.00$

$101-125-\$ 6.50$

$126-150 \quad 57.00$

$\begin{array}{ll}151.175 & \$ 7.75\end{array}$

$176-200 \quad 58.50$

$\begin{array}{ll}201-225 & \$ 8.75\end{array}$

$226-250+\quad \$ 9.00$

$251-275 \quad \$ 10.00$

$\begin{array}{ll}276-300 & \$ 10.25\end{array}$ 
33679000628810

BODY-CENTERED CUBIC ION CORRELATION

EXPERIMENT

Compiled by

J.L. Brimha11

Apri1 1977

BATTELLE

Pacific Northwest Laboratories

Richland, Washington 99352 
.

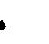

. 


\section{CONTENTS}

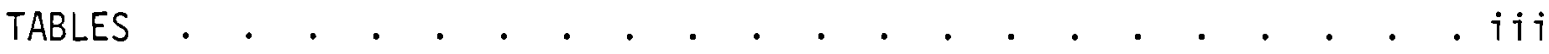

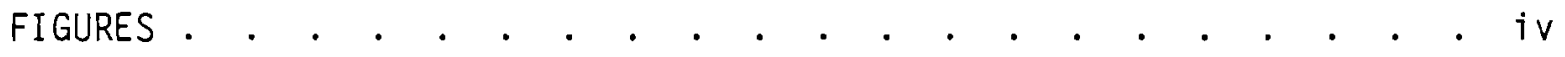

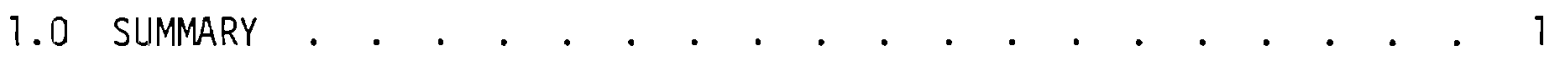

2.0 INTRODUCTION . . . . . . . . . . . . . . . . . . 2

3.0 INTERLABORATORY COMPARATIVE EXPERIMENT USING DIFFERENT IONS . . 3

3.1 THE CORRELATION EXPERIMENT . . . . . . . . . . . . . . 3

3.2 EXPERIMENTAL RESULTS - PART 1 .

4.0 INTERLABORATORY COMPARISON OF A COMMON MICROGRAPH . . . . . 12

5.0 INTERLABORATORY COMPARISON OF MEASUREMENTS ON A "ROUND ROBIN" TEM FOIL . . . . . . . . . . . . . . . . . . . . . . . 14 REFERENCES . . . . . . . . . . . . . . . . . . . 16

APPENDIX A: EXPERIMENTAL DETAILS OF PART 1 OF BODY-CENTERED CUBIC ION CORRELATION PROGRAM . . . . . . . . . . . A-1

APPENDIX B: DATA ACQUISITION FROM PART 2 - ANALYSIS OF A COMMON MICROGRAPH IN THE BODY-CENTERED CUBIC ION CORRELATION PROGRAM . . . . . . . . . . . . . . . . B-1

APPENDIX C: INTERLABORATORY COMPARISON OF ROUND ROBIN TEM FOIL OF THE BODY-CENTERED CUBIC ION CORRELATION PROGRAM . . C-1 


\section{$\underline{\text { TABLES }}$}

1 Experimental Test Matrix. . . . . . . . . . . . 3

2 Vendors Chemical Analysis of Molybdenum Ingot. . . . . . . 6

3 Chemical Analysis After Vacuum Anneal . . . . . . . . 6

4 Microstructural Data for $700^{\circ} \mathrm{C}$. . . . . . . . . . . 8

5 Microstructural Data for $800^{\circ} \mathrm{C}$. . . . . . . . . . . 8

6 Microstructural Data for $900^{\circ} \mathrm{C}$. . . . . . . . . 8

7 Microstructural Data for $1000^{\circ} \mathrm{C}$. . . . . . . . . . . 8

8 Void Parameters from Measurements On a Common Micrograph . . . 13

9 Microstructural Parameters from Measurements of "Round Robin" 14

A.2-1 Void Microstructures in Ion Bombarded Molybdenum. . . . . . A-5

A.3-1 Pre-Treatment of BCC Ion Correlation Experiment Molybdenum
Specimens. . . . . . . . . . . . . . A-6

A.3-2 Irradiation Parameters . . . . . . . . . . . . . . A-10

A.3-3 Damage Microstructure in the Irradiated Specimens . . . . . A-12

B.5-1 Void Data from the BCC-ICE "Standard" Photomicrograph . . . B-il

C.1-1 Data for Mo "Round Robin" Tem Foil . . . . . . . . . . C C-1

C.7-1 Void Parameters Obtained from NRL Round Robin Sample. . . . C-16 


\section{FIGURES}

1 Micrograph Showing Grain Structure of Molybdenum After $1600^{\circ} \mathrm{C}$ Anneal 130X. . . . . . . . . . . . . . . . . 7

2 Transmission Electron Micrograph of Molybdenum Shown in Figure 1,32,000X... . . . . . . . . . . . . . 7

3 Swelling Rate in Molybdenum Bombarded by Different Ions at $900^{\circ} \mathrm{C}$. . . . . . . . . . . . . 9

4 Temperature Dependence of Swelling in Molybdenum Bombarded by Different Ions... . . . . . . . . . . . . . 9

5 "Common Micrograph" Measured by All Sites Participating in Part B of BCC-ICE................ . . 13

A.3-1 Detail of the Sample Holder Assembly. . . . . . . . . A-7

A.3-2 Damage Curve for $17 \mathrm{MeV} \mathrm{Cu}$ on Molybdenum Calculated Using the E-DEP-1 Code of Ref. (2). Also indicated on the figure are the TEM analysis zone and the location of the deposited copper ions.

A.3-3 Void Size Distributions in Five of the Six Irradiated UW Molybdenum Specimens. . . . . . . . . . . . A-14

B.1-1 Histogram of Void Size Distribution Measured on the "Common Micrograph". . . . . . . . . . . . . . B-3

B.3-1 Histogram of Void Size Distribution and Cumulative Distribution Measured on the "Common Micrograph" . . . . . . .

B.4-1 Histogram of Void Size Distributions Measured on the "Common Micrograph" . . . . . . . . . . . B-9

B.7-1 Histogram and Cumulative Frequency-Distribution Curve for Void Sizes Measured on "Common Micrograph". . . . . . B-14

B.8-1 Histogram of Void Size Distribution Measured on the "Common Micrograph" . . . . . . . . . . . . . B-16

C.1-1 Histogram of Void Size Distribution Measured on the TEM "Round Robin" Specimen . . . . . . . . . . . . $\mathrm{C}-2$

C.3-1 Histogram of Distribution of the Measurements of Foil Thickness on the TEM "Round Robin" Specimen... . . . . . C-5

C.3-2 Histogram of the Void Size Distribution Measured on the TEM "Round Robin" Specimen . . . . . . . . . . . . C-7

C.7-1 Histogram and Cumulative Frequency-Distribution Curve of the Void Data Obtained from NRL "Round Robin" Mo Specimen . . . C-15 


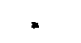

-

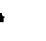




\subsection{SUMMARY}

This report includes the results of an interlaboratory correlation experiment involving eight laboratory sites studying the ion irradiation of molybdenum. The program was sponsed by the Materials and Radiation Effects Branch ( $M$ and RE) of the Division of Magnetic Fusion Energy (DMFE) of the Energy Research and Development Administration (ERDA). The program was titled Body-Centered Cubic Ion Correlation Program (BCC-ICE) and was comprised of tinree parts.

The first part compared the radiation damage produced in a reference specimen of molybdenum by ions of different masses and different energies. The results showed that the swelling rate and temperature dependence of swelling due to different heavy ions can be compared on a gross dpa (atomic displacements per atom) basis. The swelling rate due to protons was significantly higher than heavy ions and gross dpa is not a good basis for comparison. Other factors such as differences in dose rate and environmental vacuum may have some effect and these remain to be explored.

The second part of the program compared measurements on a common micrograph supplied to all participants in the program. The results from all the sites agreed very we11. The value of standard deviation in the measurement of void volume fraction corresponded to $10 \%$ of the average measured value and the spread between highest and lowest reported value was $35 \%$.

The third part of the program compared the microstructural characteristics of a transmission electron microscope (TEM) specimen that was passed from site to site ("round robin"). The results of this part of the experiment showed greater variations from the different participants than the results from the common micrograph. One of the principal sources of discrepancy was the measurement of the foil thickness which was necessary for computation of void number density. The standard deviation in the measurements of void volume fraction (swelling) corresponded to $20 \%$ of the measured average value. The spread between the highest and lowest value was $70 \%$. This latter value gives an idea of the conceivable differences in results due to experimental techniques between two experiments. 


\subsection{INTRODUCTION}

Ion bombardment is a rapid, simple, and inexpensive way to simulate damage in metals. A variety of ions, ranging from electrons to tantalum ions, are used. $(1,2)$ Although results are generally compared on a calculated dpa basis (dpa = atom displacements per atom), there is little experimental evidence to support this procedure. Correlation factors are needed to compare, for example, the damage due to nickel ions to that due to nitrogen ions.

There are correlation programs underway in the iron and nickel base alloy system, mostly in systems with fcc lattice structure. However, the refractory metals that show promise for controlled thermonuclear reactor (CTR) application have bcc lattice structure and respond differently to irradiation than do fcc metals.

DMFE/M and RE requested that an ion correlation program be instituted to explore these problems. Selected participants in the Body-Centered Cubic Ion Correlation Experiment (BCC-ICE) met in October 1974 to plan an experimental program. The following sites and personnel participated in this.
Argonne National Laboratory
A. Taylor
Atomics International
D. W. Keefer
Mass. Inst. of Technology
A. L. Bement
Naval Research Laboratory
F. A. Smidt
Oak Ridge National Laboratory
F. W. Wiffen/J. Bently
Pacific Northwest Laboratory
J. L. Brimhall/E. R. Bradley
University of Cincinnati
J. Moteff
University of Wisconsin
G. L. Kulcinski

The experimental program was comprised of three parts.

1) Interlaboratory comparison of the change in microstructure produced in identical reference material by different ions of different energies.

2) Interlaboratory comparison of measurements on a common micrograph.

3) Interlaboratory comparison of measurements on a single transmission electron microscope (TEM) specimen transferred from site to site.

This report summarized the results and conclusions of these experiments. 


\subsection{INTERLABORATORY COMPARATIVE EXPERIMENT USING DIFFERENT IONS}

The correlation experiment as initially proposed is outlined below, followed by a discussion of the results. Because of experimental difficulties, not all conditions could be met by all participants. These differences will be discussed in the course of the report.

\subsection{THE PROPOSED CORRELATION EXPERIMENT}

The material proposed for the correlation experiment was pure molybdenum, 0.001 to $0.010 \mathrm{in}$. thick. The specimens were to be cut at Pacific Northwest Laboratory (PNL) to the size specified by the participant and given identical vacuum annealing. Some materials would be reserved for chemical analysis after the annealing. There was to be no helium preinjection for standard materials. All surface preparation was to be done by the participants.

The desired conditions of temperature and dose are shown in Table 1.

TABLE 1. Experimental Test Matrix

\begin{tabular}{cccc}
$\begin{array}{c}\text { Temperature } \\
\left(C^{\circ}\right)\end{array}$ & & Dose (dpa) \\
\hline 800 & & 20 & 2 \\
900 & & 20 & 2 \\
1000 & & 20 & 2
\end{tabular}

A11 participants would bombard the material to the standard condition of $20 \mathrm{dpa}$ at $900^{\circ} \mathrm{C}$. The other dose-temperature conditions should be tested as resources permit. The dose should be evaluated at the region of subsequent observation in the microscope.

The dose rate was to be $\sim 2 \times 10^{-3} \mathrm{dpa} / \mathrm{sec}$, within a factor of two, for the standard conditions $\left(900^{\circ} \mathrm{C}, 20 \mathrm{dpa}\right)$. This dose rate would apply to the region of observation. Dose rate for protons would be the maximum feasible.

Displacement damage curves for heavy ions were to be calculated using the EDEP- 1 code of Manning and Mueller and the recommended procedures of HEDL-TME-73-76 for dpa calculation. (3) This assumes a $B$ factor of 0.8 and 
an effective displacement energy of $62 \mathrm{eV}$ for molybdenum. If requested, PNL would obtain the curves for the various ions to be used. The displacement dose for protons would be determined by procedures in HEDL-TME-73-76.

The observed region should correspond to a section in which the concentration of deposited ions at $20 \mathrm{dpa}$ is no greater than $0.02 \%$, averaged over a $1000 \AA$ section. The 2 -dpa samples should represent the same distance from the surface as the 20-dpa samples; i.e., variation in dpa should be made only by time of irradiation.

The different laboratories would do as many samples as they desire. At least one sample that has been bombarded under the standard condition $\left(900^{\circ} \mathrm{C}\right.$, $20 \mathrm{dpa}$ ) would be interchanged with one other laboratory. PNL would run samples for possible high-voltage electron microscopy (HVEM) analysis. Other laboratories could run samples for this analysis, as their resources permitted. If feasible, dummy samples would be put in a bombardment furnace for subsequent chemical analysis.

A time history of the temperature, vacuum and ion dose would be recorded for all irradiations. Gas analysis of the vacuum would be done if possible. All information relating to microstructural analysis would be recorded, including, but not limited to, void size, shape, density, dislocation density, void lattice and precipitate structure. Microstructure of unirradiated material would be analyzed by TEM after surface treatment but prior to bombardment. Analysis would be done in the region corresponding to same depth as the ion bombardment region.

In addition to these experimental conditions which were agreed upon, the recommended practice for Neutron Radiation Damage Simulation by Charged Particle Irradiation prepared by ASTM Subcommittee E10.88 would be consulted and followed as close as practicable. 


\subsection{EXPERIMENTAL RESULTS - PART 1}

The following sites completed Part 1 of the experiments using the ions and energies listed below:

\begin{tabular}{lccc} 
Sites & Ions & Energies (MeV) \\
\cline { 1 - 1 } Pacific Northwest Laboratory & $\mathrm{Ni}^{2+}$ & 5 \\
Atomics International & & $\mathrm{H}^{+}$ & 0.5 \\
University of Wisconsin & $\mathrm{Cu}^{4+}$ & $17-18.5$ \\
Naval Research Laboratory & $\mathrm{Mo}^{+}$ & 2.7
\end{tabular}

These values of ion masses and energies provide a wide range of ion irradiation conditions. The specified dose rate could not be obtained in some facilities, but the above sites did attain the specified dose of $20 \mathrm{dpa}$ at $900^{\circ} \mathrm{C}$. The vacuum in the ion irradiation chamber varied considerably among the experiments. The details of the irradiation conditions for this part of the experiment are given in Appendix A.

The vendors analys is of the original molybdenum ingot is given in Table 2. Prior to distribution to the sites, the molybdenum was annealed $2 \mathrm{hr}$ at $1600{ }^{\circ} \mathrm{C}$ in a vacuum of $1 \times 10^{-7}$ torr. An analysis of the interstitial elements after this anneal is shown in Table 3. The microstructure of the molybdenum is typical of a fully annealed state. An optical micrograph is shown in Figure 1. The grain size is approximately $60 \mu \mathrm{m}$. A transmission electron micrograph is shown in Figure 2. Some large precipitates are found widely dispersed and mostly at grain boundaries. The dislocation density was very low.

The microstructural parameters reported for the different irradiations are tabulated according to irradiation temperature and presented in Tables 4-7. The original intent of the experiment was to hold all experimental conditions constant other than ion type and energy. Because of 1 imitation of facilities, the dose rate was also not constant for all experiments. In addition, the vacuum during irradiation varied from $2 \times 10^{-6}$ to $1 \times 10^{-8}$ torr. 
TABLE 2. Vendors Chemical Analysis of Molybdenum Ingot

\begin{tabular}{ccc} 
Element & & Wt.\% \\
\cline { 1 - 1 }$C$ & & 0.005 \\
$O$ & & 0.0005 \\
$\mathrm{~N}$ & & 0.002 \\
$\mathrm{H}$ & $<0.0001$ \\
$\mathrm{Fe}$ & 0.004 \\
$\mathrm{Ni}$ & $<0.001$ \\
$\mathrm{Si}$ & & 0.001
\end{tabular}

TABLE 3. Chemical Analysis After Vacuum Anneal

$\begin{array}{cll}\text { Element } & & \text { Wt.\% } \\ D & & <0.001 \\ \text { O } & & 0.001 \\ \text { N. } & & 0.001 \\ H & & 0.0003\end{array}$

Since void volume fraction or swelling is of prime technological interest, the swelling vs. dose at $900^{\circ} \mathrm{C}$ is plotted in Figure 3 . Although there are only two points in most cases, the data show trends for the different ion species. PNL data for $5 \mathrm{MeV} \mathrm{Ni}^{2}$ at 1000 and $800^{\circ} \mathrm{C}$ are not plotted, but the swelling rate is similar to that found at $900^{\circ} \mathrm{C}$ for $5 \mathrm{MeV} \mathrm{Ni}^{2+}$ ions.

The temperature dependence of the void swelling at 2 and $20 \mathrm{dpa}$ is shown in Figure 4. Again there is only limited data but there is a clear separation between the low and high dose. The data also indicate that the temperatures which were used were below the maximum swelling temperature.

The data on the void size and density generally fall into two groups. The $\mathrm{Mo}^{+}$and $\mathrm{Ni}^{2+}$ ion data agree reasonably well and the $\mathrm{H}^{+}$and $\mathrm{Cu}^{4+}$ are somewhat similar. The void size is smaller and void density larger in the $\mathrm{Mo}^{+2}$ and $\mathrm{Ni}^{2+}$ ion experiments than in the $\mathrm{H}^{+}$or $\mathrm{Cu}^{4+}$ ion experiments. The lower dose rate in the latter case may account for much of the differences. The 


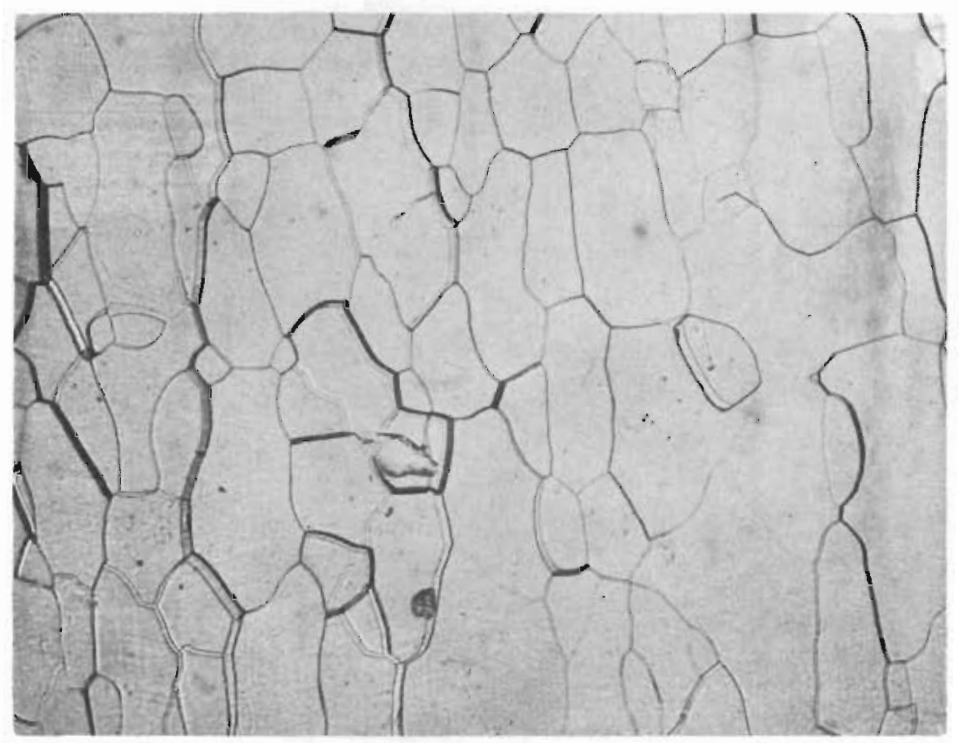

FIGURE 1. Micrograph Showing Grain Structure of Molybdenum After $1600^{\circ} \mathrm{C}$ Anneal (130 X)

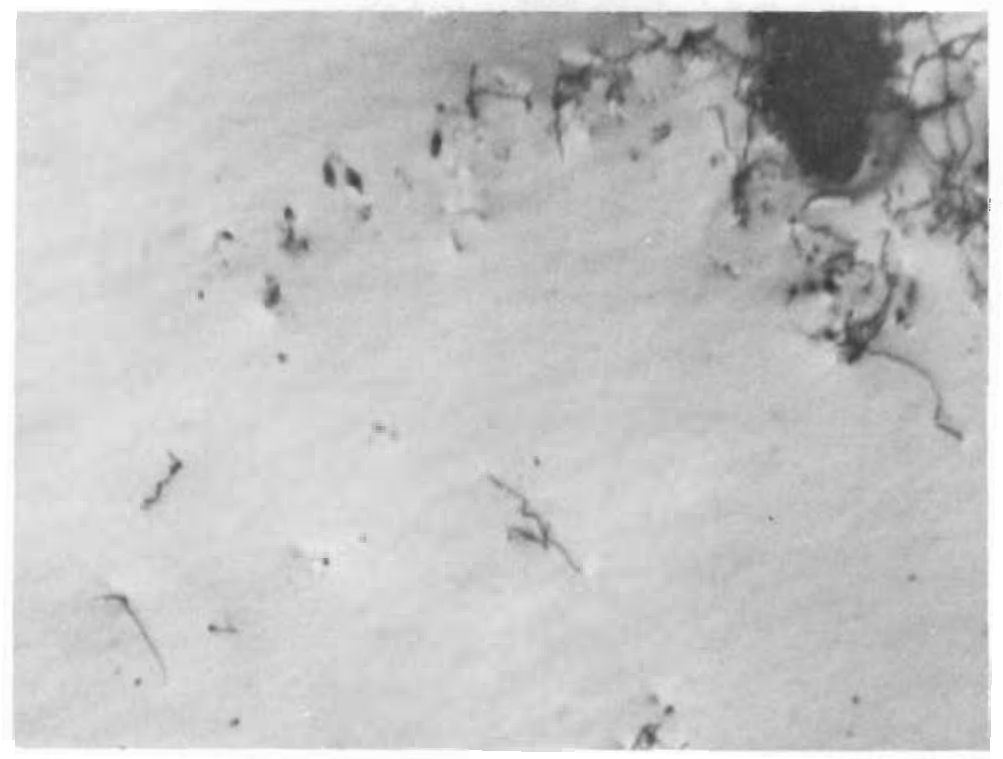

FIGURE 2. Transmission Electron Micrograph of Molybdenum After $1600^{\circ} \mathrm{C}$ Anneal $(32,000 x)$ 
TABLE 4. Microstructural Data for $700^{\circ} \mathrm{C}$

\begin{tabular}{|c|c|c|c|c|c|c|c|c|c|c|}
\hline te & $\begin{array}{c}\text { Ion Mass } \\
\text { and } \\
\text { Energy }\end{array}$ & $\begin{array}{l}\text { Dose } \\
\text { (dpa) } \\
\end{array}$ & $\begin{array}{l}\text { Dose Rate } \\
\text { (dpa/sec) }\end{array}$ & $\begin{array}{l}\text { Void } \\
\text { Dia } \\
\text { (nm) } \\
\end{array}$ & $\begin{array}{r}\text { Void } \\
\text { Density } \\
\left(n / m^{3}\right) \\
\end{array}$ & $\begin{array}{l}\text { Void Vol. } \\
\text { Fraction }\left(\begin{array}{l}\dot{a} \\
0\end{array}\right)\end{array}$ & $\begin{array}{l}\text { Void } \\
\text { Lattice } \\
\text { (nm) } \\
\end{array}$ & $\begin{array}{l}\text { Loop Oia } \\
(\mathrm{nm}) \\
\end{array}$ & $\begin{array}{l}\text { Loop } \\
\text { Oens ity } \\
\left(\mathrm{n} / \mathrm{m}^{3}\right)\end{array}$ & $\begin{array}{c}\text { Total Line } \\
\text { Oensity } \\
\left(n / m^{2}\right) \\
\end{array}$ \\
\hline & $18 \mathrm{meV} \mathrm{Cu}^{4+}$ & 1.0 & $4 \times 10^{-4}$ & 4.8 & $1 \times 10^{22}$ & 0.08 & (a) & 7.6 & $2 \times 10^{21}$ & $9 \times 10^{13}$ \\
\hline
\end{tabular}

(a) Not observed.

TABLE 5. Microstructural Data for $800^{\circ} \mathrm{C}$

\begin{tabular}{|c|c|c|c|c|c|c|c|c|c|c|}
\hline Site & $\begin{array}{c}\text { Ion Mass } \\
\text { and } \\
\text { Energy }\end{array}$ & $\begin{array}{l}\text { Oose } \\
\text { (dpa) }\end{array}$ & $\begin{array}{l}\text { Dose Rate } \\
\text { (dpa/sec) }\end{array}$ & $\begin{array}{l}\text { Void } \\
\text { Dia } \\
\text { (nm) } \\
\end{array}$ & $\begin{array}{c}\text { Void } \\
\text { Density } \\
\left(\mathrm{n} / \mathrm{m}^{3}\right) \\
\end{array}$ & 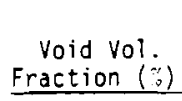 & $\begin{array}{l}\text { Void } \\
\text { Lattice } \\
(n m) \\
\end{array}$ & $\begin{array}{c}\text { Looo Dia } \\
\text { (nm) }\end{array}$ & $\begin{array}{l}\text { Loop } \\
\text { Density } \\
\left(\mathrm{n} / \mathrm{m}^{3}\right)\end{array}$ & $\begin{array}{l}\text { Total Line } \\
\text { Oens }{ }^{\text {ty }} \\
\left(\mathrm{n} / \mathrm{m}^{2}\right) \\
\end{array}$ \\
\hline PNL & $5 \mathrm{meV} \mathrm{Ni}{ }^{2+}$ & 20 & $3 \times 10^{-3}$ & 4.4 & $5 \times 10^{22}$ & 0.65 & (a) & 10.0 & $1.4 \times 10^{22}$ & $6.4 \times 10^{14}$ \\
\hline PNL & $5 \mathrm{meV} \mathrm{Ni}{ }^{2+}$ & 2 & $1 \times 10^{-2}$ & $\leq 2.0$ & Iow & (b) & (a) & 15.0 & $6.7 \times 10^{20}$ & $8.7 \times 10^{13}$ \\
\hline PNL & $5 \mathrm{meV} \mathrm{Ni}{ }^{2+}$ & 20 & $1 \times 10^{-2}$ & $\leq 2.0$ & low & (b) & (a) & 30.0 & $.3-1 \times 10^{21}$ & $1-2 \times 10^{14}$ \\
\hline NRL & $2.7 \mathrm{meV} \mathrm{Mo}{ }^{+}$ & 2 & $2.5 \times 10^{-3}$ & 3.6 & $6.1 \times 10^{22}$ & 0.2 & (a) & 10.5 & $5.6 \times 10^{21}$ & $5.6 \times 10^{16}$ \\
\hline NRL & $2.7 \mathrm{meV} \mathrm{Mo}{ }^{+}$ & 20 & $2.5 \times 10^{-3}$ & 5.6 & $8.1 \times 10^{22}$ & 1.01 & 31.0 & (a) & (a) & $4.1 \times 10^{16}$ \\
\hline UW i & $17 \mathrm{meV} \mathrm{Cu}{ }^{4+}$ & 2.2 & $4-8 \times 10^{-4}$ & 4.4 & $1.7 \times 10^{22}$ & 0.11 & 34.0 & 16.0 & $2 \times 10^{19}$ & $9 \times 10^{12}$ \\
\hline$A I$ & $0.5 \mathrm{meV} \mathrm{H}^{+}$ & 8 & $2 \times 10^{-4}$ & 3.6 & $4.8 \times 10^{23}$ & 1.4 & - & - & -- & -- \\
\hline AI & $0.5 \mathrm{meV} \mathrm{H}^{+}$ & 12 & $2 \times 10^{-4}$ & 3.5 & $5.9 \times 10^{23}$ & 1.4 & -- & - & - & $\cdots$ \\
\hline
\end{tabular}

(a) Not observed

(b) Hot determined

TABLE 6. Microstructrual Data for $900^{\circ} \mathrm{C}$

\begin{tabular}{|c|c|c|c|c|c|c|c|c|c|c|}
\hline$\underline{\text { Site }}$ & $\begin{array}{c}\text { Ion Mass } \\
\text { and } \\
\text { Energy }\end{array}$ & $\begin{array}{l}\text { Dose } \\
\text { (dpa) } \\
\end{array}$ & $\begin{array}{l}\text { Dose Rate } \\
\text { (dpa/sec) }\end{array}$ & $\begin{array}{l}\text { Void } \\
\text { Oia } \\
(\mathrm{nm}) \\
\end{array}$ & $\begin{array}{c}\text { Void } \\
\text { Density } \\
\left(n / m^{3}\right) \\
\end{array}$ & $\begin{array}{l}\text { Void Vol. } \\
\text { Eraction }(\%)\end{array}$ & $\begin{array}{l}\text { Void } \\
\text { Lattice } \\
\text { (nm) }\end{array}$ & $\begin{array}{l}\text { Loop Dia } \\
(\mathrm{nm}) \\
\end{array}$ & $\begin{array}{l}\text { Loop } \\
\text { Dens ity } \\
\left(n / m^{3}\right)\end{array}$ & $\begin{array}{c}\text { Total Line } \\
\text { Oensity } \\
\left(n / m^{3}\right) \\
\end{array}$ \\
\hline PNL & $5 \mathrm{meV} \mathrm{Ni}{ }^{2+}$ & 2 & $3 \times 10^{-3}$ & 3.4 & $9.3 \times 10^{22}$ & 0.47 & (a) & 34.0 & $4.3 \times 10^{19}$ & $3.8 \times 10^{13}$ \\
\hline PNL & $5 \mathrm{meV} \mathrm{Ni}^{2+}$ & 20 & $3 \times 10^{-3}$ & 5.4 & $8 \times 10^{22}$ & 2.0 & 35.0 & 35.0 & $1.8 \times 10^{19}$ & $5.6 \times 10^{13}$ \\
\hline PNL & $5 \mathrm{meV} \mathrm{Ni}{ }^{2+}$ & 2 & $1 \times 10^{-2}$ & 3.7 & $4 \times 10^{22}$ & 0.3 & (a) & 16.5 & $3.8 \times 10^{20}$ & $8.7 \times 10^{13}$ \\
\hline PNL & $5 \mathrm{meV} \mathrm{Ni}^{2+}$ & 20 & $1 \times 10^{-2}$ & 6.4 & $5 \times 10^{22}$ & 1.85 & 34.0 & 27.0 & $2.6 \times 10^{19}$ & $6 \times 10^{13}$ \\
\hline NRL & $3.2 \mathrm{meV} \mathrm{Mo}{ }^{+}$ & 2 & $2.5 \times 10^{-3}$ & 4.0 & $8.2 \times 10^{22}$ & 0.34 & (a) & 5.9 & $1.8 \times 10^{22}$ & $6.8 \times 10^{14}$ \\
\hline NRL & $3.2 \mathrm{meV} \mathrm{Mo}{ }^{+}$ & 20 & $2.5 \times 10^{-3}$ & 8.0 & $5.8 \times 10^{22}$ & 2.07 & 35.0 & (a) & (a) & $5.4 \times 10^{14}$ \\
\hline UWi & $18.7 \mathrm{meV} \mathrm{Cu}{ }^{4+}$ & 1.0 & $5 \times 10^{-4}$ & 7.8 & $6 \times 10^{21}$ & 0.17 & (a) & (a) & (a) & (b) \\
\hline UWi & $17 \mathrm{meV} \mathrm{Cu}{ }^{4+}$ & 1.9 & $4 \times 10^{-4}$ & 9.8 & $6.5 \times 10^{21}$ & 0.39 & (a) & (a) & (a) & $5 \times 10^{13}$ \\
\hline UWi & $17 \mathrm{meV} \mathrm{Cu}{ }^{4+}$ & 19.0 & $5 \times 10^{-4}$ & 7.5 & $3 \times 10^{22}$ & 0.87 & 34.0 & 42.0 & $7 \times 10^{18}$ & $1 \times 10^{13}$ \\
\hline AI & $0.5 \mathrm{meV} \mathrm{H}{ }^{+}$ & 3 & $2 \times 10^{-4}$ & 14.0 & $6 \times 10^{21}$ & 1.1 & (a) & & & \\
\hline AI & $0.5 \mathrm{meV} \mathrm{H}^{+}$ & 6 & $2 \times 10^{-4}$ & 14.0 & $1.2 \times 10^{22}$ & 2.9 & (a) & & & \\
\hline AI & $0.5 \mathrm{meV} \mathrm{H}^{+}$ & 16 & $2 \times 10^{-4}$ & 17.0 & $1.14 \times 10^{22}$ & 5.15 & (a) & & & \\
\hline
\end{tabular}

(a) Not observed

(b) Not determined

TABLE 7. Microstructural Data for $1000^{\circ} \mathrm{C}$

\begin{tabular}{|c|c|c|c|c|c|c|c|c|c|c|}
\hline Site & $\begin{array}{c}\text { Ion !'ass } \\
\text { arc! } \\
\text { Energy }\end{array}$ & $\begin{array}{l}\text { Dose } \\
\text { (dpa) }\end{array}$ & $\begin{array}{l}\text { Dose Rate } \\
\text { (dpa/sec) } \\
\end{array}$ & $\begin{array}{l}\text { Void } \\
\text { Dia } \\
\underline{(n m)} \\
\end{array}$ & $\begin{array}{c}\text { Void } \\
\text { Density } \\
\left(\mathrm{n} / \mathrm{m}^{3}\right) \\
\end{array}$ & $\begin{array}{l}\text { Void vol. } \\
\text { Fraction }(\%)\end{array}$ & $\begin{array}{l}\text { Void } \\
\text { Lattice } \\
\text { (nm) } \\
\end{array}$ & $\begin{array}{l}\text { Loop Dia } \\
(\mathrm{nm}) \\
\end{array}$ & $\begin{array}{l}\text { Loop } \\
\text { Dens } i \text { ty } \\
\left(\mathrm{n} / \mathrm{m}^{3}\right) \\
\end{array}$ & $\begin{array}{c}\text { Total Line } \\
\text { Density } \\
\left(\mathrm{n} / \mathrm{m}^{3}\right) \\
\end{array}$ \\
\hline PNL & $5 \mathrm{meV} \mathrm{Ni}{ }^{2+}$ & 21 & $3 \times 10^{-3}$ & 5.3 & $2.1 \times 10^{22}$ & 0.45 & 38.0 & (a) & (a) & $1.7 \times 10^{13}$ \\
\hline PNL & jmeV $\mathrm{Ni}^{2+}$ & 2 & $1 \times 10^{-2}$ & 3.8 & $9 \times 10^{22}$ & $0.48-0.96$ & 40.0 & 23.0 & $1-5 \times 10^{19}$ & $2.6 \times 10^{13}$ \\
\hline PNL & $5 \mathrm{meV} \mathrm{Ni}{ }^{2+}$ & 20 & $1 \times 10^{-2}$ & 6.4 & $7.5 \times 10^{22}$ & 3.0 & 40.0 & (a) & (a) & $5 \times 10^{13}$ \\
\hline Uwi & $18.7 \mathrm{meV} \mathrm{Cu}^{4+}$ & 1.3 & $5 \times 10^{-4}$ & 25.2 & $5.8 \times 10^{20}$ & 0.75 & (a) & (a) & (a) & $1 \times 10^{13}$ \\
\hline
\end{tabular}




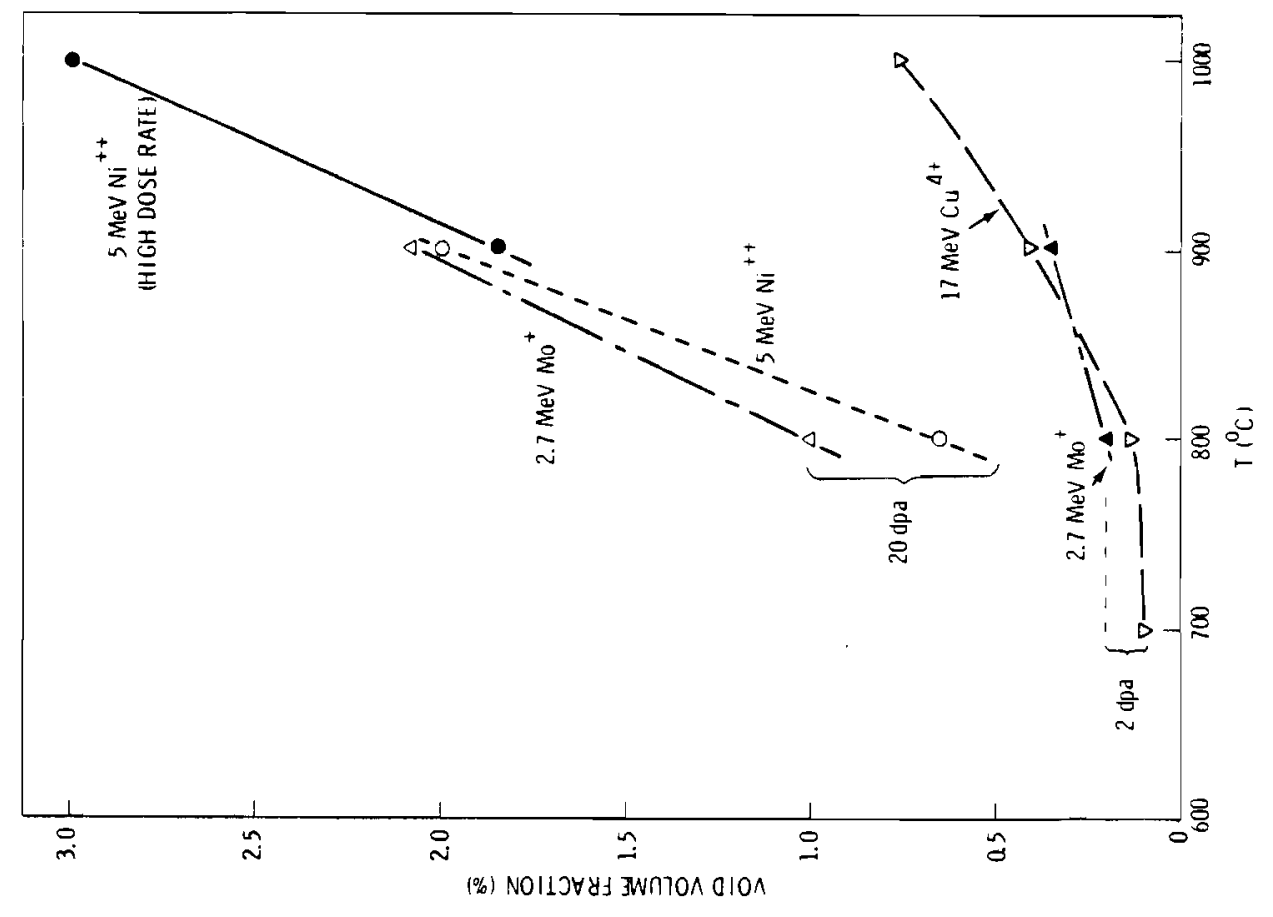

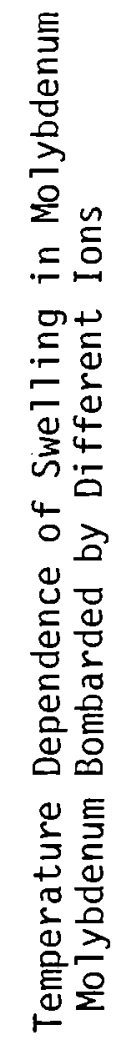

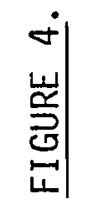

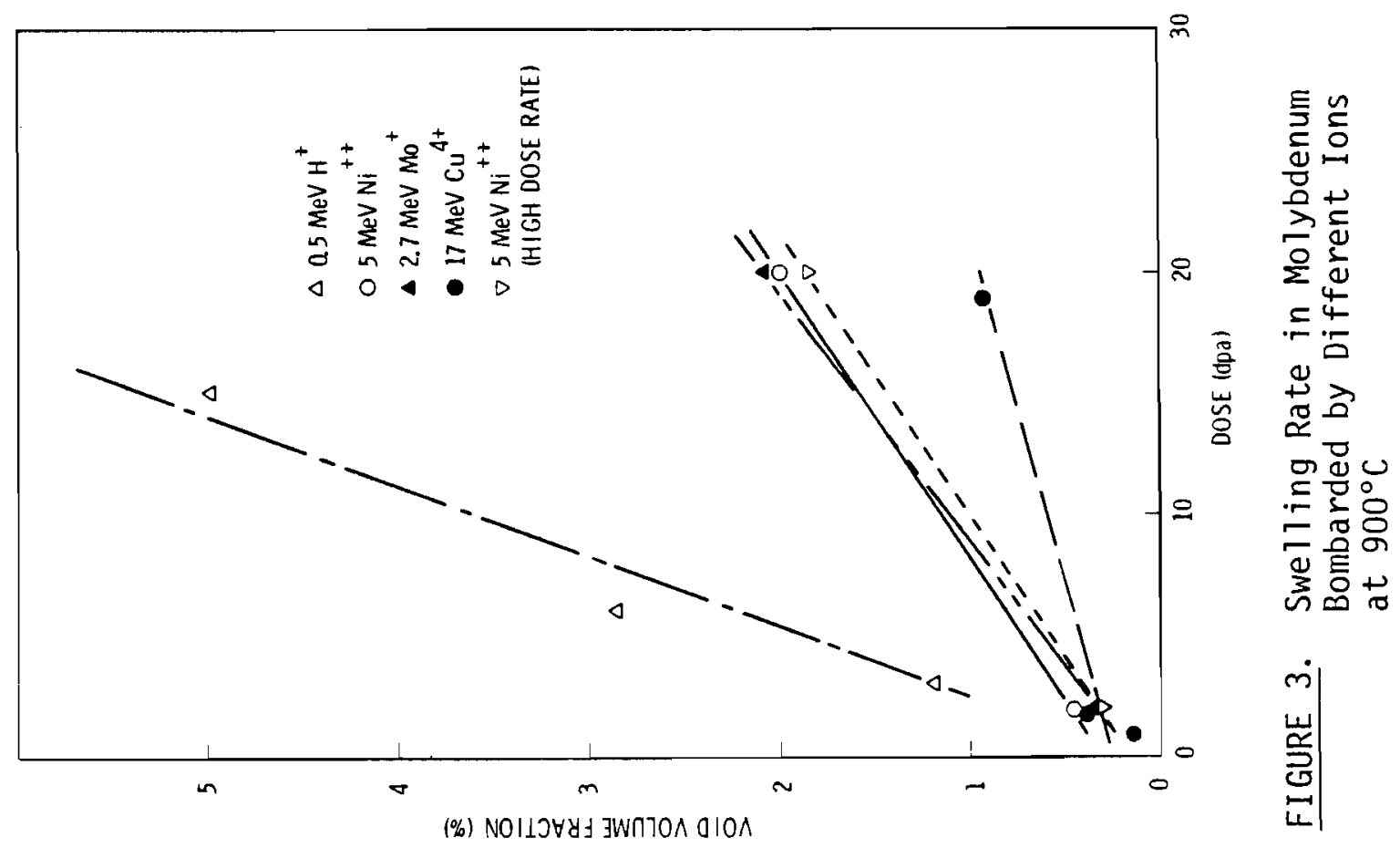


void nucleation rate is proportional to the displacement rate so a higher dose rate should produce a greater void density if other conditions are equal. $(4,5)$ However, the data from dose rates higher than the standard condition do not show large differences.

Since changes in void size and density tend to compensate, a comparison of the void volume fraction is more meaningful. At the low doses, the absolute values of swelling are within a factor of two for the heavy ions and somewhat higher for protons. At $20 \mathrm{dpa}$, the protons give much greater swelling than do the heavy ions. This is reflected in the much higher swelling rate from protons than the heavy ions. The swelling rate from $\mathrm{Ni}^{2+}$ and $\mathrm{MO}^{+}$ions agree even for $\mathrm{Ni}^{2+}$ data using a higher dose rate. The swelling rate for $\mathrm{Cu}^{4+}$ ions is somewhat lower for no obvious reason. The dose rate in the $\mathrm{Cu}^{4+}$ experiment rate in the proton experiment is also low, but yet a high swelling rate is obtained.

Differences in void size and, hence, swelling can aiso be attributed to differences in interpretation of void shape. The assumed void shape ranged from pure cubes to spheres. Although this will result in differences in absolute values of void swelling, the swelling rate should not be affected.

It seems reasonable to conclude that dpa can be used as a basis for comparing swelling results obtained from different heavy ion bombardments. This does not hold true for protons and a correction factor should be applied. This conclusion agrees with work in iron-nickel alloys in which the swelling rate from protons is much higher than that from either heavy ions or neutrons. The difference is probably due to the different PKA spectra produced by proton bombardment compared to heavy ion bombardment.

The data are rather sparse in the plot of swelling versus temperature. However the agreement is reasonable among the different heavy ion experiments. The peak in the swelling occurs above $1000^{\circ} \mathrm{C}$, if we assume the curve does not have a very sharp peak. At $20 \mathrm{dpa}$, there is only a slight difference between the high and low dose rates.

At $2 \mathrm{dpa}$, there is no consistent difference between the $\mathrm{Mo}^{+}$and $\mathrm{Cu}^{4+}$ data, even though the $\mathrm{Cu}^{4+}$ data represent a lower dose rate. The difference 
in dose rate in these experiments may not be sufficient to affect differences in the void swelling outside of the experimental scatter band.

A significantly reduced swelling value is found at $1000^{\circ} \mathrm{C}$ for the highdose $(20 \mathrm{dpa})$, low-dose rate specimen in the $\mathrm{Ni}^{++}$ion experiments. This is believed to be related to the concurrent formation of precipitates in this specimen. The precipitates are further believed to be a result of the deposited nickel ions. The presence of a precipitate is also reported in the $\mathrm{Cu}^{4+}$ experiments which may explain their low swelling value at 19 dpa (see Appendix A). These results do point up the problems from implantation of the bombarding ion. The effects of the implanted ion is more severe with higher temperatures and high doses.

The above results further suggest that examinaton should be from a region as far from the maximum damage zone as possible, particularly when a foreign ion is used. In most cases, this will be a compromise between free surface proximity and the proximity of the maximum damage zone (deposited ion zone). In these experiments, the maximum damage zone was examined only in the $\mathrm{Mo}^{+}$irradiations. Since this is a self-ion, little effect was expected. However, at high temperatures and low dose rates, diffusion can increase the zone of influence of the deposited ion beyond the peak damage zone, as was evident in some of the $\mathrm{Ni}^{++}$irradiations.

One additional factor which may affect the results but has not been fully explored is the level of vacuum in the various experiments. The $\mathrm{Cu}^{4+}$ experiment had a much higher vacuum than the others. This higher vacuum may explain some of the differences observed in that data, but any further discussion would be speculation at this point. 


\subsection{INTERLABORATORY COMPARISON OF A COMMON MICROGRAPH}

One micrograph which depicted typical void microstructures in good contrast was selected for measurements of void parameters (Figure 5). The Naval Research Laboratory copied this micrograph and distributed it to all sites participating in the program. Each site measured the void size, determined the void number density (foil thickness was given), and the void volume fraction. The details of the measurement techniques and complete data acquired as supplied by the individual sites are given in Appendix B. The important void parameters from this comparative experiment are given in Table 8 .

Measurements of the average void size agreed. The standard deviation was only $2.2 \AA(0.22 \mathrm{~nm})$, which is as good as can be expected based on the degree of judgment in determining the boundaries of a void. The spread in the measurement of void density is somewhat surprising in that this measurement only involves counting voids. The variations reflect differences in interpretation as to what is a void and differences in the accounting for voids that intersect surfaces and edges. The greatest variation is in the void volume fraction. The standard deviation was 0.21 which corresponds to $10 \%$ of the average value of 1.99 . If one looked at the differences between the maximum and minimum values, then the difference is $~ 35 \%$. Therefore, it is conceivable that two experimenters under the most optimum conditions could reach considerably different values, but still have similar results. 


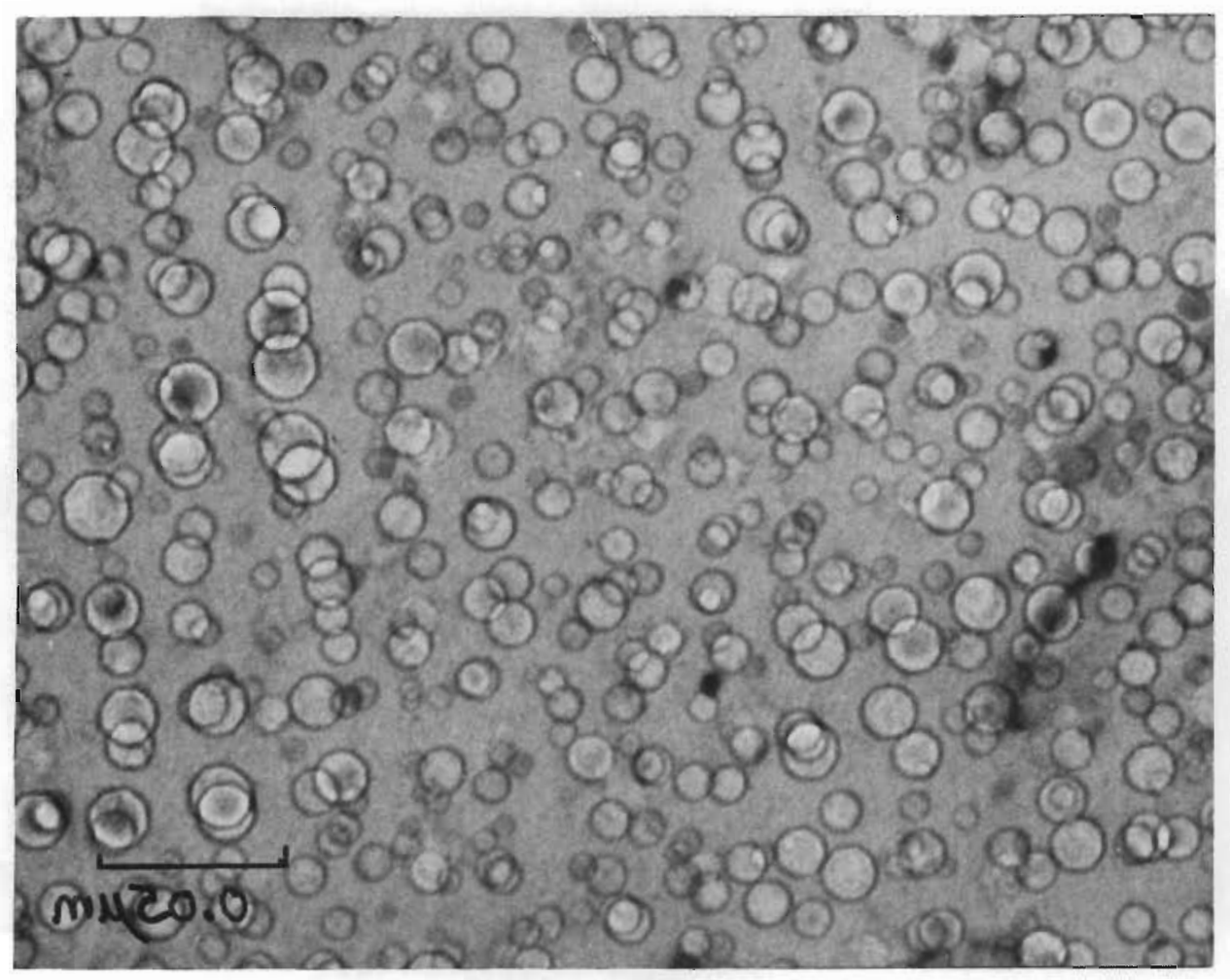

FIGURE 5. "Common Micrograph" Measured by A11 Sites Participating in Part 2 of BCC-ICE

TABLE 8. Void Parameters from Measurements On a Common Micrograph

\begin{tabular}{|c|c|c|c|c|}
\hline Site & $\begin{array}{l}\text { Void Dia. } \\
(\mathrm{nm})\end{array}$ & $\begin{array}{l}\text { Number } \\
\text { Meas. }\end{array}$ & $\begin{array}{l}\text { Void Density } \\
\left(\mathrm{n} / \mathrm{m}^{3}\right) \\
\end{array}$ & $\begin{array}{l}\text { Void Vol. } \\
\text { Fraction }(\%)\end{array}$ \\
\hline AI & 7.9 & 1840 & $5.96 \times 10^{22}$ & 1.96 \\
\hline ANL & 8.2 & 1703 & $6.4 \times 10^{22}$ & 2.2 \\
\hline MIT & 7.8 & 1280 & $5.1 \times 10^{22}$ & 1.63 \\
\hline NRL & 8.0 & 1664 & $5.85 \times 10^{22}$ & 2.07 \\
\hline ORNL & 7.8 & 700 & $6.04 \times 10^{22}$ & 2.04 \\
\hline PNL & 8.2 & 600 & $5.91 \times 10^{22}$ & 2.2 \\
\hline U. Cinc. & 7.7 & 1850 & $5.57 \times 10^{22}$ & 1.68 \\
\hline U. Wisc. & 8.4 & -- & $5.86 \times 10^{22}$ & 2.2 \\
\hline Average & 8.0 & -- & $5.78 \times 10^{22}$ & 1.99 \\
\hline $\begin{array}{l}\text { Standard } \\
\text { Deviation }\end{array}$ & 0.22 & -- & $0.3 \times 10^{22}$ & 0.212 \\
\hline
\end{tabular}


5.0 INTERLABORATORY COMPARISON OF MEASUREMENTS ON A "ROUND ROBIN" TEM FOIL

In addition to variations due to measurements on a micrograph, site-tosite variation due to microscopy techniques would be expected. To evaluate these variations, the same TEM specimen, supplied by NRL, was sent to all the participating sites. Each site performed the microscopy and measurements of the void parameters. Experimental details are given in Appendix $C$. This one specimen suffered very little deterioration from all of the analyses at the sites and being mailed around the country. The results of the examination of the "round robin" specimen are given in Table 9.

TABLE 9. Microstructural Parameters from Measurements of "Round Robin" Foil

\begin{tabular}{|c|c|c|c|c|c|}
\hline Site & $\begin{array}{l}\text { Void Dia. } \\
\text { (nm) }\end{array}$ & $\begin{array}{l}\text { Number } \\
\text { Meas. }\end{array}$ & $\begin{array}{l}\text { Void Density } \\
\quad\left(n / m^{3}\right) \\
\end{array}$ & $\begin{array}{l}\text { Void Vol. } \\
\text { Fraction }(\%)\end{array}$ & $\begin{array}{l}\text { Void } \\
\text { Lattice }(\mathrm{nm})\end{array}$ \\
\hline AI & 8.2 & 2123 & $4.55 \times 10^{22}$ & 1.74 & -- \\
\hline ANL & 6.4 & -- & $12.0 \times 10^{22}$ & 2.1 & -- \\
\hline MIT & 7.44 & 875 & $10.0 \times 10^{22}$ & 2.96 & -- \\
\hline NRL & 8.0 & -- & $5.8 \times 10^{22}$ & 2.07 & 35.0 \\
\hline ORNL & 8.74 & 687 & $6.04 \times 10^{22}$ & 2.85 & 37.5 \\
\hline PNL & 8.4 & 1167 & $6.35 \times 10^{22}$ & 2.62 & 36.5 \\
\hline U. Cinc. & 8.6 & 2110 & $4.4 \times 10^{22}$ & 1.75 & -- \\
\hline U. Wisc. & 8.5 & -- & $6.4 \times 10^{22}$ & 2.6 & 35.5 \\
\hline Average & 8.04 & -- & $6.94 \times 10^{22}$ & 2.34 & 36.1 \\
\hline $\begin{array}{l}\text { Standard } \\
\text { Deviation }\end{array}$ & 0.77 & -- & $2.5 \times 10^{22}$ & 0.43 & -- \\
\hline
\end{tabular}


The agreement among the sites is not as good as that found on the "common micrograph", as would be expected. The standard deviation in the void size measurements is $7 \AA$ ( $(0.7 \mathrm{~nm})$. For the void density, the standard deviation is $2.5 \times 10^{22}$ which corresponds to more than $30 \%$ of the average measured value. Both these measurements reflect differences in magnification, and the density measurement has the additional problem of determining foil thickness. In the computation of void volume fraction, errors in the magnification cancel out as they appear both in the numerator and denominator. The standard deviation of the measurements of void volume fraction is about twice that found for measurements on the common micrograph. This must be due to differences in microscopy conditions, particularly to variations in the measurement of foil thickness.

The spread in the results in this part of the experiment represents the best agreement attainable among different experimenters since all sites were looking at exactly the same specimen. The spread between the maximum and minimum value is approximately $70 \%$. Therefore, it is conceivable but unlikely that differences of this magnitude are insignificant. There is a high probability, however, that differences in the void volume fraction of less than $35 \%$ between two experimenters are not meaningful. 


\section{REFERENCES}

1. G. L. Kulcinski, "A Review of Ion Simulation of High Temperature Neutron Damage and Void Formation." In: Applications of Ion Beams to Metals, Plenum Press, New York, NY, p. 613, 1974.

2. J. L. Brimhal1, "Ion Bombardment Simulation - A Review Related to Fusion Radiation Damage." In: Radiation Effects and Tritium Technology for Fusion Reactors Vol. I, CONF-750989. Available from National Technical Information Service, Springfield, VA 22161, p. 1-73, March 1976.

3. D. G. Doran, J. R. Beeler, N. D. Dudey, and M. J. Fluss, Report of the Working Group on Displacement Models and Procedures for Damage Calculations, HEDL-TME-73-76, Hanford Engineering Development Laboratory, Richland, WA.

4. H. Wiedersich, J. J. Barton, and J. L. Katz, "Effect of Mobile He on Void Nucleation in Materials During Irradiation." J. Nucl. Mat., 51:287, 1974.

5. J. E. Westmoreland, J. A. Sprague, F. A. Smidt, and P. R. Malmberg, "Dose Rate Effects in Ion Bombarded Nicke1." Radiation Effects, 26:1, 1975. 


\section{APPENDIX A}

EXPERIMENTAL DETAILS OF PART 1 OF

BODY-CENTERED CUBIC ION CORRELATION PROGRAM 
APPENDIX A

\author{
EXPERIMENTAL DETAILS OF PART I OF \\ BODY-CENTERED CUBIC ION CORRELATION PROGRAM
}

This appendix contains detailed descriptions of the experiments performed in Part 1 of the BCC-ICE program. The material is presented as supplied by the participants. There has been no attempt to organize it into a uniform format, al though some editing has been done for purposes of condensation.

\title{
A.1 ATOMICS INTERNATIONAL BCC ION CORRELATION EXPERIMENT DATA SHEET FOR EXPERIMENTAL PARAMETERS
}

I. Material Chemistry

A. Chemical analysis of base material (see body of report)

B. Chemical analysis after pre-irrad. treatment (see body of report)

C. Chemical analysis after ion bombardment

C.1 - Analysis of entire specimen Chemical analysis has not been done. A sample irradiated at $900^{\circ} \mathrm{C}$ and a sample held at $900^{\circ} \mathrm{C}$ in the irradiation target chamber are available for analysis.

C.2 - Analysis of damage zone We do not feel this is required in the case of proton irradiation. Ion microprobe mass analysis of proton-irradiated Type 316 stainiess steel and tantalum has shown the hydrogen content to be uniform throughout the sample, including the damage zone.

II. Pretreatment

A. Electropolishing (solution, temperature, surface removal, etc.) $12 \% \mathrm{H}_{2} \mathrm{SO}_{4}$ in methyl alcohol. -25 to $-40^{\circ} \mathrm{C} .2 .5 \times 10^{-3} \mathrm{~cm}$.

B. Other preparation (mechanical polish, chemical etch, etc.) None

C. Surface smoothness

Mirror 


\section{Irradiation Parameters}

\section{A. Specimen Environment}

\begin{tabular}{|c|c|c|c|c|c|c|c|}
\hline $\begin{array}{l}\text { Spec. } \\
\text { Ident. }\end{array}$ & $\left|\begin{array}{c}\text { Ten:o } \\
(\circ 0)\end{array}\right|$ & $\begin{array}{c}\text { Temp } \\
\text { Variaticn } \\
\pm\end{array}$ & $\mid \begin{array}{c}\text { Tinie } \\
\text { (pre-irrad) }\end{array}$ & Time & \begin{tabular}{c|c|} 
Time & Temp \\
(post-irrad) & (post-irrad) \\
\end{tabular} & Vac. & $\begin{array}{l}\text { Vacuum } \\
\text { ( } 1 \text { cov to } \\
\text { righ value) }\end{array}$ \\
\hline Mi & 900 & 5 & $23 \mathrm{~min}$ & \begin{tabular}{ll|}
17 & $\mathrm{hr}$ \\
34 & $\min$
\end{tabular} & $\begin{array}{l}\text { At } 700^{\circ} \mathrm{C} \text { within } 1=\mathrm{m} \text {, } \\
\text { at roco tere in } 3 \text { in. }\end{array}$ & & $\begin{array}{l}1.8 \times 10^{-6} \\
\text { to } 2.8 \times 10^{-5} \\
\end{array}$ \\
\hline M4 & 900 & 5 & $18 \mathrm{~min}$ & $\begin{array}{ll}8 \mathrm{mr} \\
38 & \mathrm{~min}\end{array}$ & $\begin{array}{l}\text { At } 700^{\circ} \mathrm{C} \text { within } 1 \text { min, } \\
\text { at roon }=e \pi 0 \text { in } 8=i n \text {. }\end{array}$ & & $\begin{array}{l}2.0 \times 10^{-6} \\
502.8 \times 10^{-6}\end{array}$ \\
\hline M6 & 900 & $<5$. & $19 \mathrm{~min}$ & $\begin{array}{l}4 \mathrm{hr} \\
30 \mathrm{~min}\end{array}$ & $\begin{array}{l}\text { At } 700^{\circ} \mathrm{C} \text { within } 0 . \overline{\text { and }} \\
\text { at room tem? in ? min. }\end{array}$ & & $\begin{array}{l}3.2 \times 10^{-6} \\
\text { to } 5.0 \times 10^{-6}\end{array}$ \\
\hline $\begin{array}{c}\text { M10 } \\
+ \\
M 11 *\end{array}$ & 900 & $5 * *$ & 7 oin & $\begin{array}{ll}10 & \mathrm{hr} \\
53 & \mathrm{~min}\end{array}$ & $\begin{array}{l}\text { At } 700^{\circ} \mathrm{C} \text { within } 2.4 \mathrm{~min} \\
\text { at }=000 \text { temp in } 27 \mathrm{~min}\end{array}$ & & $\leq 3.0 \times 10^{-6}$ \\
\hline$\stackrel{M}{M}$ & 950 & $50 \cdots$ & $3 \operatorname{ain}$ & $\begin{array}{l}4 \text { ins } \\
52 \text { min }\end{array}$ & & & $\begin{array}{l}1.0 \times 10^{-6} \\
\text { to } 6.0 \times 10^{-6}\end{array}$ \\
\hline $\mathrm{MI} 4$ & 800 & $<5$ & $18 \mathrm{~min}$ & $\begin{array}{l}16 \mathrm{hr}, \\
2 \min \end{array}$ & $\begin{array}{l}\text { At } 600^{\circ} \mathrm{C} \text { within } 0.5 \text { min, } \\
\text { at roog temo in } 6 \text { min. }\end{array}$ & & $\begin{array}{l}4.8 \times 10^{-6} \\
\operatorname{tn} 8.0 \times 10^{-6}\end{array}$ \\
\hline MS & 800 & $<5$ & $12 \mathrm{~min}$ & $\begin{array}{ll}10 & \mathrm{hr} \\
43 \mathrm{~min}\end{array}$ & $\begin{array}{l}\text { At } 600^{\circ} \mathrm{C} \text { within } 0.5 \mathrm{~min} \text {, } \\
\text { at room te }=p \text { in } \sim 6 \mathrm{~min}\end{array}$ & & $\leq 3.0 \times 10^{-6}$ \\
\hline
\end{tabular}

Gas Analys is of Vaclim: ione

\section{B. Beam Variables}

\begin{tabular}{|c|c|c|c|c|c|}
\hline $\begin{array}{l}\text { Spec. } \\
\text { Ident. }\end{array}$ & $\begin{array}{l}\text { Highest } \\
\text { Current }\end{array}$ & $\begin{array}{l}\text { Lowest } \\
\text { Cwrent }\end{array}$ & $\begin{array}{l}\text { Averace } \\
\text { Curyont }\end{array}$ & $\begin{array}{l}\text { Integrated } \\
\text { Fluerice } \\
\end{array}$ & $\begin{array}{c}\text { Bnam } \\
\text { Unifiomity(?) }\end{array}$ \\
\hline$M 3$ & $\begin{array}{l}1.78 \times 10^{15} \\
\mathrm{n} / \mathrm{cm}^{2}-\mathrm{s}\end{array}$ & $\begin{array}{l}1.59 \times 10^{25} \\
0 / \mathrm{cm}^{2}-5\end{array}$ & $\begin{array}{l}1.71 \times 10^{15} \\
0 / c==^{2}-5\end{array}$ & $\begin{array}{l}1.09 \times 10^{20} \\
=/ \mathrm{cm}^{2}\end{array}$ & \multirow[t]{7}{*}{$\begin{array}{l}\leq \pm 10 \% \text { over } 2.3 \mathrm{~cm}^{2} \\
\text { sample area. }\end{array}$} \\
\hline$M^{4}$ & $1.75 \times 10^{15}$ & $1.59 \times 10^{15}$ & $1.71 \times 20^{15}$ & $5.45: 10^{-9}$ & \\
\hline $\mathrm{N} 6$ & $1.88 \times 10^{25}$ & $1.53 \times 10^{25}$ & $1.77 \times 10^{15}$ & $2.73 \times 10^{19}$ & \\
\hline $\begin{array}{l}1910 \\
+\mathrm{N} 11\end{array}$ & $1.88 \times 10^{1 \equiv}$ & $2.63 \times 10^{15}$ & $1.72 \times 10^{15}$ & $6.75 \times 20^{19}$ & \\
\hline $\begin{array}{l}Y 12 \\
+\quad N 13 \\
\end{array}$ & \multicolumn{2}{|c|}{$\begin{array}{l}\text { Tyoical jean fluc- } \\
\text { tuations. }\end{array}$} & $1.65 \times 10^{15}$ & $3.38 \times 10^{19}$ & \\
\hline Hil4 & \multicolumn{2}{|c|}{$\begin{array}{l}\text { Myoical beam fluc- } \\
\text { tuaticns. }\end{array}$} & $1.77 \times 10^{15}$ & $1.01 \times 10^{20}$ & \\
\hline :115 & $1.80 \times 10^{15}$ & $1.69 \times 10^{15}$ & $1.75 \times 10^{15}$ & $6.75 \times 10^{19}$ & \\
\hline
\end{tabular}

- Sample l:1l was shielded from the beam but kept at the irradiation terperature.

- Operator error caused severe temperature oversioot. specimen spent $40 \mathrm{~s}$ Over $900^{\circ} \mathrm{C}$ and reached a maximu temperature of $1000^{\circ} \mathrm{C}$ momentarily.

* "Leater and temperarure sersin problens resulted in an estimated decrease in.

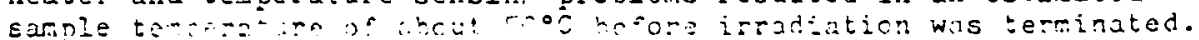


IV. Post-Irradiation Examination

A. Data or parameters common to al1 specimens

Magnification accuracy: Within $6 \%$

Tilt stage accuracy: $\pm 0.5^{\circ}$

Average foil thickness + estimated error: Typical foil thickness

is $1 \times 10^{-6} \mathrm{~cm}$. Estimated error is $+25 \%$.

Diffraction contrast conditions:

voids: absorption

dislocations: Imaging of dislocations was done as mandated

by those areas of the sample which were transparent to 100

$\mathrm{KeV}$ electrons.

Focus conditions:

voids: overfocused

dislocations: sharp

Void dimension measured: Void diameters defined by the central portion of the Fresnel fringe.

B. Data Specific to Indiviaual Specimens

\begin{tabular}{|c|c|c|c|c|c|c|c|c|c|c|c|c|}
\hline $\begin{array}{c}\text { Specimen } \\
\text { Identification }\end{array}$ & $\begin{array}{c}\text { Surface } \\
\text { Removal(s) } \\
\end{array}$ & $\begin{array}{l}\text { Calculated } \\
\text { OPAL: }\end{array}$ & $\begin{array}{l}\text { Mean Yoid } \\
\text { Size ond } \\
\text { siajist }\end{array}$ & $\begin{array}{c}\text { Total vymber } \\
\text { sf } \\
\text { voias sized } \\
\end{array}$ & $\begin{array}{l}\text { Yumber } \\
\text { of Areas } \\
\text { Sampled }\end{array}$ & $\begin{array}{c}\text { void } \\
\text { Seometry }\end{array}$ & $\begin{array}{c}\text { Void } \\
\text { Jensiey } \\
\end{array}$ & $\begin{array}{l}\text { Range of } \\
\text { Dersitity } \\
\text { Values }\end{array}$ & $\begin{array}{l}\text { Total Mumber } \\
\text { of voids } \\
\text { counteg } \\
\end{array}$ & $\begin{array}{l}\text { Areas } \\
\text { Samplade }\end{array}$ & $\begin{array}{c}\text { void } \\
\text { volume } \\
\text { reraction } \\
\end{array}$ & $\begin{array}{l}\text { Estimated } \\
\text { Error" } \\
\end{array}$ \\
\hline 43 & $\begin{array}{l}1.6 \times 10^{-3} \\
.2 \times 10^{-4} \mathrm{rm}\end{array}$ & $\begin{array}{r}15+2 \\
-1\end{array}$ & $170 A^{2}$ & 1107 & 4 & $\begin{array}{l}\text { (100) with } \\
(110) \text { Trunc. }\end{array}$ & $1.1 \times 10^{16} / \mathrm{cm}^{3}$ & $\begin{array}{l}0.96 \times 10^{16} \\
\text { to } 1.3 \times 10^{16}\end{array}$ & $110 ?$ & 4 & 4.9: & $3.5 \cdot 6.2$ \\
\hline 44 & $\begin{array}{l}9.0 \times 10^{-4} \\
=2 \times 10^{-4}\end{array}$ & $6.0: 0.4$ & 140 & 522 & 4 & $\begin{array}{l}(100) \text { with } \\
(110) \text { Trunc. }\end{array}$ & $1.2 \times 10^{15}$ & $\begin{array}{l}1.1 \times 10^{16} \\
\text { to } 1.3 \times 10^{16}\end{array}$ & 622 & 4 & $2.8=$ & $2.1 .4 .1:$ \\
\hline 46 & $\begin{array}{l}1.0 \times 10^{-3} \\
=2 \times 10^{-4}\end{array}$ & $3.1: 0.2$ & 140 & 749 & 3 & $\begin{array}{l}(100) \text { with } \\
(110) \text { Trune. }\end{array}$ & $5.9 \times 10^{15}$ & $\begin{array}{l}4.2 \times 10^{15} \\
\text { to } 3.6 \times 1.3^{15}\end{array}$ & 749 & 3 & $1.1 \%$ & J.92-1.3\% \\
\hline
\end{tabular}

Yumbers Juoted are Joserved Variations from Area to Area 


\section{A.2 NAVAL RESEARCH LABORATORY}

A beam of 2.7 MeV Mo ions was obtained from the NRL 5.5 MV Van de Graff accelerator using the modified Hill-Nelson source developed by NRL. (1) Suitable beam currents were obtained using a sputtering electrode of naturally occurring molybdenum. A magnetically analyzed beam of ${ }^{98} \mathrm{Mo}^{+}$with a beam current of $2100 \mathrm{nA}$ was defocused across the area to be irradiated $\left(0.109 \mathrm{~cm}^{2}\right)$ to assure uniformity of flux across the sample. The beam current on the sample was $20 \mathrm{nA}$ or $0.185 \mu \mathrm{A} / \mathrm{cm}^{2}$ and fluctuated less than $\pm 25 \%$ during an irradiation.

Damage produced by this ion beam was calculated with the E-DEP-1 Code of Manning and Mueller $(2)$ assuming $E_{d}$ of $63 \mathrm{eV}$, an efficiency of 0.8 , and a density of $6.4 \times 10^{22}$ atoms $/ \mathrm{cm}^{3}$. Peak damage of $20 \mathrm{dpa}$ was calculated for $157.5 \mathrm{uC}$ total integrated charge. Maximum damage occurs at a depth of $0.3 \mu \mathrm{m}$ and varied less than $20 \%$ from $0.13 \mu \mathrm{m}$ to $0.40 \mu \mathrm{m}$. Dose rate was $2.5 \times 10^{-3} \mathrm{dpa} / \mathrm{sec}$.

The irradiation chamber previously employed was modified for these experiments to incorporate a specimen furnace of lower thermal inertia and higher temperature capability and the addition of a titanium sublimation pump. Vacuum at the sample at temperature during these runs was approximately $1 \times 10^{-6}$ Torr. A single specimen was irradiated during each run and the temperature of the sample was lowered immediately upon completion of the bombardment to minimize possible annealing effects. A total of five specimens were irradiated as follows: 2 specimens at $900^{\circ} \mathrm{C}$ to $20 \mathrm{dpa} ; 1$ specimen at $900^{\circ} \mathrm{C}$ to $2 \mathrm{dpa}, 1$ specimen at $800^{\circ} \mathrm{C}$ to $20 \mathrm{dpa}$; and 1 specimen at $800^{\circ} \mathrm{C}$ to $2 \mathrm{dpa}$.

The specimens were prepared for microscopy observation following ion bombardment in two stages. Removal of material from the front face was accomplished by pulsed electropolishing using a laser interferometer ${ }^{(3)}$ to monitor removal of $0.23 \mu$ of material. The sample was then back-thinned to transparency with a jet electropolisher using a solution of $12.5 \% \mathrm{H}_{2} \mathrm{SO}_{4}$ in methanol. The specimens were examined in a JEM-200A electron microscope equipped with a side entry goniometer tilting stage, with the microscope operated at $200 \mathrm{kV}$. Voids were imaged under weakly diffracting absorption contrast conditions using the out-of-focus phase contrast technique of Rühle. Foil thickness was determined from stereomeasurements on pairs of photographs taken at tilt angles of 10 to 14 degrees. Accuracy of the thickness measurements is estimated to be $\pm 20 \%$. 
Voids were found in all the four samples examined and were homogeneously distributed. Voids in the $20 \mathrm{dpa}$ samples appear to be truncated octahedra while those in 2 dpa samples appear to be nearly spherical. A void lattice was observed in the $20 \mathrm{dpa}$ samples at both 800 and $900^{\circ} \mathrm{C}$ but not in the 2 dpa samples. A summary of the observations is provided in Table A.2-1. Each point represents the average of two determinations.

TABLE A.2-1. Void Microstructures in Ion-Bombarded Molybdenum

\begin{tabular}{|c|c|c|c|c|c|}
\hline $\begin{array}{l}\text { Temp. } \\
\left({ }^{\circ} \mathrm{C}\right)\end{array}$ & dpa & $N_{v}\left(\mathrm{~cm}^{-3}\right)$ & $\bar{D}(\stackrel{0}{A})$ & $\Delta V / V(\%)+$ & $\begin{array}{l}\text { Void } \\
\text { Lattice } \\
\text { Spacing } \\
(\AA)\end{array}$ \\
\hline 800 & 2 & $6.1 \times 10^{16}$ & 36 & 0.20 & - \\
\hline 800 & 20 & $8.1 \times 10^{16}$ & 56 & 1.01 & 310 \\
\hline 900 & 2 & $8.2 \times 10^{16}$ & 40 & 0.34 & - \\
\hline 900 & 20 & $5.8 \times 10^{16}$ & 80 & 2.07 & 350 \\
\hline
\end{tabular}

\section{REFERENCES}

1. J. K. Hirvonen, Nuclear Instruments and Methods 116:9, 1974.

2. I. Manning and G. P. Mueller, Computer Physics Communications 7:85, 1974.

3. J. A. Sprague, Rev. Sci. Insts. 46:1171, 1975. 


\section{A.3 UNIVERSITY OF WISCONSIN}

I. Experimental Procedure

A. Irradiation Procedure

The material supplied to UW was in strip form $7 \mathrm{~cm} \times 1.25 \mathrm{~cm} \times 0.15 \mathrm{~mm}$ thick. To accomodate this material into the UW sample holder (Figure A.3-1), two $3.2 \mathrm{~mm}$-diameter and five $4.8 \mathrm{~mm}$-diameter holes were spark machined in the sample strips. The strips were also spark machined in half (making two $3.5 \mathrm{~cm} \times 1.25 \mathrm{~cm} \times 0.15 \mathrm{~mm}$ thick strips). This was done to facilitate the subsequent preparation of specimens for TEM examination. After the spark machining process but prior to irradiation, the specimen strips were electropolished in a $15 \% \mathrm{H}_{2} \mathrm{SO}_{4}, 85 \%$ methyl alcohol solution at $-20^{\circ} \mathrm{C}$ and 10 volt to give a smooth surface. Table A.3-1 summarizes the pretreatment of the specimens.

\section{TABLE A.3-1. Pretreatment of BCC Ion Correlation} Experiment Molybdenum Specimens

A. Electropolishing (solution, temperature, surface removal, etc.). Polished in $15 \% \mathrm{H}_{2} \mathrm{SO}_{4}$, $85 \%$ methyl alcohol at $-20^{\circ} \mathrm{C}$ and $10 \mathrm{~V}$ to smooth surface after strip preparation in $\mathrm{B}$.

B. Other preparation (mechanical polish, chemical etch, etc.). Spark machined seven holes in strips, then spark machined strips in half followed by polish in A.

C. Surface smoothness.

Generally very smooth, with some preferential grain attack.

The specimens were irradiated using the UW tandem Van de Graaff accelerator as described elsewhere. (1) Briefly, the specimens were bombarded with $\sim 25$ particle nA of either 17.0 or $18.8 \mathrm{MeV} \mathrm{Cu}^{4+}$ ions. The charge state of the $\mathrm{Cu}$ beam was determined by elastic scattering of the beam off of a thin gold foil. (1) The energy $E$ of the beam is given by $E=(q+1) V$, where $q$ is the charge state of the beam and $V$ is the accelerator dome voltage (measured with a generating voltmeter). 


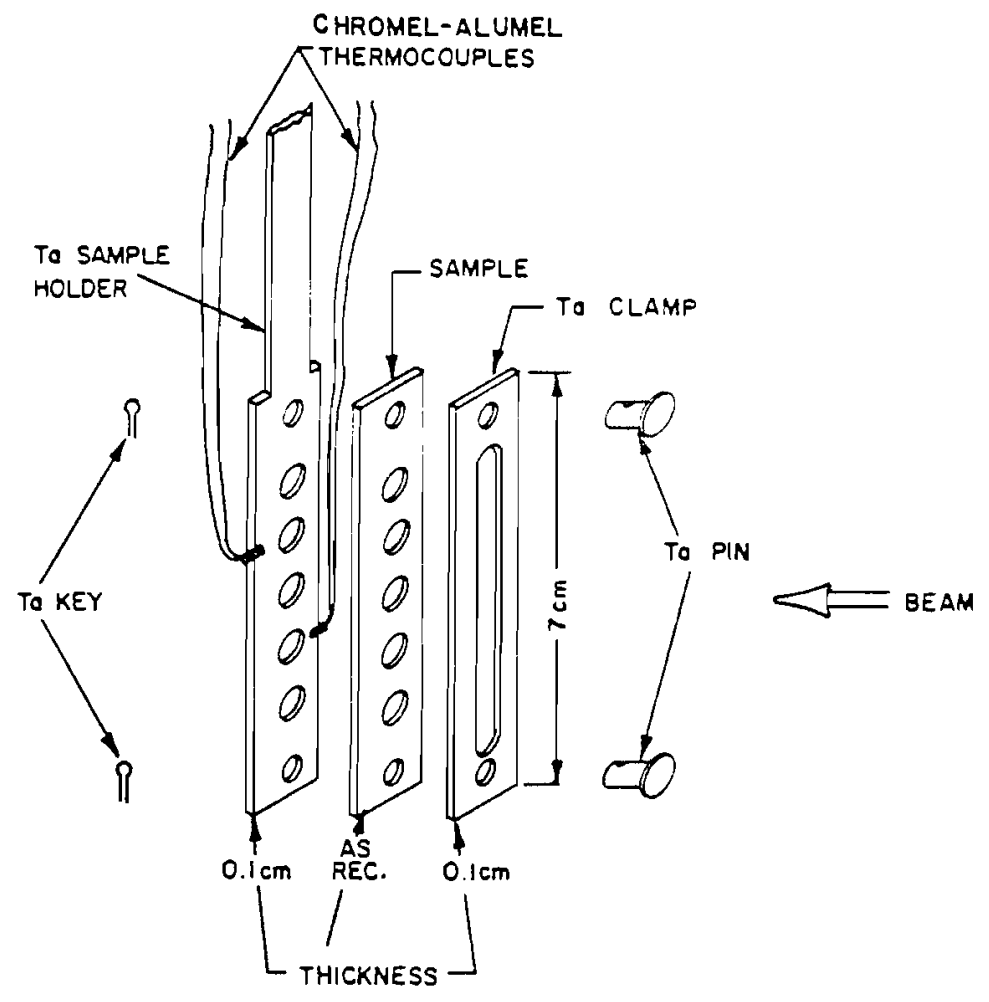

FIGURE A.3-1. Detail of the Sample Folder Assembly

The samples were irradiated in three separate groups. The first group contained six specimens of which two were irradiated at $1000^{\circ} \mathrm{C}$, two at $900^{\circ} \mathrm{C}$, and two at $800^{\circ} \mathrm{C}$ to damage levels near $1 \mathrm{dpa}$ (approximately $1 \mu \mathrm{m}$ from the surface). These irradiations were carried out at pressures near $1 \times 10^{-8} \mathrm{Torr}$. The specimens were irradiated from highest to lowest temperature to minimize post-irradiation annealing effects. The second group also contained six specimens of which one was irradiated at $1000^{\circ} \mathrm{C}$, two at $900^{\circ} \mathrm{C}$ and two at $800^{\circ} \mathrm{C}$ to damage level near $2 \mathrm{dpa}$. The sixth specimen in this group was irradiated at $700^{\circ} \mathrm{C}$ to $\sim 1 \mathrm{dpa}$. The pressure during irradiation of these specimens was near $5 \times 10^{-9}$ Torr. The last group contained only one specimen. It was irradiated at $900^{\circ} \mathrm{C}$ to $19 \mathrm{dpa}$ at a pressure near $1 \times 10^{-8}$ Torr. Partial pressure analysis prior to the first $1000^{\circ} \mathrm{C}$ run revealed that the residual gas in the sample chamber was composed of $57 \% \mathrm{H}_{2}, 18 \% \mathrm{CO}, 22 \% \mathrm{H}_{2} \mathrm{O}, 2 \% \mathrm{CO}_{2}$, and $1 \% \mathrm{CH}_{4}$. 
The particle flux for all but the 19 dpa specimens was determined by periodically measuring the beam current striking an insertable Faraday cup. Knowledge of the charge state of the beam allows the beam particle current to be calculated. The total fluence was then calculated from knowledge of the irradiation time (about $2 \mathrm{hr}$ for the $2 \mathrm{dpa}$ specimens). The current striking the $19 \mathrm{dpa}$ specimens was measured directly and integrated to obtain the fluence. The displacement damage versus depth curve as well as the position of the deposited copper ions is shown in Figure A.3-2. The dpa values were calculated with the E-DEP-1 Code ${ }^{(2)}$ assuming $E_{d}=61.7 \mathrm{ev}$, an efficiency of 0.8 , and an atom density of $6.42 \times 10^{22} / \mathrm{cm}^{3}$. The dpa rate at the region of analys is ( $\sim 1 \mu \mathrm{m}$ from the sample surface, see below) is $\sim 4 \times 10^{-4} \mathrm{dpa} / \mathrm{sec}$.

To minimize the effects of the sample surface and the deposited $\mathrm{Cu}$ ions, TEM analysis of the damage was done $\sim 1 \mu \mathrm{m}$ from the sample surface (Figure A.3-2). This analysis zone is $>1 \mu \mathrm{m}$ from the deposited Cu atoms. A diffusion calculation shows that for the $2 \mathrm{dpa}$ specimens the deposited $\mathrm{Cu}$ atoms move $<0.2 \mu \mathrm{m}$ and for the $19 \mathrm{dpa}$ specimens $<0.6 \mu \mathrm{m}$ from their initial position during the course of the irradiation.

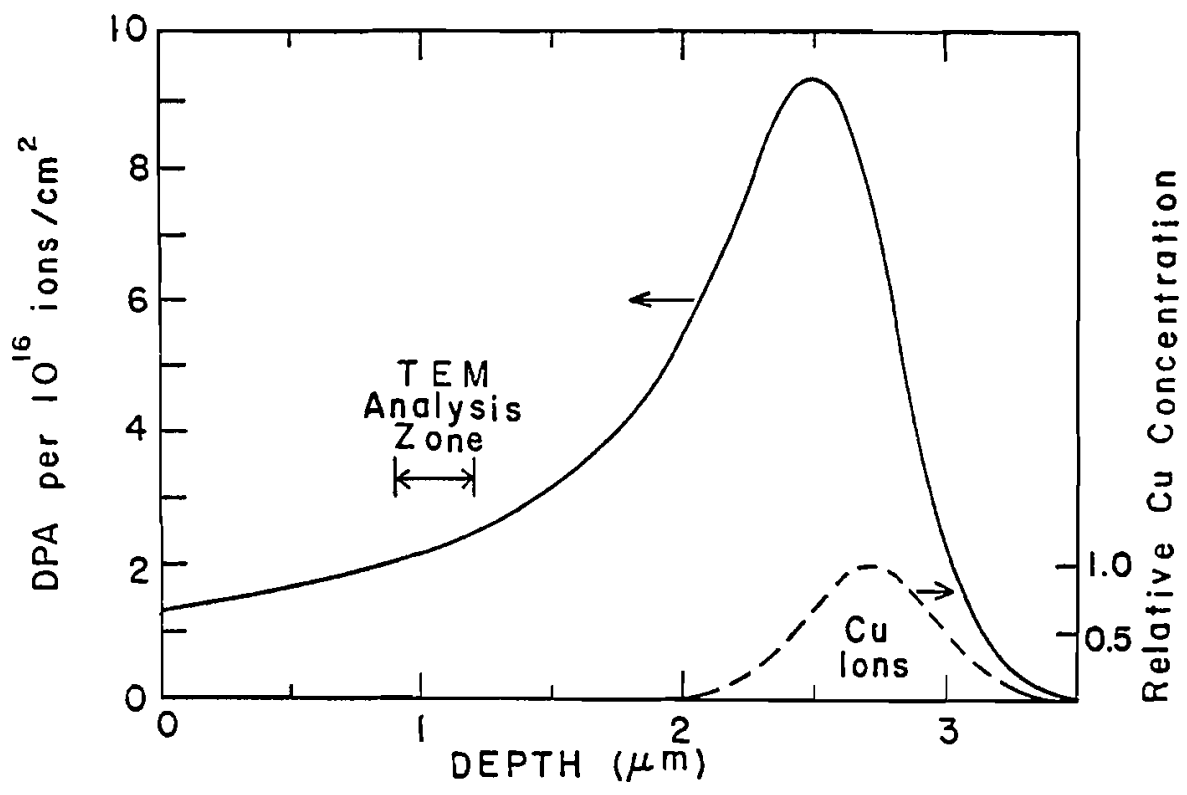

FIGURE A.3-2. Damage Curve for $17 \mathrm{MeV} \mathrm{Cu}$ on Molybdenum Calculated Using the E-DEP-1 Code of Ref. (2). Also indicated on the figure are the TEM analysis zone and the location of the deposited copper ions. 
Therefore, impurity effects due to the use of a copper beam may not be a problem.* The ability to do the TEM analysis away from both the surface and the stopped ions is one of the advantages of using 17-19 heV as opposed to 2-5 MeV heavy ion beams. Table A.3-2 summarizes the irradiation parameters for each of the six irradiated samples which were successfully analyzed on the electron microscope.

After irradiation, the same electropolishing conditions used in the pre-irradiation polish were used to remove $\sim 1 \mu \mathrm{m}$ from the irradiated surface. The amount of surface removed was determined to with \pm 0.1 um by optical interference microscopy. The $3 \mathrm{~mm}$-diameter TEM specimens were then cut from the sample strip and back thinned to perforation in a Fischione jet electropolisher with the same polishing solution but at $-50^{\circ} \mathrm{C}$ and $70 \mathrm{~V}$.

B. Transmission Electron Microscopy Procedure

The specimens were examined in a Jeolco 100B electron microscope operated at $120 \mathrm{kV}$ voltage. Voids were imaged under weak diffraction conditions at high magnification and focused as precisely as possible to minimize the surrounding dark fringes for void size measurement. The magnification of the electron microscope was determined to be accurate to within $+5 \%$. Dislocations and loops were imaged under a two beam condition in typical areas to get the average densities. Photographs of interesting grain boundary areas or any unusual features were also taken.

The foil thickness was determined by the stereo pair technique. The average tilt angle was about 9 degrees from the zero degree horizontal position. The accuracy of the tilt angle is about \pm 10 minutes. Foil thicknesses ranged from $\sim 500 \AA$ near the edge of the foil to a maximum of $2400 \AA$. Photographs of stereo pairs were not taken for the $800^{\circ} \mathrm{C}, 2.2 \mathrm{dpa}$ and $700^{\circ} \mathrm{C}$, 1.0 dpa specimens because the images of the small voids and the background contrast were too variable when the specimens were tilted. The thicknesses of these two foils were estimated by the degree of transparency using the observed thickness range from $500 \AA$ to $\sim 2500 \AA$ in other specimens. * A small amount of precipitation was observed in the 19 dpa specimen as dis-
cussed in Section 2 . 
TABLE A.3-2. Irradiation Parameters.

A. Specimen Environment

\begin{tabular}{|c|c|c|c|c|c|c|c|}
\hline $\begin{array}{l}\text { Spec. } \\
\text { Ident. }\end{array}$ & $\begin{array}{l}\text { Temp } \\
\left({ }^{\circ} \mathrm{C}\right)\end{array}$ & $\begin{array}{c}\text { Temp. } \\
\text { Variation } \\
\left({ }^{\circ} \mathrm{C}\right)\end{array}$ & $\left\{\begin{array}{c}\text { Time } \\
\text { (pre-irrad) }\end{array}\right.$ & $\left|\begin{array}{c}\text { Time } \\
\text { (irrad) }\end{array}\right|$ & $\begin{array}{l}\text { Time at Temp. } \\
\text { (post-irrad) }\end{array}$ & $\begin{array}{l}\text { Vac. } \\
\text { (Torr) }\end{array}$ & $\begin{array}{c}\text { Vacuum (Torr) } \\
\text { (low to high } \\
\text { value) } \\
\end{array}$ \\
\hline 2 & 1000 & \pm 3 & $\begin{array}{l}\text { Annea led by } \\
\text { PNL at } 1600^{\circ} \mathrm{C} \\
\text { for } 2 \text { hours } \\
\text { near } 10^{-6} 6 \\
\text { Torr. }\end{array}$ & $\mid \begin{array}{l}47 \mathrm{~min} \\
\text { ( } \text { Eeam on } \\
39 \text {, off } \\
8)\end{array}$ & $\begin{array}{l}140 \mathrm{~min} \text { at } 900^{\circ} \mathrm{C} \\
160 \mathrm{~min} \text { at } 800^{\circ} \mathrm{C}\end{array}$ & $\begin{array}{l}2.5 \\
10^{x}-8\end{array}$ & $\begin{array}{l}2.2 \times 10^{-8} \\
\pm 0 \\
2.8 \times 10^{-8}\end{array}$ \\
\hline 3 & 900 & \pm 4 & & $\begin{array}{l}112 \text { min } \\
\text { (Beam on } \\
30, \text { off } \\
82)\end{array}$ & $\begin{array}{l}55 \text { min at } 900^{\circ} \mathrm{C} \\
160 \mathrm{~min} \text { at } 800^{\circ} \mathrm{C}\end{array}$ & $\begin{array}{c}9.2 \\
x-9 \\
10^{-9}\end{array}$ & $\begin{array}{l}8.1 \times 10^{-9} \\
\text { to } \\
1.0 \times 10^{-8}\end{array}$ \\
\hline 9 & 900 & \pm 2 & & $\begin{array}{l}85 \text { min } \\
\text { (Beam on } \\
84 \text {, off } \\
1)\end{array}$ & $\begin{array}{l}325 \mathrm{~min} \text { at } 800^{\circ} \mathrm{C} \\
50 \mathrm{~min} \text { at } 700^{\circ} \mathrm{C}\end{array}$ & $\begin{array}{c}4.9 \\
x-9 \\
10^{-9}\end{array}$ & $\begin{array}{l}4.6 \times 10^{-9} \\
\text { to } \\
5.2 \times 10^{-9}\end{array}$ \\
\hline 10 & 800 & \pm 5 & & $\begin{array}{l}195 \text { min } \\
\text { (Beam on } \\
113 \text {, } \\
\text { off } 82 \text { ) }\end{array}$ & $\begin{array}{l}120 \mathrm{~min} \text { at } 800^{\circ} \mathrm{C} \\
50 \mathrm{~min} \text { at } 700^{\circ} \mathrm{C}\end{array}$ & $\begin{array}{c}4.3 \\
x-9 \\
10^{-9}\end{array}$ & $\begin{array}{l}3.8 \times 10^{-9} \\
\text { to } \\
4.7 \times 10^{-9}\end{array}$ \\
\hline 12 & 700 & \pm 10 & & $\begin{array}{l}40 \text { min } \\
\text { (Beam on } \\
29, \text { off } \\
11) \text {. }\end{array}$ & $\begin{array}{l}\text { Cooled immediate- } \\
\text { ly after irradia- } \\
\text { tion }\end{array}$ & $\begin{array}{c}4.4 \\
x-9 \\
10^{-9}\end{array}$ & $\begin{array}{l}3.8 \times 10^{-9} \\
\text { to } \\
4.8 \times 10^{-9}\end{array}$ \\
\hline 13 & 900 & \pm 10 & & $\begin{array}{l}1691 \mathrm{~min} \\
\text { (Beam on } \\
1118, \\
\text { off } 573 \text { ) }\end{array}$ & $\begin{array}{l}145 \mathrm{~min} \text { at } 625^{\circ} \mathrm{C} \\
80 \mathrm{~min} \text { at } 575^{\circ} \mathrm{C} \\
65 \mathrm{~min} \text { at } 525^{\circ} \mathrm{C}\end{array}$ & $\begin{array}{c}1.4 \\
x-8 \\
10^{-8}\end{array}$ & $\begin{array}{l}6.0 \times 10^{-9} \\
\text { to } \\
7.0 \times 10^{-8}\end{array}$ \\
\hline
\end{tabular}

Gas Analysis of Vacuum $57 \% \mathrm{H}_{2}, 18 \% \mathrm{CO}, 22 \% \mathrm{H}_{2} \mathrm{O}, 2 \% \mathrm{CO}_{2}, 1 \% \mathrm{CH}_{4}$ at $1000^{\circ} \mathrm{C}$.

B. Beam Variables (17-19 $\mathrm{MeV} \mathrm{Cu}^{4+}$ ions)

\begin{tabular}{cccccc}
$\begin{array}{c}\text { Spec. } \\
\text { Ident. }\end{array}$ & $\begin{array}{c}\text { Highest } \\
\text { Current } \\
\text { (particle nA) }\end{array}$ & $\begin{array}{c}\text { Lowest } \\
\text { Current } \\
\text { (particle } n A)\end{array}$ & $\begin{array}{c}\text { Average } \\
\text { Current } \\
\text { (particle nA) }\end{array}$ & $\begin{array}{c}\text { Integrated Fluence } \\
\text { (particle nA-hr) (ions) }\end{array}$ Uniformity \\
\hline 2 & 32 & 19 & 31 & 18 & $4.1 \times 10^{14}$ \\
\hline 3 & 40 & 23 & 32 & 16 & $3.6 \times 10^{14}$ \\
9 & 27 & 12 & 21 & 30 & $6.7 \times 10^{14}$ \\
10 & 23 & 8 & 17 & 32 & $7.1 \times 10^{14}$ \\
12 & 38 & 9 & 29 & 14 & $3.2 \times 10^{14}$ \\
13 & 18 & 6 & 13 & 234 & $5.3 \times 10^{15}$
\end{tabular}


The accuracy of the foil thickness obtained from the stereo pairs is $\pm 15 \%$ while the uncertainty of the thickness obtained from the transparency measurements is estimated to be $\pm 50 \%$.

\section{Electron Micrograph Analysis Procedure}

The average void diameters and void size distributions were measured with a Zeiss particle size analyzer. For the $1000^{\circ} \mathrm{C}, 1.3 \mathrm{dpa}$ specimen, edges of the cubic voids in the (100) foil orientation were measured. For specimens irradiated at 900,800 and $700^{\circ} \mathrm{C}$, the diameters were measured assuming spherical void morphology and using the center of the dark fringe surrounding the void. Because the edge of the voids on the surface were polished by the solution, voids intersecting the surface were not counted. A corrected foil thickness of $t-\bar{d}$ was used to determine the void density, where $\bar{d}$ is the average void diameter.

II. Results

We examined six samples irradiated in the temperature range $700-1000^{\circ} \mathrm{C}$ as discussed in section 2-A. Voids were found in each of these specimens and in general were homogeneously distributed. Dislocation loops were observed only in the specimens irradiated to $\sim 2 \mathrm{dpa}$ at $700^{\circ} \mathrm{C}$ and $800^{\circ} \mathrm{C}$ and in the specimen irradiated to $19 \mathrm{dpa}$ at $900^{\circ} \mathrm{C}$.

The voids in the specimen irradiated at $1000^{\circ} \mathrm{C}$ were cubes of $\{110\}$ faces with $\{110\}$ facets. The voids became more spherical as the irradiation temperature decreased. The average void size varied from $\sim 45 \AA$ at lower temperature to $\sim 250 \AA$ at $1000^{\circ} \mathrm{C}$. The volume swelling value at $1000^{\circ} \mathrm{C}$ included a correction for the observed truncations. Swelling values at all other temperatures were calculated by $\Delta V / V=\frac{\pi}{6} p_{V}\left\langle d^{3}\right\rangle$ avg.

A summary of the damage microstructure observed in the examined specimen is contained in Table A.3-3. The uncertainties given in Table A.3-3 are arrived at in the following manner: surface removal, the uncertainty in the interference microscopy determination is $\pm 0.1 \mu \mathrm{m}$; dpa value, $\pm 21 \%$ due to $\pm 20 \%$ beam profile nonuniformity $(1)$ and $\pm-5 \%$ due to the uncertainty in the surface thickness removal (added in quadrature); mean void size $+5 \%$ due to the uncertainty in the measurement of the microscope magnification; 
TABLE A.3-3. Damage Microstructure in the Irradiated Specimens

\begin{tabular}{|c|c|c|c|c|c|c|c|c|c|}
\hline $\begin{array}{c}\text { Specimen } \\
\text { Number }\end{array}$ & $\begin{array}{l}\text { Irradiation } \\
\text { Temp. } \\
\left({ }^{\circ} \mathrm{C}\right) \\
\end{array}$ & $\begin{array}{l}\text { Calculated } \\
\text { dpa (\%) } \\
\pm \text { Error } \\
\end{array}$ & $\begin{array}{l}\text { Surface } \\
\text { Rem. }(\mu \mathrm{m}) \\
\text { Error }(\mu \mathrm{m})\end{array}$ & $\begin{array}{l}\text { Mean Void } \\
\text { Size }(\AA)\end{array}$ & $\begin{array}{c}\text { Total Number } \\
\text { of } \\
\text { Voids Sized } \\
\end{array}$ & $\begin{array}{l}\text { Number } \\
\text { of Areas } \\
\text { Sampled } \\
\end{array}$ & $\begin{array}{l}\text { Void } \\
\text { Density } \\
\left(\mathrm{cm}^{-3}\right) \\
\end{array}$ & $\begin{array}{c}\text { Areas } \\
\text { Sampled }\end{array}$ & $\begin{array}{c}\text { Void } \\
\text { Volume } \\
\text { Fraction } \\
(\%) \\
\end{array}$ \\
\hline 2 & 1000 & $1.3 \pm 0.3$ & $0.9 \pm 0.1$ & 252 & 354 & 2 & $5.8 \times 10^{14}$ & 1 & 0.76 \\
\hline 3 & 900 & $1.0 \pm 0.2$ & $0.9 \pm 0.1$ & 78 & 393 & 2 & $6.0 \times 10^{15}$ & 1 & 0.17 \\
\hline 9 & 900 & $1.9 \pm 0.4$ & $0.9 \pm 0.1$ & 98 & 230 & 1 & $6.6 \times 10^{15}$ & 1 & 0.39 \\
\hline 10 & 800 & $2.2 \pm 0.5$ & $1.0 \pm 0.1$ & 44 & 340 & 1 & $1.7 \times 10^{16}$ & 1 & 0.11 \\
\hline 12 & 700 & $1.0 \pm 0.2$ & $1.1 \pm 0.1$ & 48 & 259 & 1 & $1.0 \times 10^{16}$ & 1 & 0.08 \\
\hline 13 & 900 & $19 \pm 4$ & $1.2 \pm 0.1$ & 75 & 1305 & 2 & $3.0 \times 10^{16}$ & 1 & 0.87 \\
\hline
\end{tabular}

$\frac{D}{n}$

\begin{tabular}{|c|c|c|c|c|c|c|c|c|c|}
\hline $\begin{array}{c}\text { Specimen } \\
\text { Number }\end{array}$ & $\begin{array}{c}\text { Estimated } \\
\text { Error } \\
( \pm \%) \\
\end{array}$ & $\begin{array}{l}\text { Mean Loop } \\
\text { Diameter } \\
(\AA)\end{array}$ & $\begin{array}{l}\text { Standard } \\
\text { Deviation } \\
(\AA) \\
\end{array}$ & $\begin{array}{c}\text { Total No. } \\
\text { of } \\
\text { Loops Sized } \\
\end{array}$ & $\begin{array}{r}\begin{array}{r}\text { Num } \\
\text { of } \\
\text { Areas }\end{array} \\
\end{array}$ & $\begin{array}{l}\text { nber } \\
\text { Sampled }\end{array}$ & $\begin{array}{c}\text { Loop } \\
\text { Density } \\
\left(\mathrm{cm}^{-3}\right) \\
\end{array}$ & $\begin{array}{c}\text { Line } \\
\text { Density } \\
\left(\mathrm{cm}^{-2}\right) \\
\end{array}$ & $\begin{array}{c}\text { Total } \\
\text { Dislocation } \\
\text { Density }(a) \\
\end{array}$ \\
\hline 2 & 0.15 & $-\cdot$ & -- & -- & No Loops & Detected & -- & $1 \times 10^{9}$ & $1 \times 10^{9}$ \\
\hline 3 & 0.03 & --- & -- & -- & No Loops & Detected & -- & ND & ND \\
\hline 9 & 0.08 & -- & -- & -- & No Loops & Detected & -- & $5 \times 10^{9}$ & $5 \times 10^{9}$ \\
\hline 10 & 0.06 & 160 & 65 & 6 & & 2 & $2 \times 10^{13}$ & $8 \times 10^{8}$ & $9 \times 10^{8}$ \\
\hline 12 & 0.04 & 76 & 27 & 72 & & 1 & $2 \times 10^{15}$ & $4 \times 10^{9}$ & $9 \times 10^{9}$ \\
\hline 13 & 0.17 & 420 & 60 & 4 & & 2 & $7 \times 10^{12}$ & $1 \times 10^{9}$ & $1 \times 10^{9}$ \\
\hline
\end{tabular}

ND - Not Determined

(a) - Loop + Line 
void density $\pm 25 \%$ due to $\pm 15 \%$ uncertainty in foil thickness and $\pm 5 \%$ in the microscope calibration (added twice) except for specimens 10 and 12 where this error is $+60 \%$ due $\pm 50 \%$ uncertainty in foil thickness plus $+5 \%$ in the microscope calibration; and void volume fraction, $+20 \%$ due to the $\pm 15 \%$ uncertainty in the foil thickness and $\pm 5 \%$ in the microscopic calibration (added only once due to cancelation in the $\rho_{v}\left\langle d^{3}\right\rangle$ avg. product) except for specimens 10 and 12 where this error is $\pm 55 \%$ due to $\pm 50 \%$ uncertainty in the foil thickness and $\pm 5 \%$ in the microscope calibration. Figure A.3-3 contains histograms of the void size distributions.

Randomly distributed precipitates were observed in the $900^{\circ} \mathrm{C}, 19 \mathrm{dpa}$ specimen. These precipitates could affect the void microstructure in this specimen. No precipitates were observed in any other specimen. Some void depleted zones were observed at grain boundaries with widths varying from 300 to $700 \AA$ at $900^{\circ} \mathrm{C}$. The change in the void size is reduced for narrower depleted zones. This can be explained by differences in the effectiveness of the grain boundaries as defect sinks. The beginning of a void superlattice was observed in the $800^{\circ} \mathrm{C}, 2.2 \mathrm{dpa}$ specimen. A void lattice with better alignment was found in the $900^{\circ} \mathrm{C}, 19 \mathrm{dpa}$ specimen though the alignment was still not perfect. The void lattice spacing is about $340 \AA$ in both specimens.

Loop and network dislocation densities were also determined when the foil thickness was determined from stereo pair analysis. The values obtained are given in Table A.3-3. The loop density decreased from $2 \times 10^{15} \mathrm{~cm}^{-3}$ at $700^{\circ} \mathrm{C}$ to $2 \times 10^{13} \mathrm{~cm}^{-3}$ at $800^{\circ} \mathrm{C}$. At $900^{\circ} \mathrm{C}$, loops were observed only in the $19 \mathrm{dpa}$ high dose specimen. No $100 \mathrm{ps}$ were found at $1000^{\circ} \mathrm{C}$ and $1.3 \mathrm{dpa}$. 


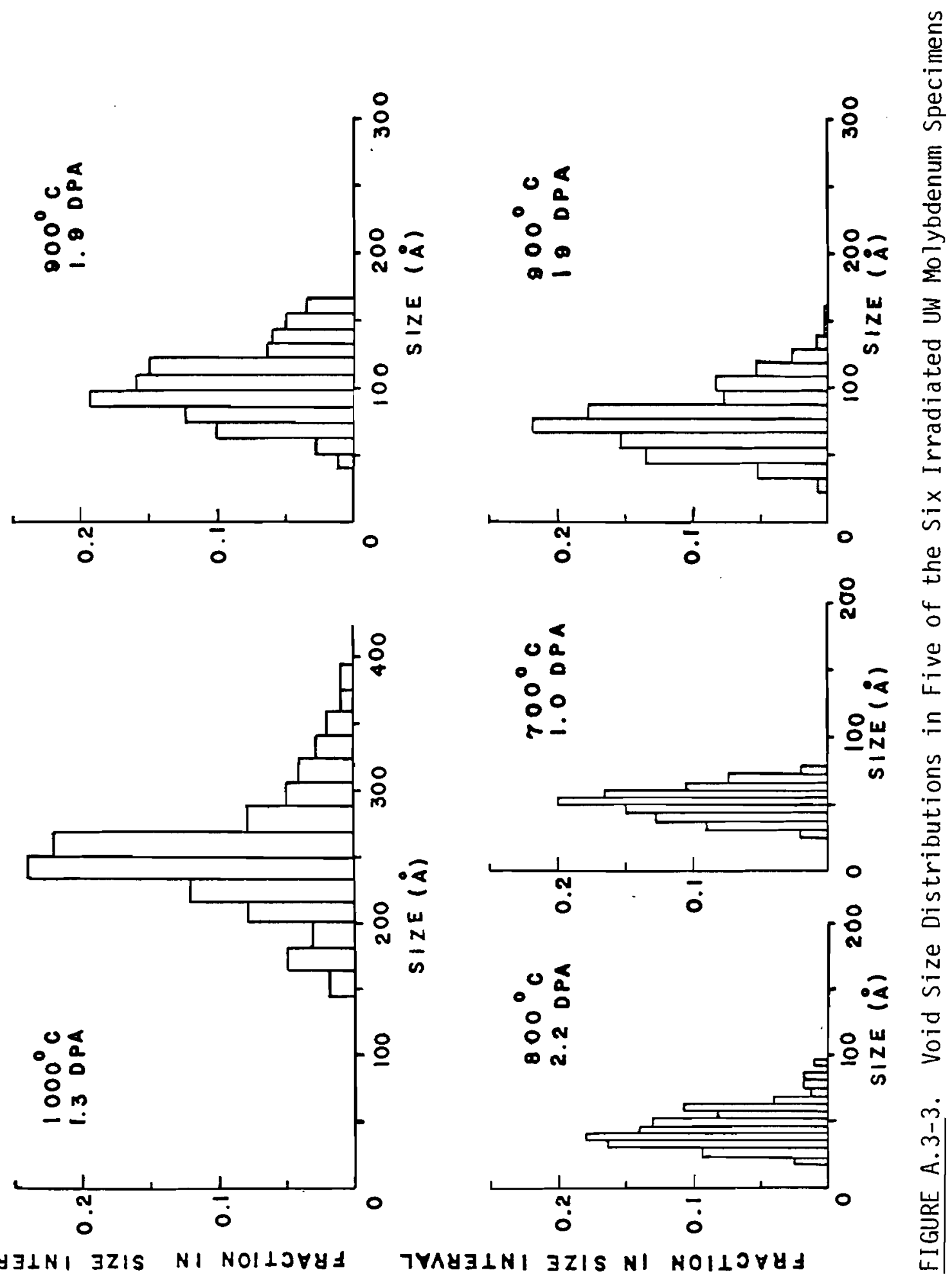




\section{REFERENCES}

1. H. V. Smith, Jr., and R. G. Lott, Nucl. Instr. Meth. (in press). R. G. Lott and H. V. Smith, Jr., Proc. of Symp. on Experimental Methods for Charged-Particle Irradiations, D. Kramer (ed.), CONF-750947, p. 82, September 1975.

2. I. Manning and G. P. Muet7er, Comp. Phys. Comm. 7: 1974. 


\section{A.4 PACIFIC NORTHWEST LABORATORY BCC ION CORRELATION EXPERIMENT DATA SHEET FOR EXPERIMENTAL PARAMETERS}

I. Material Chemistry - See Body of Report

II. Pretreatment

A. Electropolishing (solution, temperature, surface removal, etc.) $12 \% \mathrm{H}_{2} \mathrm{SO} 4$ in Methyl Alcohol, $-55^{\circ} \mathrm{C}, 20$ volts for 2 minutes

B. Other preparation (mechanical polish, chemical etch, etc.) Ground flat and mechanically polished prior to electropolish

III. Post-Irradiation Examination

A. Data or parameters common to all specimens

Magnification accuracy

$\pm 5 \%$

Tilt stage accuracy $+5 \%$

Average foil thickness + estimated error

voids:

$500 \mathrm{~A} \pm 20 \%$ a $93 \%$ confidence level

dislocation:

$2000 \AA+20 \%$ @ $93 \%$ confidence level

Diffraction contrast conditions

voids:

kinematic $s \gg 0$

dislocations:

near dynamical condition (s positive)

Focus conditions

voids:

under focus

dislocations:

at focus

Void dimension measured

$<100\rangle$ cube edge 


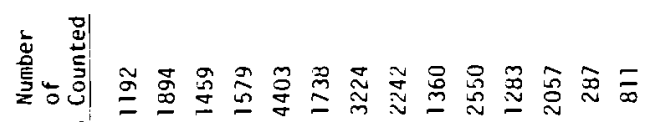
כ)

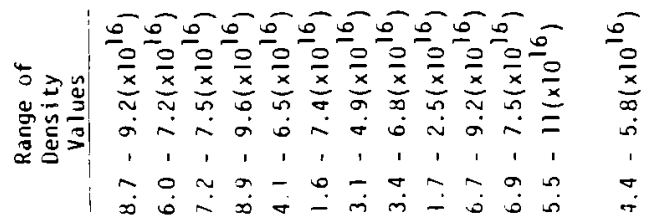

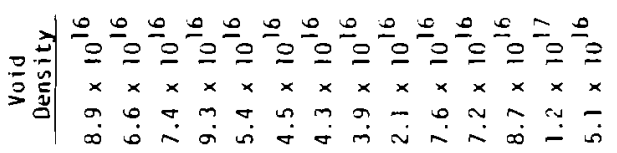

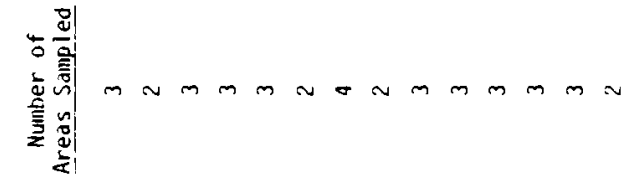

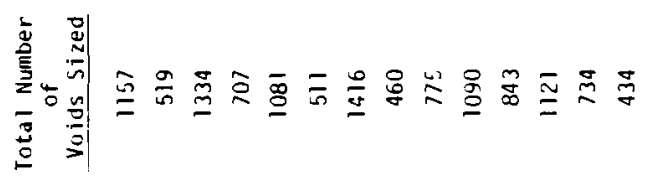

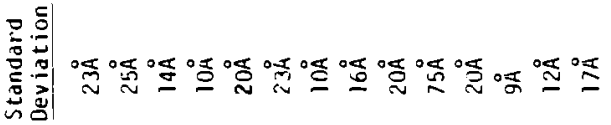

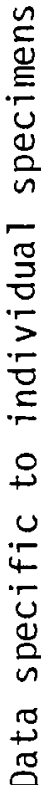

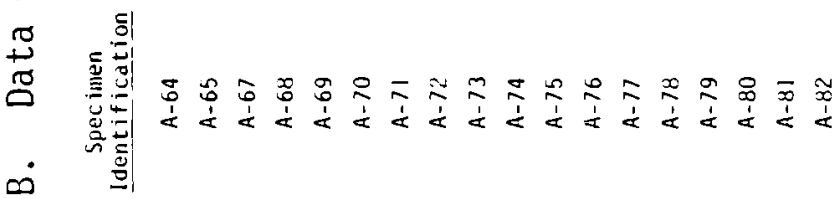

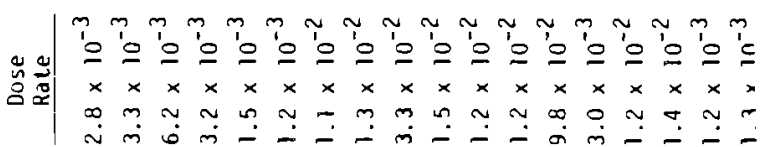

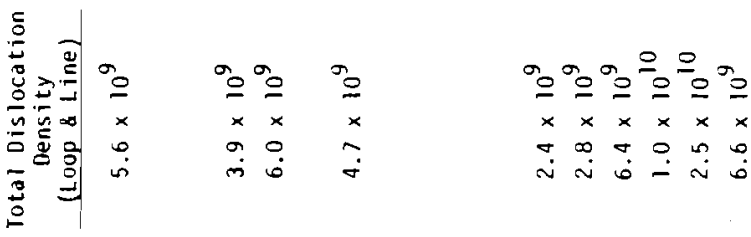

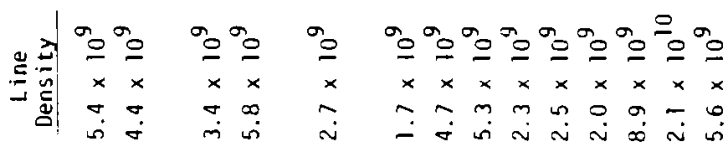

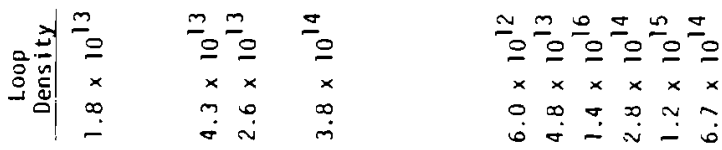

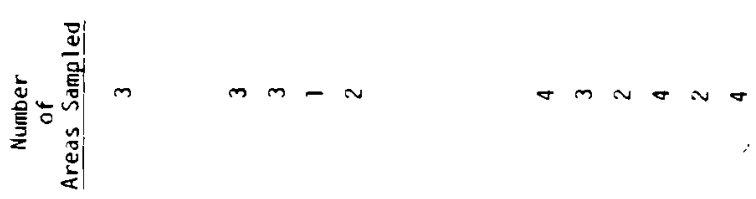

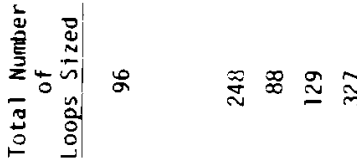

品只品巻吉

焉:

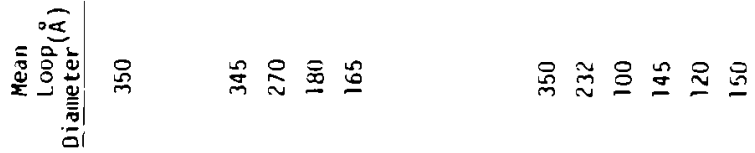

蛋|

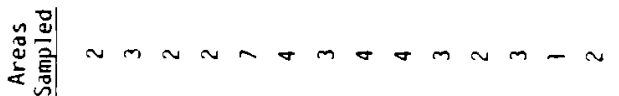

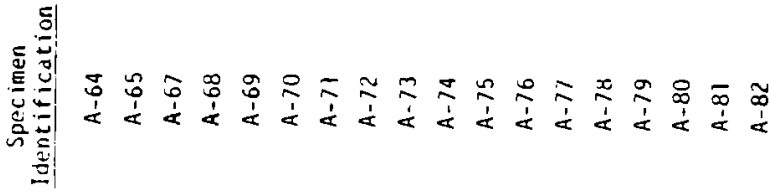




\section{Irradiation Parameters}

A. Specimen Environment

\begin{tabular}{|c|c|c|c|c|c|c|c|}
\hline $\begin{array}{l}\text { Spec. } \\
\text { Ident. }\end{array}$ & $\begin{array}{c}\text { Temp } \\
{ }^{2} \\
\end{array}$ & $\begin{array}{l}\text { Temo } \\
\text { vartation } \\
\pm \partial^{\circ} c \\
\end{array}$ & $\begin{array}{c}\text { Time } \\
\text { (pre-irrad) } \\
\text { Hours } \\
\end{array}$ & $\begin{array}{l}\text { Time } \\
\text { (irrad) } \\
\text { Hours } \\
\end{array}$ & $\begin{array}{c}\text { Tine } \\
\text { (post-irrad) } \\
\text { Hours } \\
\end{array}$ & $\begin{array}{c}\text { Temp. } \\
\text { (post-irrad) } \\
\text { oc }\end{array}$ & $\begin{array}{l}1 \mathrm{rac}-6 \\
\times 10^{-6} \\
\end{array}$ \\
\hline$A-54$ & 900 & $j$ & 1.9 & 2.0 & 8.0 & 900 & 1.5 \\
\hline$A=65$ & 900 & 5 & 3.9 & 1.9 & 6.1 & 900 & 1.4 \\
\hline$\lambda-67$ & 900 & 5 & 7.7 & .7 & 3.5 & 900 & 1.2 \\
\hline$A-68$ & 900 & 5 & 3.7 & .2 & 3.0 & 900 & 1.2 \\
\hline A-б9 & 900 & 5 & 10.9 & .4 & .5 & 900 & 1.0 \\
\hline$A-70$ & 900 & 5 & 11.3 & .4 & .1 & 900 & 1.0 \\
\hline$A-71$ & 900 & 5 & 11.3 & .05 & .05 & 900 & 1.0 \\
\hline$A-72$ & 900 & 5 & 11.8 & .05 & 0 & & 1.0 \\
\hline \multirow[t]{2}{*}{$\dot{n}=73$} & 1000 & 5 & 0 & 1.8 & 1.0 & 1000 & 2.3 \\
\hline & & & & & 3.3 & 200 & \\
\hline \multirow[t]{2}{*}{$\therefore-74$} & 1300 & $j$ & $i .2$ & .4 & .5 & 1000 & $i .5$ \\
\hline & & & & & 3.5 & 800 & \\
\hline \multirow[t]{2}{*}{$A+75$} & 1000 & 5 & 2.1 & .5 & .2 & 1000 & 1.3 \\
\hline & & & & & 3.5 & 800 & \\
\hline \multirow[t]{2}{*}{$A-76$} & 1000 & 5 & 2.6 & .05 & .2 & 1000 & 1.6 \\
\hline & & & & & 3.5 & 300 & \\
\hline$x^{2}=77$ & 1000 & 5 & 3.7 & .05 & 3.5 & 300 & 1.5 \\
\hline \multirow[t]{2}{*}{$A=78$} & 1000 & 5 & 2.7 & & & & \\
\hline & 300 & 5 & 1.3 & 2.1 & 0 & & 1.0 \\
\hline \multirow[t]{2}{*}{ A-79 } & 1000 & 5 & 2.3 & & & & \\
\hline & 800 & 5 & 0 & 5 & 2.7 & 300 & .9 \\
\hline \multirow[t]{2}{*}{$A-80$} & 1000 & 5 & 2.8 & & & & \\
\hline & 800 & 5 & .5 & .5 & 2.2 & 300 & .9 \\
\hline \multirow[t]{2}{*}{$A-81$} & 1000 & 5 & 2.9 & & & & \\
\hline & 200 & 5 & .9 & .05 & 2.2 & 800 & .9 \\
\hline \multirow[t]{2}{*}{$A-82$} & 1000 & 5 & 2.8 & & & & \\
\hline & 300 & 5 & 1.0 & .05 & 2.1 & 800 & .8 \\
\hline
\end{tabular}

B. Beam Variables

\begin{tabular}{|c|c|c|c|c|c|}
\hline $\begin{array}{l}\text { Spec. } \\
\text { Ident. }\end{array}$ & $\begin{array}{c}\text { Highest } \\
\text { Current (ma) }\end{array}$ & $\begin{array}{c}\text { Lowest } \\
\text { Current (ma) } \\
\end{array}$ & $\begin{array}{c}\text { Average } \\
\text { Current (ma) } \\
\end{array}$ & $\begin{array}{l}\text { Integrated } \\
\text { Fluence } \\
\text { ions/cm }\end{array}$ & $\begin{array}{c}\text { Beam } \\
\text { Uni formity(?) }\end{array}$ \\
\hline$A-64$ & .038 & .020 & .028 & $3.3 \times 10^{16}$ & Unknown \\
\hline$A-65$ & .035 & .020 & .028 & $3.3 \times 10^{16}$ & \\
\hline$A-67$ & .040 & .028 & .030 & $1.5 \times 10^{16}$ & \\
\hline$A-68$ & .028 & .028 & .028 & $3.2 \times 10^{15}$ & \\
\hline$A-69$ & .120 & .120 & .120 & $3.3 \times 10^{16}$ & \\
\hline$A-70$ & .120 & .120 & .120 & $3.3 \times 10^{16}$ & \\
\hline$A-71$ & .120 & .120 & .120 & $3.3 \times 10^{15}$ & \\
\hline$A-72$ & .120 & .120 & .120 & $3.3 \times 10^{15}$ & \\
\hline$A-73$ & .035 & .028 & .028 & $3.2 \times 10^{16}$ & \\
\hline A- 74 & .120 & .130 & .122 & $3.3 \times 10^{16}$ & \\
\hline$A-75$ & .120 & .120 & .120 & $3.2 \times 10^{16}$ & \\
\hline$A-76$ & .120 & .142 & .131 & $3.5 \times 10^{15}$ & \\
\hline$A-77$ & .120 & .085 & - & $3.5 \times 10^{15}$ & \\
\hline$A-78$ & .033 & .005 & .053 & $3.1 \times 10^{16}$ & \\
\hline$A-79$ & .120 & .120 & .120 & $3.3 \times 10^{16}$ & \\
\hline$A-80$ & .120 & .120 & .120 & $3.3 \times 10^{16}$ & \\
\hline$A-81$ & .120 & .120 & .120 & $3.3 \times 10^{15}$ & \\
\hline$A-82$ & .120 & .120 & .120 & $3.3 \times 10^{15}$ & \\
\hline
\end{tabular}




\section{APPENDIX B}

DATA ACQIJISITION FROM PART 2

ANALYSIS OF A COMMON MICROGRAPH IN THE

BODY-CENTERED CUBIC ION CORRELATION PROGRAM 


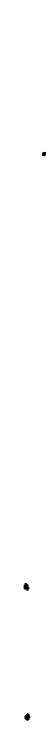


APPENDIX B

\author{
DATA ACQUISITION FROM PART 2 \\ ANALYSIS OF A COMMON MICROGRAPH IN THE \\ BODY-CENTERED CUBIC ION CORRELATION PROGRAM
}

This appendix contains detailed description of the data acquisition from Part 2 - Analysis of a Common Micrograph in the BCC-ICE program. Some editing of the material has been done but the context remains basically as supplied by the participants.

\title{
B. 1 ATOMICS INTERNATIONAL ANALYSIS OF PHOTOMICROGRAPHS AT ATOMICS INTERNATIONAL
}

A Zeiss Particle-Size Analyzer is used to count and size voids. The perimeter of each void is assumed to lie in the center of the encircling overfocus fringe. In those instances where the voids are irregularly shaped, the area of the light spot on the analyzer is adjusted until the operator feels the area matches that of the void image on the photomicrograph. Whenever possible, the analyzer is operated in the "reduced" linear mode so that the intervals on the analyzer represent the minimum uncertainty in size.

The void populations in the analyzer intervals are fed into a computer program. This program confirms the number of voids in each interval and supplies the total number of voids counted, the void diameter represented by the center of each size interval, the fraction of voids falling within the interval, the void density, the average void diameter, the foil volume, the total void volume, the void volume fraction $(\Delta V / V)$ and the swelling $\left(\Delta V / V-\Delta V=\Delta V / V_{0}\right)$. When more than one photomicrograph is being analyzed, the program supplies the above information for each photograph and for the entire sample represented by al1 photographs.

\footnotetext{
*In counting the NRL photoaraph this mode was used, and each analyzer interval spanned about 4.6 A.
} 
The computer program is based on the following relationships. The void density, $\rho_{v}$, is given by

$$
\rho_{v}=\frac{n_{t} M^{2}}{L_{1} L_{2} t}\left(\mathrm{~cm}^{-3}\right)
$$

where $n_{t}$ is the total number of voids counted, $M$ is the magnification of the photomicrograph, $L_{1}$ and $L_{2}$ are the dimensions in $\mathrm{cm}$ of the photomicrograph area analyzed, and $t$ is the foil thickness in $\mathrm{cm}$. On the analyzer, the center of the $i$ th interval, $\bar{x}_{j}$, is given in $\mathrm{mm}$. The diameter of a void falling within this interval is given by

$$
\bar{d}_{j}(\mathrm{~cm})=3.33 \times 10^{-2} \bar{x}_{i} / M
$$

if the analyzer is operated in the reduced mode. The average diameter for all voids in the photomicrograph, $\bar{d}$, is then

$$
\bar{d}=\sum_{i} \frac{n_{i}}{n_{t}} \bar{d}_{j}=\frac{3.33 \times 10^{-2}}{M n_{t}} \sum_{i} \bar{x}_{i} n_{i}
$$

where $n_{i}$ is the number of voids in the $i$ th interval. The average volume, $\bar{v}_{i}$, of a void falling within the $i \frac{\text { th }}{i n t e r v a l}$ is

$$
\bar{v}_{i}\left(\mathrm{~cm}^{3}\right)=\frac{\pi}{6}\left(\bar{d}_{i}\right)^{3}=1.94 \times 10^{-5} \bar{x}_{i}^{3} / \mathrm{M}^{3} .
$$

$\bar{V}_{i}$ is summed for all intervals to obtain $\Delta V$. The void volume fraction and swelling are then obtained from the known values of $\Delta V$ and $V$, the foil volume represented by the photomicrograph. Relationships identical to (2), (3), and (4) except for numerical constants are used when the analyzer has been operated in the "standard" mode.

Void Parameters Measured on Common Micrograph:

Number of voids counted $\quad 1842$

Average diameter

Standard Deviation

$79 \AA$

Void Density

$22 \AA$

$\Delta V / V_{0}$

$5.96 \times 10^{16} \mathrm{voids} / \mathrm{cm}^{3}$

$2.00 \%$

Void size distribution is shown in Figure B.1-1. 


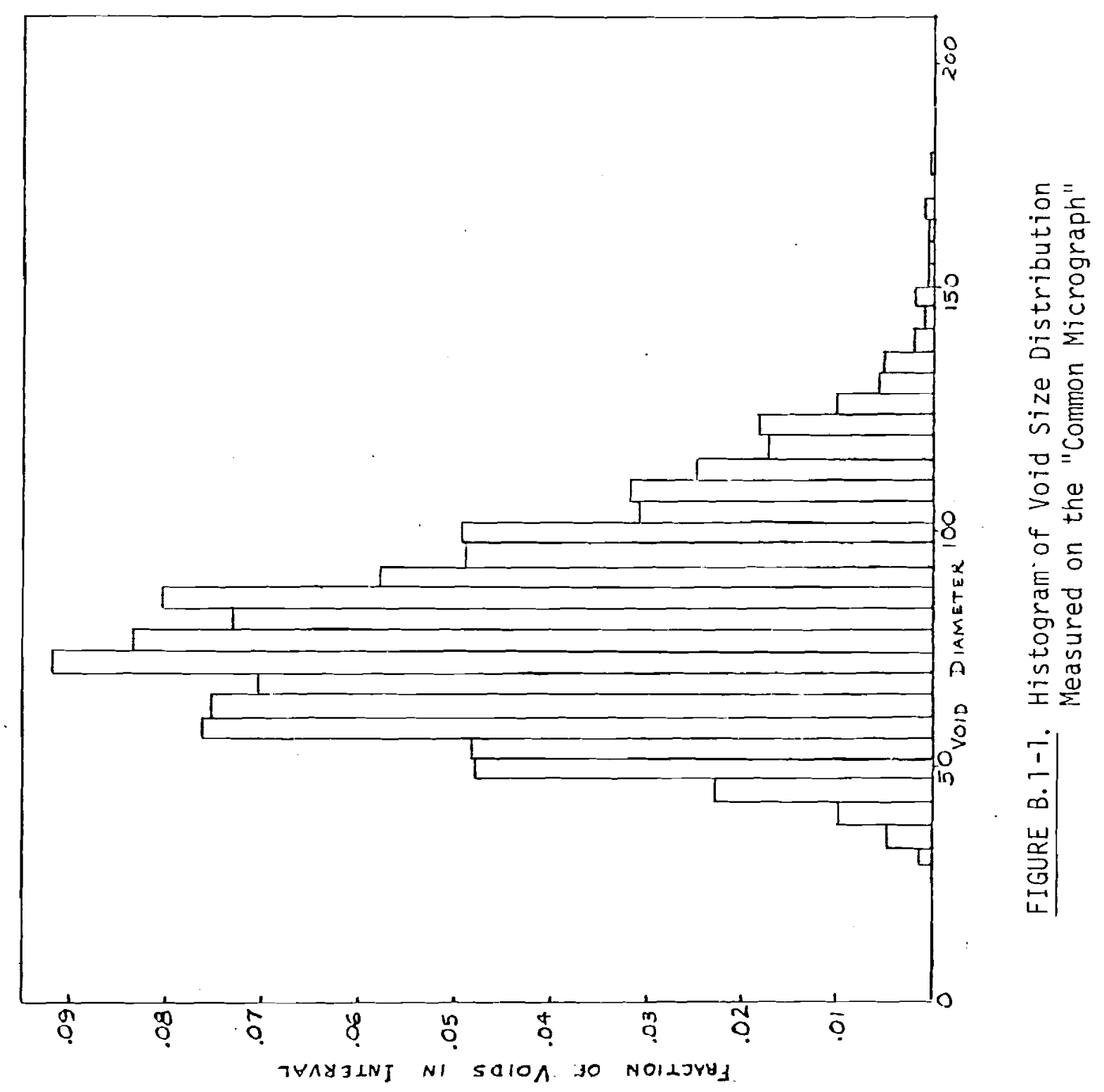




\section{B.2 ARGONNE NATIONAL LABCRATORY}

The following data on measurements of the common micrograph was supplied by ANL:

$\begin{array}{ll}\text { No. of voids counted } & 1703 \\ \text { Average diameter } & 82.1 \AA \\ \text { Standard deviation } & 27.5 \AA \\ \text { Void density } & 6.14 \times 10^{16} \text { voids } / \mathrm{cm}^{3} \\ \text { Void Volume Fraction } & 2.2 \%\end{array}$




\section{B.3 MASSACHUSETTS INSTITUTE OF TECHNOLOGY}

Procedures:

A. Void counting

The void size distribution was measured with a Zeiss TGZ3 Particle Size Analyzer using a portion of the micrograph $(19.98 \times 19.08 \mathrm{~cm}$.). Every void that was visible was counted; using a reduced, exponential scale. The true diameter of the void was taken as equivalent to the outer portion of the dark contrast ring surrounding each image. Edge effects were accounted for by counting only the voids whose centers lie within the field of view. Surface effects and overlap were ignored for the present.

B. Data Reduction and Analysis

The reduction of raw data was straightforward. The counts from each size class were multiplied by the appropriate exponential mode correction factors given in the Zeiss manual and a histogram and cumulative distribution curve were generated in the conventional manner. A correction accounting for the voids whose centers lie outside of the plane of the foil was used:

$$
N_{i}^{C}=N_{i}^{0} /\left(1+I C_{i} / t\right)
$$

where $\mathrm{N}_{i}^{C}$ = corrected number of voids for each size class,

$N_{i}^{0}=$ observed number of voids for each size class,

IC $C_{i}=$ Interval Center for each size class,

and $t=$ foil thickness

As a check for normality, the cumulative curve was plotted on nomal probability paper. Descriptive parameters for the distribution curve--mean, standard deviation, skewness and kurtosis--were calculated by the standard formulas. The volume fraction was found from the following relation:

$$
V_{V}=\frac{\sum V}{1 w t / M^{2}}
$$

Where $\Sigma V=$ Summation of individual void volumes; $1 \& \mathrm{~W}=$ enlarged dimensions of examined region, $t$ = actual thickness, $M$ = magnification. 


\section{Discussion:}

A problem exists in determining a size distribution--the observers tendency to place more weight on the larger objects than on the smaller. Using linear class intervals will result in higher accuracy for the larger objects than the smaller. When the scale is changed to exponential intervals, there is constant measuring accuracy for all sizes. As is pointed out by Rïhle, (1) the true diameter of the void may correspond to different contrast features depending upon the foil thickness, void size, foil orientation and focussing conditions. For this micrograph, the true diameter was taken as the dark ring surrounding each image, with the voids assumed spherical.

A difficulty in determining volume fraction arises with edge and surface effects. The edges of the field of view cut many of the voids--requiring a convention for taking this into account. The convention used here was to count only those images whose centers lie within the boundaries. The voids which are physically cut by the surface lead to the same problem. The previous convention cannot be adopted because of the impossibility of determining which voids have centers outside of the foil thickness. Since, on the average, an equal number of voids have centers outside of the foil as within, their effects on the volume fraction may be ignored. There will be a broadening of the distribution curve due to this effect (especially at the low end). It should also be recognized that the surface voids will be somewhat enlarged by the etching process, but this may be essentially ignored, since the surface voids (in this sample) occupy approximately . $13 \%$ of the volume.

Inspection of the micrograph showed that loss of voids through overlap could be essentially ignored--although the methods of Hilliard $(2)$ to account for overlap are being applied to the data. Due to the small loss through overlap, the relation for volume fraction was extremely simple. 
The void parameters are shown below and the void size distribution in Figure B.3-1.

$\begin{array}{lll}\text { Number of Voids } & = & 1280.04 \\ \text { Average Diameter } & = & 77.60 \AA \\ \text { Average Area } & =0.52 \mathrm{E}+04 \AA^{2} \\ \text { Average Volume } & =0.32 \mathrm{E}+06 \AA^{3} \\ \text { Thickness } & =1050.0 \AA \\ \text { Volume Fraction } & =0.016335 \\ \text { Voids/cc } & =0.51 \mathrm{E}+17 \\ \text { Variance } & =578.18 \AA^{2} \\ \text { Standard Deviation } & =24.05 \AA \\ \text { Skewness } & =0.57 \\ \text { Kurtosis } & =3.30\end{array}$

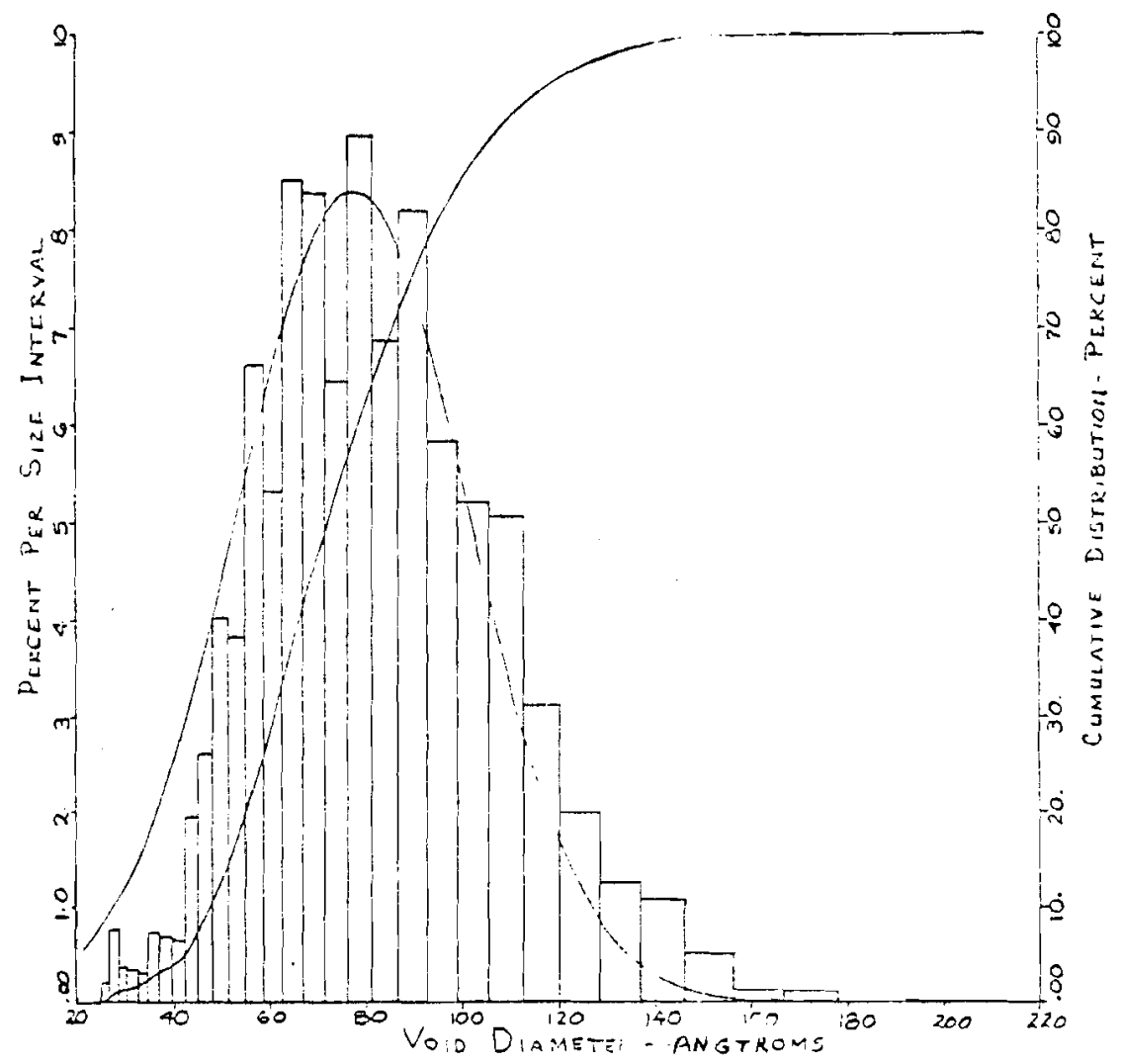

FIGURE B.3-1. Histogram of Void Size Distribution and Cumulative Distribution Measured on the "Common Micrograph" 


\section{REFERENCES}

1. M. R. Rühle, Radiation Induced Voids in Metals, AEC Symposium Series 26,1971 .

2. J. E. Hilliard, "The Counting and Sizing of Particles in Transmission Microscopy", Trans. AIME, 224: 906, 1962. 


\section{B.4 NAVAL RESEARCH LABORATORY}

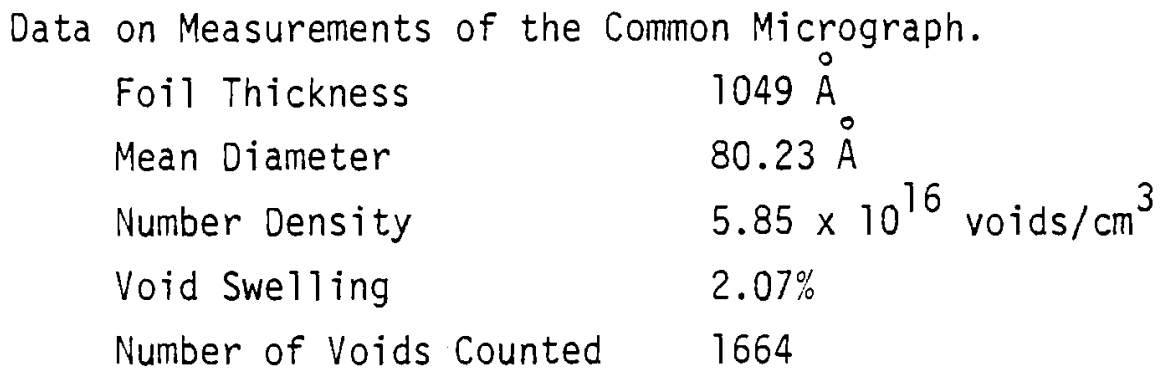

The void size distribution is shown in Figure B.4-1.

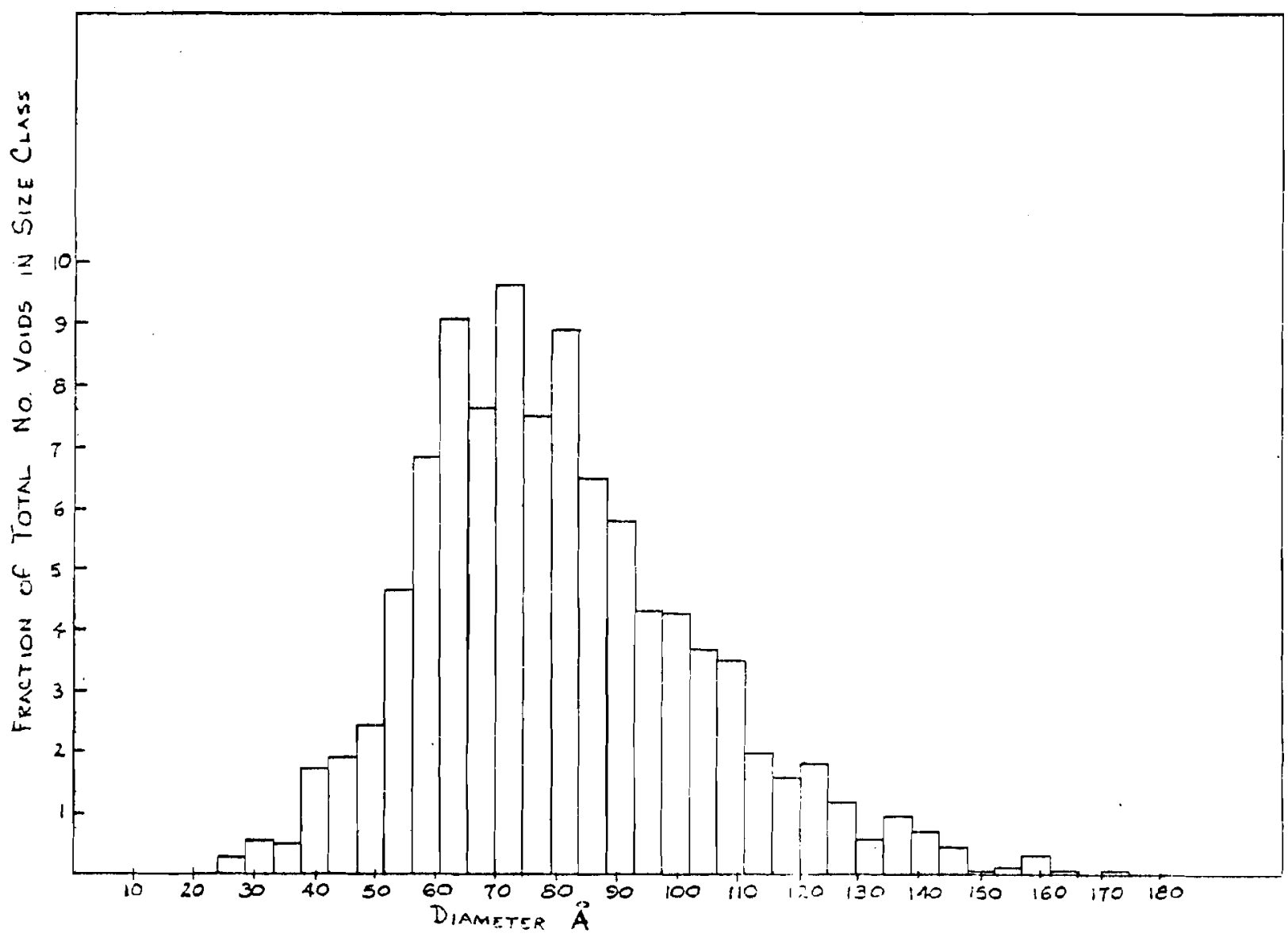

FIGURE B.4-1. Histogram of Void Size Distribution Measured on the "Common Micrograph" 


\section{B.5 OAK RIDGE NATIONAL LABORATORY}

Void Sizing of Common Micrograph

Information supplied:

Foil Thickness $=1050 \AA$

Magnification $=400,000 \times$

From the contrast exhibited by the voids the micrograph was underfocussed slightly and the true size of the voids is given by the diameter measured to the inside of the dark Fresnel-like fringe. (Normally with such small voids better delineation is obtained in the slightly overfocussed condition, say, $\sim 1 \mu \mathrm{m}$. )

Void size distributions were obtained using a calibrated Zeiss particle size analyzer (for three areas and a total of 713 voids). The data were processed to yield the following parameters:

(1) Mean void size $\sum_{i} n_{i} d_{i} / \sum_{i} n_{i}=78.4 \AA$

(First moment of size distribution.)

Standard deviation $=2.0 \AA$ *

(2) Volume averaged mean void size $\left(\sum \sum_{i}^{3} d_{i} / \sum_{i} \eta_{i}\right)^{1 / 3}=86.5 \AA$

(Third moment of size distribution)

Standard deviation $=3.2 \AA$ *

(3) Void density $=6.04 \times 10^{16} \mathrm{~cm}^{-3}$

Standard deviation $=0.15 \times 10^{16} \mathrm{~cm}^{-3}$ *

(4) Void volume fraction $=2.04 \%$

Standard deviation $=0.20 \%$

* Standard deviation of the measurements.

NOTE: Some difficulty was experienced in fitting the size of the aperture on the particle size analyzer to the inside of the dark Fresnel-1ike fringe and a comparison with measurements using a 10x eyepiece and graticule indicates that the measured sizes are probably approximately 2 or $3 \%$ larger $(\Delta V / V \sim 6$ to $9 \%$ too large). 


\section{B.6 PACIFIC NORTHWEST LABORATORY VOID SIZE AND VOID DENSITY DETERMINATION OF THE BCC-ICE "STANDARD" PHOTOMICROGRAPH}

The standard photomicrograph provided by NRL has been analyzed for void size and void density. The void size was measured by three persons using two techniques, namely a calibrated $7 \chi$ measuring eyepiece and a Ziess particlesize analyzer. Approximately 600 voids were measured from representative areas of the micrograph with the same areas being measured by each person. The void density was determined by counting the voids in two $100 \mathrm{~cm}^{2}$ areas of the micrograph. The results from two independent measurements show the void density to be $5.91 \pm .06 \times 10^{16} \mathrm{~cm}^{-3}$.

The void size data and the calculated swelling values are given in Table B.5-1. The combined data show mean void diameters of $82 \AA$ and $87 \AA$, respectively, for the measurements made with the Ziess particle-size analyzer and the measuring eyepiece. The mean void diameters obtained by the three individuals show maximum differences of $12 \AA$ when the particle size analyzer was used and $6 \AA$ with the measuring eyepiece. In all cases, the void perimeter was assumed to coincide with the inside of the dark underfocus ring and thus the variations observed reflect the different interpretations of this dimmension.

TABLE B.5-1. Void Data from the BCC-ICE "Standard" Photomicrograph

\begin{tabular}{lcc}
\multicolumn{3}{c}{ Measuring Eyepiece } \\
Void & Standard SwelTing \\
Size & Deviation \\
d $(A)$ & $S(A)$ & $\frac{\Delta V}{V O}(\%)$
\end{tabular}

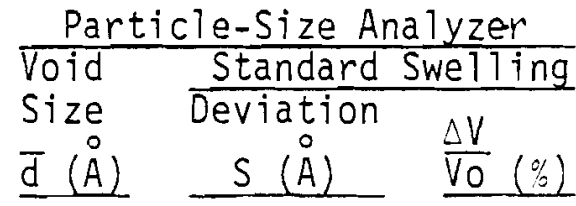

Person A
Person B
Person C
Combined
Data

83

25 .

2.4

79

21

2.0

89

24

2.8

89

25

2.9

89

25

2.9

77

23

1.9

87

25

2.7

82

23

2.2

Void Density $=5.91 \pm .06 \times 10^{16} \mathrm{~cm}^{-3}$ 


\section{B.7 UNIVERSITY OF CINCINNATI}

\section{Experimental Procedure}

The void sizes and numbers in one of the two identical micrographs supplied by NRL were measured and counted using a TGZ 3 Zeiss Particle Size Analyzer operated at a linear-distribution-reduced mode. All visible voids with images lying wholly within the field of area $(19.05 \times 24.80 \mathrm{~cm})$ and those with images intersected by the edges of the micrograph but with their centers lying within the boundaries were measured and counted. The actual void size was taken as the inner diameter of the dark contrast ring for small voids (approximately up to $80 \AA$ ), and as the outer diameter of the dark contrast ring for larger voids. For nonspherical voids the equivalent-area diameters were determined.

The true number of voids for each size class was calculated as follows:

$$
n_{i}^{t}=\frac{n_{i}}{1+\overline{d i / t}}
$$

where $n_{i}^{t}=$ true number of voids for $i$-th size class

$$
\begin{aligned}
n_{i} & =\text { observed number of voids for } i \text {-th size class } \\
\bar{d} i & =\text { interval center of } i \text {-th size class } \\
t & =\text { thickness of the specimen }
\end{aligned}
$$

The following equations were used to determine void parameters:

$$
\begin{gathered}
N v=\frac{\sum n_{i}^{t} M^{2}}{L w t} \\
\overline{d v}=\frac{\sum n_{i}^{t} \overline{d i}}{\sum n_{i}^{t}}
\end{gathered}
$$




$$
\begin{aligned}
& \bar{D} v=\left(\frac{\sum n_{i}^{t}(\bar{d} i)^{3}}{\sum n_{i}^{t}}\right)^{1 / 3} \\
& \frac{\Delta v}{v}=\frac{\pi}{6}(\bar{D} v)^{3} \cdot N v \\
& S=\left|\frac{\sum n_{i}^{t}(\bar{d} i-d v)^{2}}{\sum n_{i}^{t}}\right|^{1 / 2}
\end{aligned}
$$

where $N v=$ void number density

$$
M=\text { magnification of the micrograph }
$$

$L, W=$ length and width of the micrograph, respectively

$\bar{d} v=$ average void diameter

$\overline{D V}=$ diameter of the void with the average volume.

$\Delta V / V=$ void volume fraction

$S=$ standard deviation

\section{Results and Discussion}

The observed number of voids, $n_{i}$, represents the total number of voids in the $i$-th size class whose images lie wholly within the field of view including those sectioned at the surface of the foil, and those whose images are intersected by the edges of the micrograph but with the centers lying within the boundaries of the micrograph. Since $n_{j}$ contains the voids whose centers lie outside the specimen surface as well as inside, the true number of voids, $n_{i}^{t}$, is represented by relationship (1) in the previous section. The sizing and counting of surface voids do not introduce a significant source of error for the following reason: Although it should be realized that there is a possibility of preferential attack to the surface voids by the electrolyte during the tninning process, which could lead to enlarged void sizes (i.e. surface effect), the surface voids also suffer a truncation effect; that is, the diameters of the segments of the voids truncated by the specimen 
surface are generally smaller than the major diameters of the voids. Therefore, these two effects act in the opposite sense and cancel each other to some extent.

A histogram and a cumulative frequency-distribution curve are shown in Figure B.7-1. The histogram was generated by plotting the true number of voids against the interval centers, while the cumulative frequency-distribution curve was obtained by plotting the cumulative percentages against the upper interval limits. The void parameters were calculated using the relationships (2) through (6) and are given below. In general the number of small voids is underestimated because of an overlap effect and because of the reduced

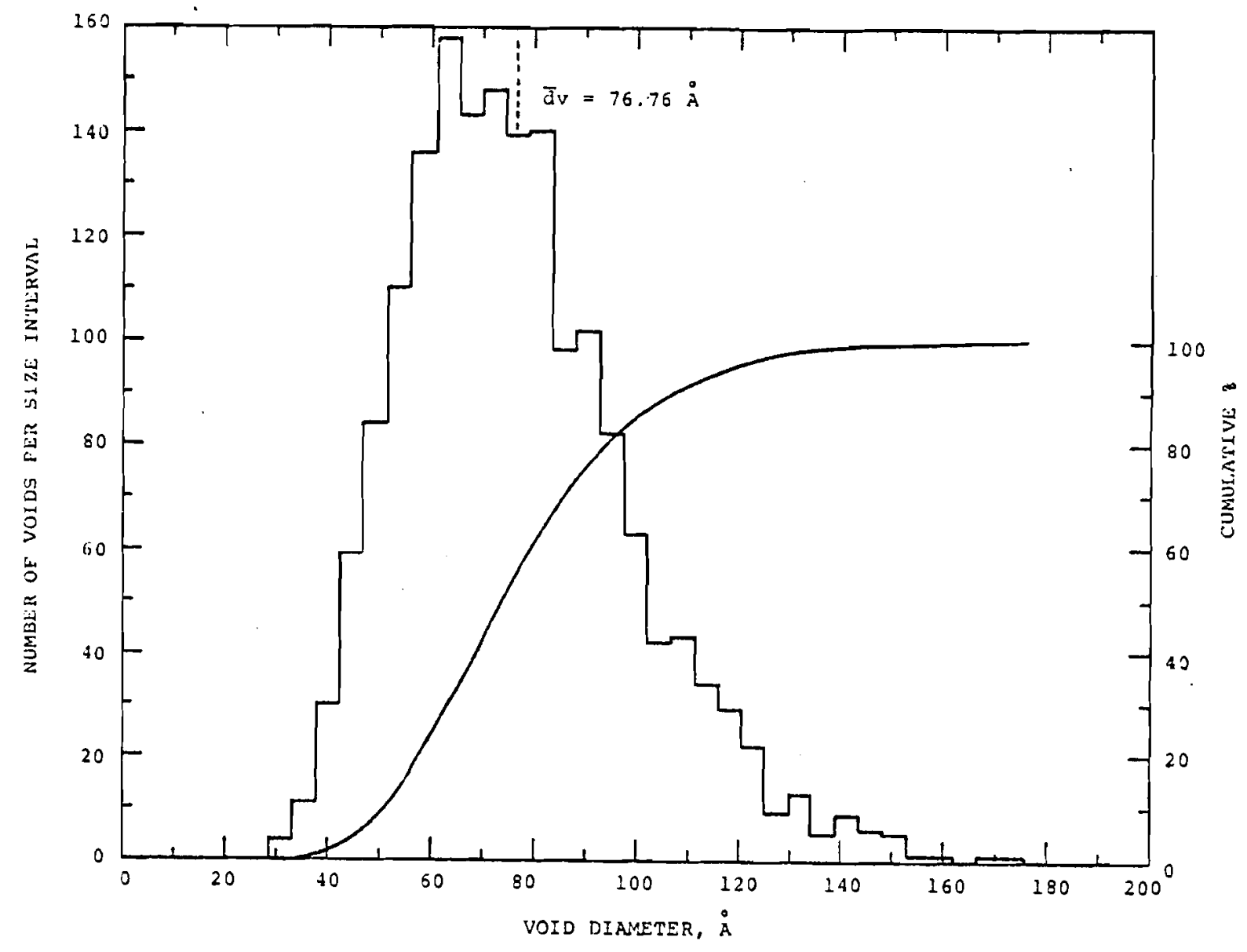

FIGURE B.7-1. Histogram and Cumulative Frequency-Distribution Curve for Void Sizes Measured on "Common Micrograph" 
sampling probability on the specimen surface (sampling effect). Although these effects are neglected in this study, it seems that these are contribution factors for the positively skewed void size distribution, as shown in the histogram in Figure B.7-l and the calculated skewness value $(=0.382)$.

\section{Void Parameters Obtained From Common Micrograph}

Void Number Density, $\mathrm{Nv}=5.57 \times 10^{16} \mathrm{voids} / \mathrm{cm}^{3}$

Mean Void Diameter, $\overline{d v}=76.76 \AA$

Diameter of the Void with the Average Volume, $\bar{D} v=83.18 \AA$

Void Volume Fraction, $\Delta V / V=1.678 \%$

Standard Deviation, $S=22.28 \AA$

Median Diameter $=73.92 \AA$

Skewness $=0.382$

Specimen Thickness, $t=1050 \AA$

Magnification, $M=400,000 X$ 


\section{B.8 UNIVERSITY OF WISCONSIN}

Measurements on duplicate copies of a common micrograph supplied by NRL were made using the techniques of counting and sizing voids that was previously described (see Appendix A.3). The foil thickness determined by NRL (1050 $\AA_{\text {) }}$ for this common micrograph was used to calculate the void volume fraction. The results of this experiment are shown below. The void size distribution is shown in Figure B.8-1.
Average void size
$84 \AA$
Void density
$5.86 \times 10^{16} \mathrm{voids} / \mathrm{cm}^{3}$
Void Volume Fraction
$2.2 \%$

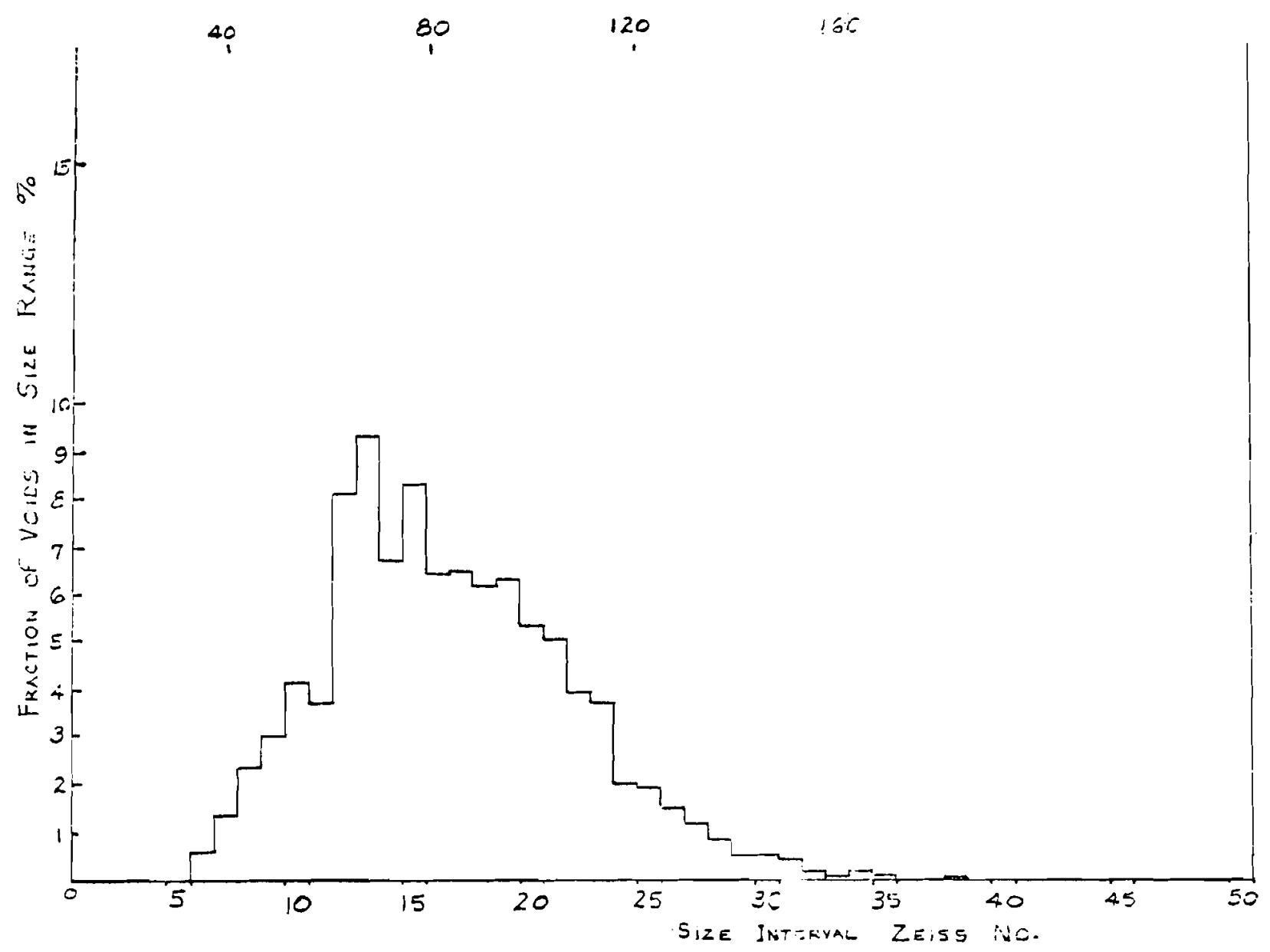

FIGURE B.8-1. Histogram of Void Size Distribution Measured on the "Common Micrograph" 


\section{APPENDIX C}

INTERLABORATORY COMPARISON OF ROUND ROBIN TEM FOIL

OF THE

BODY-CENTERED CUBIC ION CORRELATION PROGRAM 



\section{INTERLABORATORY COMPARISON OF ROUND ROBIN TEM FOIL \\ OF THE BODY-CENTERED CUBIC ION CORRELATION PROGRAM}

This appendix contains detailed description of the techniques and experimental results from Part 3 - Interlaboratory Comparison of Round Robin Tem Foil of the BCC-ICE program. Some editing of the material has been done but the content remains basically as supplied by the participants.

\section{C.1 ATOMICS INTERNATIONAL}

The data are presented in Table C.1-1, where they are categorized according to photographs taken of four different foil areas. Composite values are also given in the table; these should be used in comparison of our results with those obtained by other laboratories. A histogram showing the void size distribution is given in Figure C.1-1, along with a normal distribution fitted to the data.

Stereo analysis was used to determine the foil thickness; voids were used to establish the upper and lower surfaces of the foil. Counting and sizing of voids was done with a Zeiss particle-size analyzer operated in the reduced, 1 inear mode.

\section{IABLE C.1-1 Data for Mo "Round Robin" Tem Foil}

\begin{tabular}{|c|c|c|c|c|c|c|}
\hline $\begin{array}{l}\text { Photo } \\
\text { Plate } \\
\text { Number }\end{array}$ & $\begin{array}{c}\text { Foil } \\
\text { Thickness } \\
(\AA) \\
\end{array}$ & $\begin{array}{l}\text { Number } \\
\text { of Voids } \\
\text { Counted } \\
\end{array}$ & $\begin{array}{l}\text { Void } \\
\text { Density } \\
\left(\mathrm{cm}^{-3}\right)\end{array}$ & $\begin{array}{c}\text { Average } \\
\text { void Size } \\
(\AA) \\
\end{array}$ & $\begin{array}{l}\text { Void } \\
\text { Volume } \\
\text { Fraction (\%) }\end{array}$ & Swelling (\%) \\
\hline $2-414$ & 850 & 613 & $4.55 \times 10^{16}$ & 89 & 1.98 & 2.02 \\
\hline $4-414$ & 500 & 499 & $3.71 \times 10^{16}$ & 77 & 1.20 & 1.22 \\
\hline $6-414$ & 400 & 529 & $5.20 \times 10^{16}$ & 82 & 1.98 & 2.02 \\
\hline $12-414$ & 400 & 482 & $4.74 \times 10^{16}$ & 81 & 1.68 & 1.71 \\
\hline \multirow[t]{2}{*}{$\overline{\text { Composite }}$} & - & 2123 & $4.55 \times 10^{16}$ & 82 & 1.71 & 1.74 \\
\hline & & & $C-1$ & & & \\
\hline
\end{tabular}




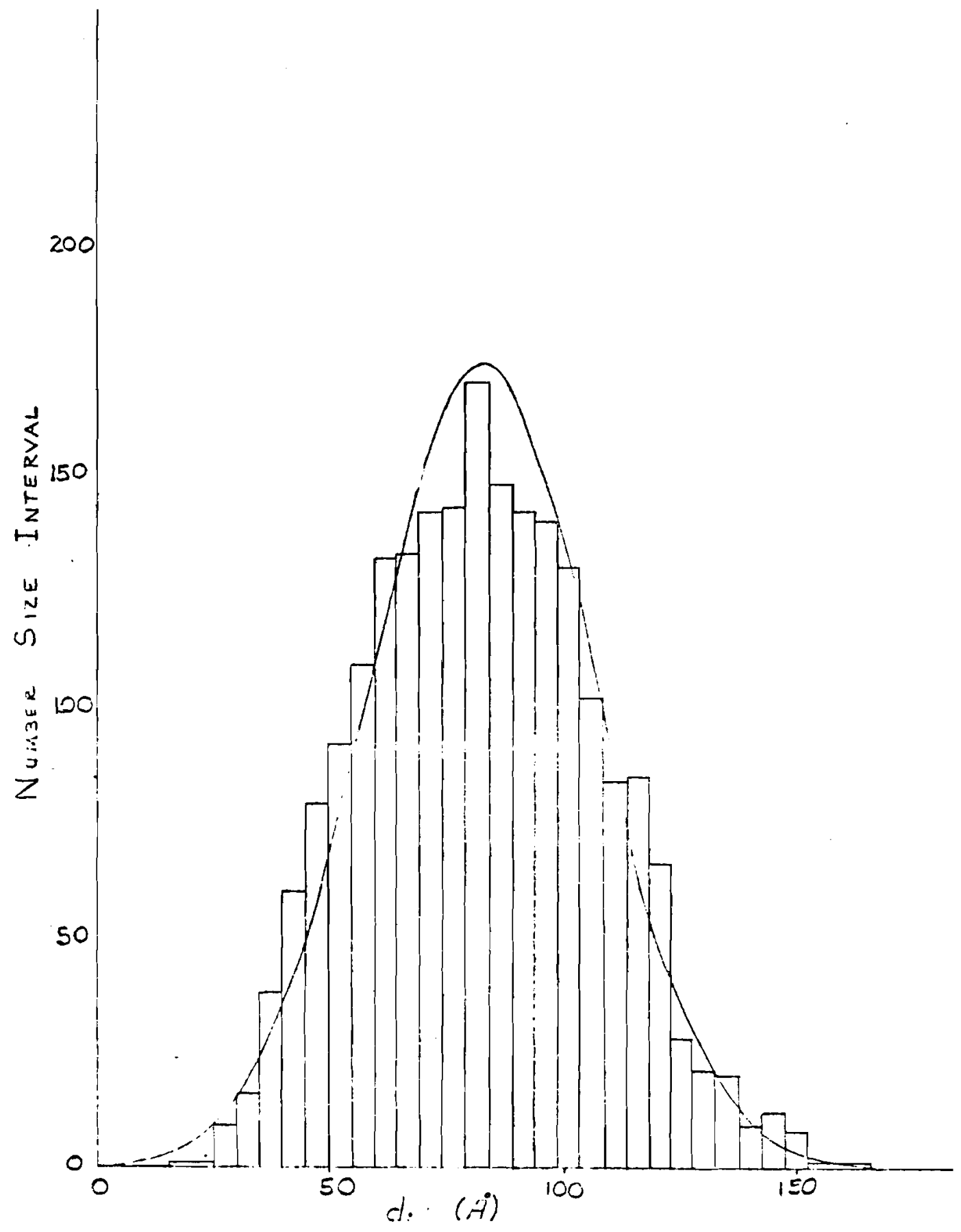

FIGURE C.j-1. Histogram of Void Size Distribution Measured on the TEM "round robin" Specimen. 


\section{C.2 ARGONNE NATIONAL LABORATORY}

Void parameters determined on "round robin" specimen:

$\begin{array}{ll}\text { Void size } & 64 \AA \\ \text { Void density } & 1.2 \times 10^{17} \\ \text { Void swelling } & 2.1 \%\end{array}$




\section{C.3 MASSACHUSETTS INSTITUTE OF TECHNOLOGY}

Procedures:

A. Electron Microscopy:

The sample was examined using a Phillips EM300 Electron Microscope with a tilting stage. An accelerating potential of $100 \mathrm{KV}$ was used. To maximize contrast, the incident beam was deviated slightly from the exact diffracting condition for (100) planes and a small degree of underfocus. Care was taken that the optical axis conincided with the tilt axis. This removes the necessity to account for a change in magnification during tilt. Credit for the electron microscopy is due to Professor J. Vander Sande.

\section{B. Void Counting:}

The void size distribution was measured with a Zeiss TGZ3 Particle Size Analyzer. Every visible void within a reduced area of the micrograph was counted, excluding only those whose centers were outside the field of view. The reduced-exponential-distribution mode was used for more accurate counting. The true diameter of the void was taken as equivalent to the outer portion of the dark contrast ring surrounding each void.

C. Thickness Determination:

The foil thickness at the location of interest was determined using the stereo parallax technique. When the sample is properly aligned, the neight difference between two voids lying on opposite surfaces is given by:

$$
\Delta h=P / 2 M \sin \gamma / 2
$$

$$
\text { where } \quad \begin{aligned}
\Delta n & =\text { height difference, } \\
M & =\text { magnification, } \\
P & =\text { measured parallax and } \\
Y & =\text { total tilt angle. }
\end{aligned}
$$

A large number of parallax measurements were made using a vernier caliper. For reasons explained in the discussion, a distribution in height was found. The true thickness was taken to be the tail of the distribution curve shown in Figure C.3-1. 


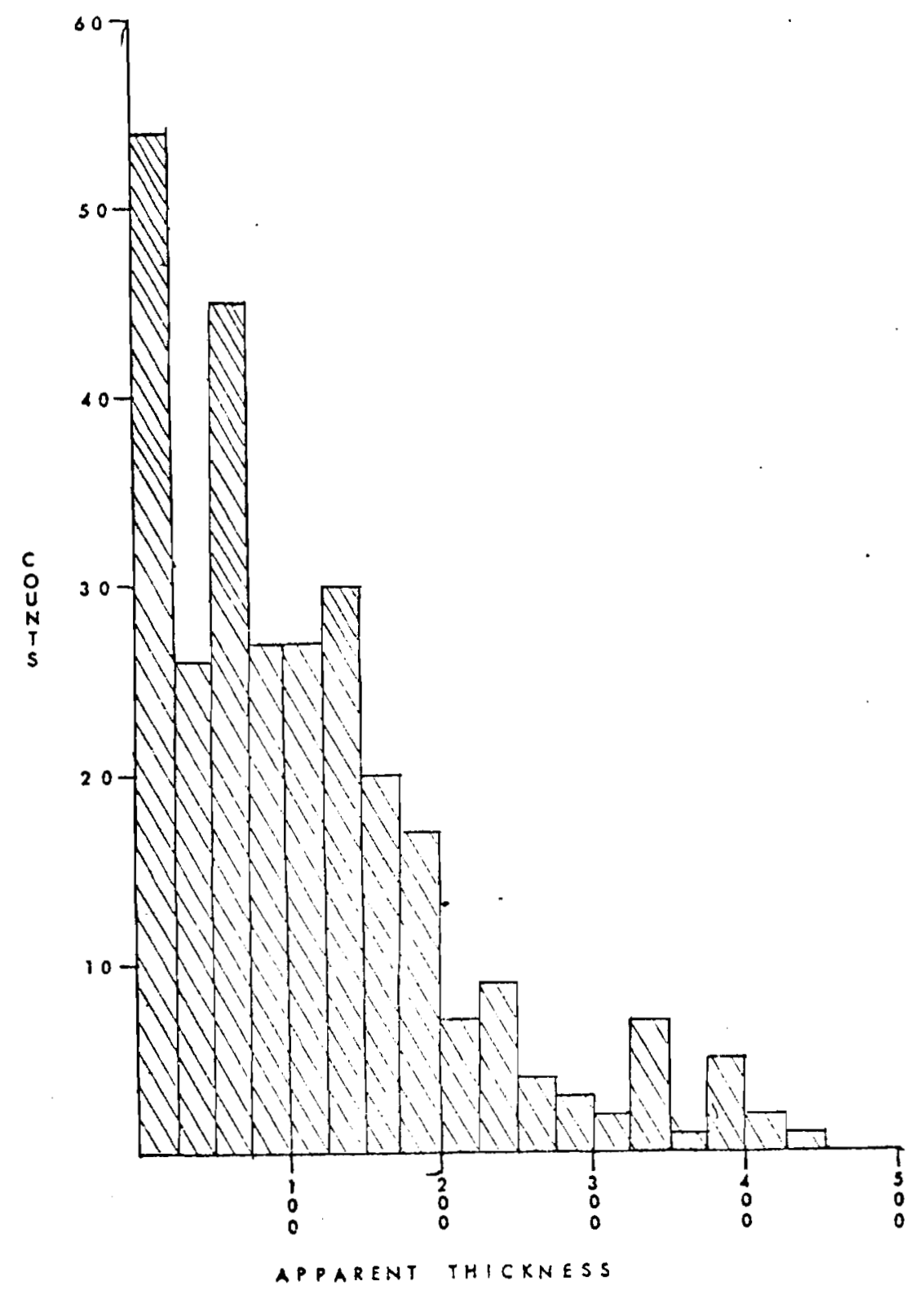

FIGURE C.3-1. Histogram of Distribution of the Measurements of Foil Thickress on the TEM "Round Robin" Specimen

D. Data Reduction and Analysis:

The raw data from the particle size analyzer were input to a Fortran Code which applied the appropriate correction factors, performed a statistical analysis and plotted the results using a Calcomp plotter. A correction accounting for the voids whose centers lie outside of the plane of the foil was used: 


$$
N_{i}^{C}=N_{i}^{0} /\left(1+I C_{i} / t\right)
$$

where $N_{i}^{C}=$ corrected number of voids for each size class,

$N_{i}^{0}=$ observed number of voids for each size class,

$I C_{i}=$ Interval Center for each size class,

and $t=$ foil thickness

\section{Discussion:}

A problem existed in determining the foil thickness as is evidenced by the distribution in Figure C.3-1. The spread in the distribution is due to two causes: 1) Difficulty in determining voids which were definitely on the surfaces--possibly due to the relatively large tilting angle of $15^{\circ}$, and 2) the dependence of the apparent height on the orientation of the void pair. It is obvious that if the projection of a line connecting the void pair is parallel to the tilt axis, the parallax will be greatly reduced. Another complication, both to this and to void counting was the disappearance of voids between the two elements of the stereo pair. A number of. voids weakly visible in one photograph, were not visible in the other. This was most probably due to a change in contrast as the specimen was tilted. The alternate technique of thickness determination utilizing thickness fringes was not applicable due to the presence of radiation damage as well as a large degree of bending evidenced by the presence of bend contours. The most appropriate solution to this problem was to take the thickness as the tail of this curve.

An error estimate was made by making duplicate measurements on one photograph to determine inaccuracies in measurement. This, coupled with an estimated inaccuracy in the tilt stage of $\pm 0.5^{\circ}$ leads to an estimate of the error in the thickness $\pm 15 \%$. This will also be the possible error in the calculated volume fraction. Within a $95 \%$ confidence level, the measured void distribution is within $9 \%$ of the true distribution.

There is definite evidence of the formation of a void superlattice. This has been observed by many investigators. As might be expected, the 
visibility of the void superlattice is highly dependent upon the orientation of the specimen. The void data are summarized below and the void size distribution plotted in Figure C.3-2.

$\begin{array}{lll}\text { Number of Voids } & = & 875.73 \\ \text { Average Diameter } & =71.41 \AA \\ \text { Average Area } & =0.49 E+04 \AA^{2} \\ \text { Average Volume } & =0.30 E+06 \AA^{3} \\ \text { Thickness } & =425.00 \AA \\ \text { Volume Fraction } & =0.029633 \\ \text { Voids/cc } & =0.10 E+18 \\ \text { Variance } & =668.56 \AA^{2} \\ \text { Standard Deviation } & =25.86 \AA \\ \text { Skewness } & =0.42 \\ \text { Kurtosis } & =3.08\end{array}$

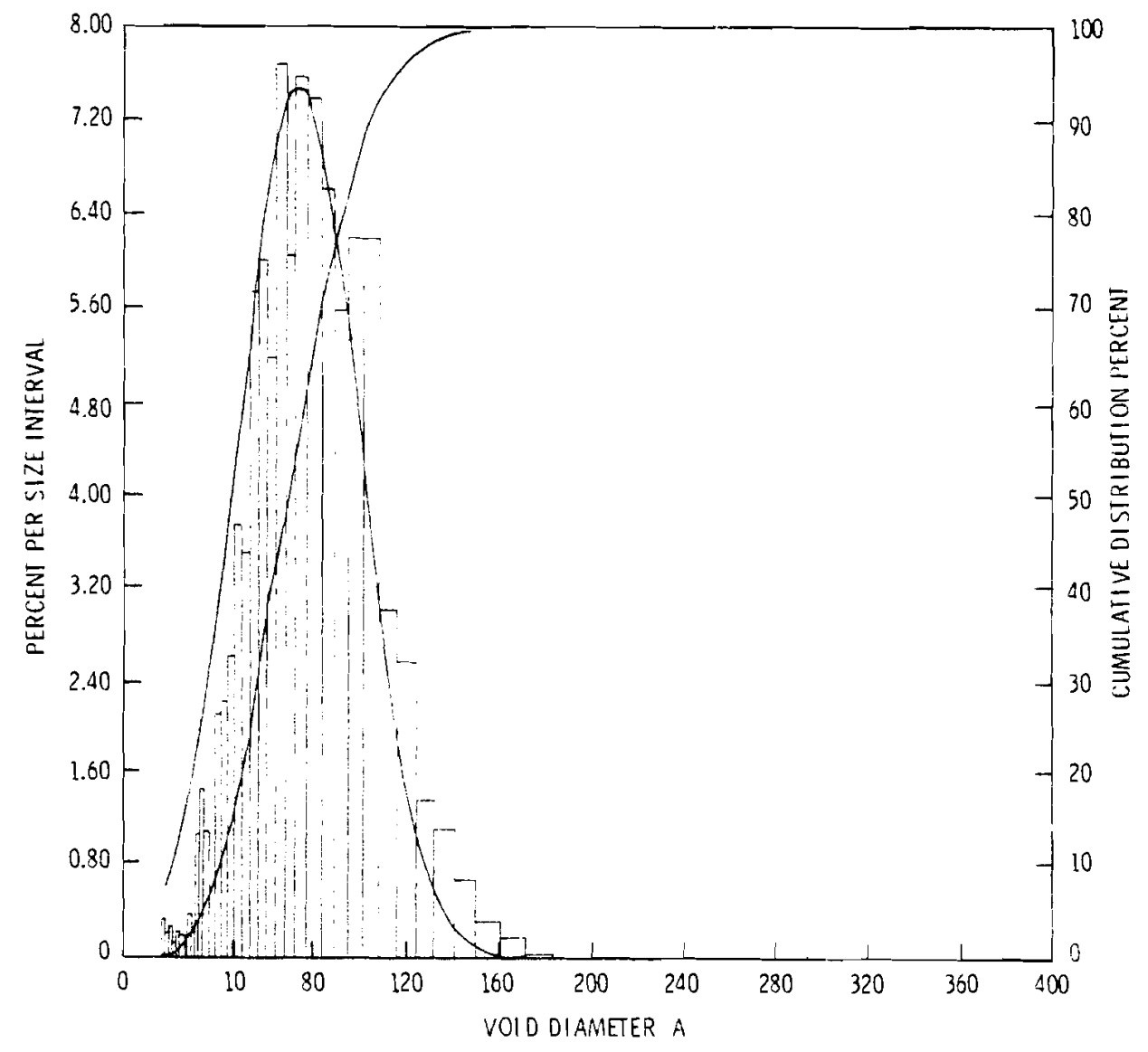

FIGURE C.3-2. Histogram of the Void Size Distribution Measured on the TEM "Round Robin" Specimen 


\section{C.4 NAVAL RESEARCH LABORATORY}

NRL supplied the "round robin" specimen. The contribution from NRL would be given in Appendix A.2 in the discussion of Part 1 of the overal1 Body-Centered Cubic Ion Correlation Program. 


\section{C.5 OAK RIDGE NATIONAL LABORATORY}

\section{"Round Robin" Specimen}

The thickness of the foil area used was determined by two independent methods. The area was imaged in dark-field at exact Bragg position using a 110-type reflection. An area at $4 \xi_{110}$ was selected. The value of $\xi_{110}$ used was $200 \AA$ (Bentley, 1974; Howie and Basinski, 1968). The second measurement was made from a bright-field stereo pair obtained using a 200 reflection. Dislocation image termination points were used to define the foil surfaces and the parallax was measured using a Hilger-Watts floating spot mirror stereoscope. The mean of many parallax measurements yielded a foil thickness of 824 A.

The voids were imaged using a $\overline{3} 30$ reflection near a 115 pole and from a through focus series a micrograph which was slightly overfocussed ( $28000 \AA$ ) was selected. The void diameter is measured to the inside of the bright Fresnel-like fringe.

Void size distributions were obtained using a calibrated Zeiss particle size analyzer for four areas and a total of 687 voids. The data were processed to yield the following parameters:

(1) Mean void size $\sum_{i} \eta_{i} d_{i} / \sum_{i} \eta_{i}=87.4 \AA$

Standard distribution $=2.0 \AA$

(2) Volume averaged mean void size $\underset{i}{\left(\sum_{i} d_{i}\right.} d_{i}^{3} / \sum_{i} \eta^{1 / 3}=96.4 \AA$

Standard deviation $=2.5 \AA$

(3) Void density $=6.04 \times 10^{16} \mathrm{~cm}^{-3}$

Standard deviation $=0.12 \times 10^{16} \mathrm{~cm}^{-3}$

(4) Void volume fraction $=2.83 \%$

Standard deviation $=0.15 \%$

* Standard deviation of the measurements 
The void lattice parameter was also determined. From measurements on micrographs at [100] beam direction, $a_{v}=375 \AA$. From measurements of the spacing of the extra spots on diffraction patterns caused by diffraction by the void lattice (Sass and Eyre, 1973) and using 110 matrix spots as a calibration, $a_{v}=378 \AA$.

\section{REFERENCES}

1. J. Bentley, Ph.D. Thesis, University of Birmingham, England (1974).

2. A. Howie and Z. S. Basinski, Phiz. Mag., 17: 1039, 1968.

3. S. L. Sass and B. L. Eyre, Phiz. Mag., 27: 1447, 1973. 


\section{C.6 PACIFIC NORTHWEST LABORATORY}

Foil thickness is determined by making parallax measurements from stereo pairs of electron micrographs using a Hilger-Watts floating spot stereoscope. The parallax measurements are converted to foil thickness by the relation:

$$
t=\frac{\Delta P}{2 M \sin \left(\frac{\Theta}{2}\right)}
$$

where $\quad t=$ the foil thickness,

$$
\Delta P=\text { the parallax, }
$$

$M=$ the magnification of the micrograph,

$\theta=$ the tilt angle between the stereo pairs.

The magnification and the tilt angle depend on the void size and void density in the specimen being examined. The magnification and tilt angles normally used range from 30 to $80 \mathrm{KX}$ and $13^{\circ}$ to $19^{\circ}$, respectively.

The procedure for obtaining the stereo pairs is as follows: First, the specimen is tilted to a positive value and the direction of tilt reversed sufficiently to remove any slop in the tilt stage. The electron transparent area is then examined to find a suitable region for the stereo pair. The criteria used for determining a suitable area include, 1) voids in good contrast, 2) the foil thickness appears uniform, 3) the number of voids in the region is sufficiently large to be statistically significant but not so large that excessive overlap occurs, and 4) a marker (i.e. ppt., etchpit, etc.) exists in the region such that the identical area can be located after tilting.

The parallax measurements are made, using the electron image negatives, on a Hilger-Watts floating spot stereoscope. An area is marked off on a photographic print of one of the stereo pairs and at least five parallax measurements are taken from this region with the average value taken as the foil thickness. The parallax measurements normally correspond to the separation between one of the foil surfaces and a void near the opposite surface. If a surface is not clearly resoluable, the maximum void to void separation is measured and the foil thickness is determined by adding one mean void diameter to the calculated void to void separation. 
The error associated with the foil thickness determinations is estimated to be less than $\pm 22 \%$. This value represents the maximum uncertainty due to the propagation of errors in the magnification (5\%), tilt angle (5\%), and parallax measurements $(10 \%)$.

The following void parameters were determined on the "round rob in" sfecimen:

$\begin{array}{ll}\text { Average void diameter } & 83.9 \AA \\ \text { Volume average void diameter } & 92.2 \AA \\ \text { Standard deviation } & 24.9 \AA \\ \text { Skewness } & 0.25 \\ \text { Total voids measured } & 1167 \\ \text { Average void density } & 6.35 \times 10^{16} \text { voids } / \mathrm{cm}^{3} \\ \text { Void volume fraction } \Delta V / V & 2.62 \% \\ \text { Void swelling } \Delta V / V o & 2.67 \% \\ \text { Void lattice parameter } & 365 \AA\end{array}$




\section{C.7 UNIVERSITY OF CINCINNATI}

\section{Experimental Procedure}

The round robin specimen supplied by NRL was examined in a JEM 200A transmission electron microscope equipped with $30^{\circ}$ tilt $-360^{\circ}$ azimuth goniometer stage, operated at $200 \mathrm{kV}$. The goniometer had been calibrated for tilting angle against the Kikuchi line shifts. Also the tilt axis of the goniometer was known fairly accurately.

Stereo-pictures of the voids were taken at different areas of the specimen with a tilting angle of $10^{\circ}$ at a magnification of $50,000 \%$. The pictures were taken with the voids imaged both in underfocused and overfocused conditons. Diffraction patterns of the specimen before and after the tilting were also obtained for a Kikuchi line analysis. The pictures were enlarged by three times; i.e., the magnification of the micrographs is $150,000 \mathrm{X}$, and the void size and density were determined by using a TGZ 3 Zeiss Particle Size Analyzer as described in the previous report.

The thickness of the specimen was calculated using the relationship:

$$
t=\frac{P}{2 M \sin \theta}
$$

where $\quad t=$ specimen thickness

$P=$ parallax

$M=$ magnification

$\theta=$ one half of the total tilting angle

The parallax, $P$, was measured at several different areas of the micrograph by using a mirror stereoscope (stereo-viewer) equipped with a micrometer head and floating mark units. The voids which appeared to be on or near the surfaces of the specimen were chosen as reference points in measuring the parallax, and the average value of the measurements obtained from several different areas of the micrograph was used to calculate the specimen thickness in the region from which the micrograph was obtained. 
The tilting angle was determined primarily by the goniometer readings, and subsequently by indexing the Kikuchi patterns before and after the tilting and thus calculating the angle between the two zone axes.

\section{Results and Discussion}

The true number of voids was calculated using the following relationship, described previously (see appendix B.7)

$$
N_{i}^{t}=\frac{N_{i}}{1+\bar{d}_{i} / t}
$$

where $\quad N_{i}^{t}=$ true number of voids for $i$-th size class.

$N_{i}=$ observed number of voids for $i$-th size class.

$\bar{d}_{i}=$ interval center of $i$-th size class.

$t=$ thickness of the specimen.

The above correction is necessary because the image of the sectioned voids with their centers outside the specimen surface lies within the field of view. As can be seen in Equation (2), the correction is significant especially for a large void size and/or a thin specimen. For a void size of $100 \AA$ and a specimen thickness of $500 \AA$, for example, the correction will make a difference of $\sim 20 \%$ in the void number density.

The histogram and the cumulative frequency-distribution curve of the corrected void data are shown in Figure C.7-1. The void parameters calculated using both the corrected and uncorrected data are presented in Table C.7-1. However, it should be noted that the void number density varies noticeably from one area of the specimen to another, and this could effect the results significantly, especially when the void pictures are taken at a high magnification. Moreover, one tends to take a picture from an area where the void population is dense, and this, too, can effect the results significantly: in this case the results represent higher-than-true average values. 


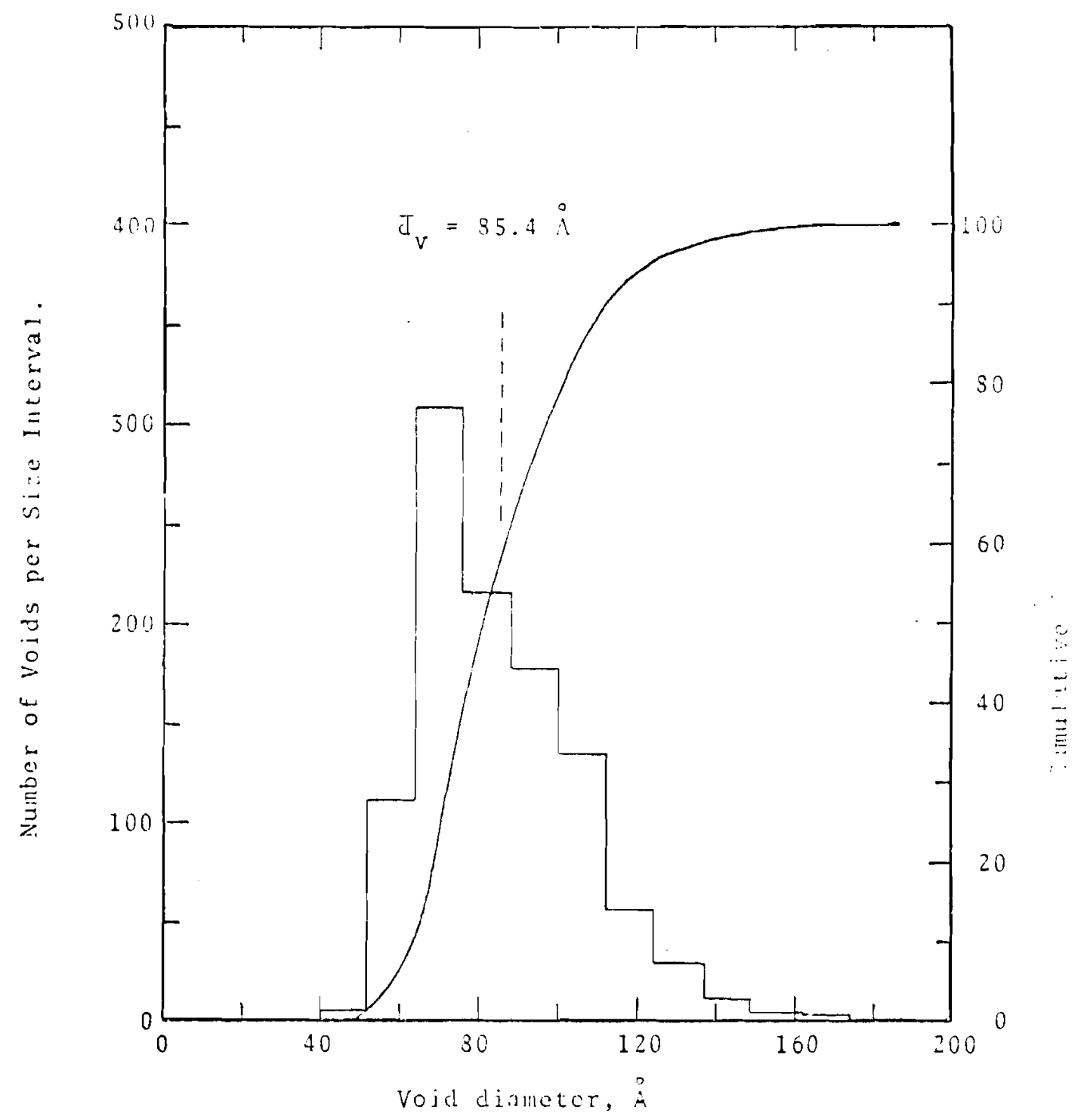

FIGURE C.7-1. Histogram and Cumulative Frequency-Distribution Curve of the Void Data Obtained from the NRL "Round Robin" Mo Specimen

In genera1, most of the uncertainty is in the determination of tilting angle, when stereomicroscopy is used for determining the void parameters. If one allows $0.5^{\circ}$ uncertainty in a goniometer tilting stage and $0.2^{\circ}$ in Kikuchi pattern analyses, the tilting angle determined in this study is consistent with each other: $10^{\circ}$ vs. $10.6^{\circ}$. Also, if the tilt axis is not perpendicular to the optical axis, the goniometer reading will be always larger than the true tilting angle, and again this is not the case in this study. 
TABLE C.7-1. Void Parameters Obtained from NRL Round Robin Sample

Void Nuntber Density, $\mathrm{N}_{v}, V_{0}$ oids $/ \mathrm{cm}^{3}$

Mean Void Diameter, $\ddot{d}_{v}, \AA$

$P \quad$ Diameter of the Void with Average Volume, $\overline{0}_{v}, \AA$

Void volume Fraction, $\Lambda V / V$.

Standard Deviation, $S, \AA$

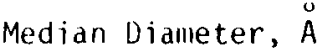

Skewness

Specimen Thickness, $t, \AA$

Magnification, M

Void Image Condition

No. of Voids Counted
Sample Area \#l

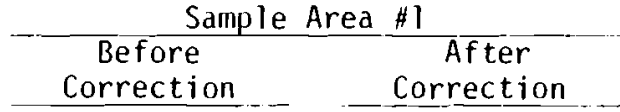

$\begin{array}{ll}4.4 \times 10^{16} \# / \mathrm{cm}^{3} & 3.8 \times 10^{16} \mathrm{H}^{3} \mathrm{~cm}^{3} \\ 86.1 \AA & 85.4 \AA \\ 91.2 \AA & 90.6 \AA \\ 1.75 \% & 1.48 \% \\ 21.0 \AA & 20.8 \AA \\ 82.3 \AA & 81.6 \AA \\ 0.54 & 0.55 \\ 615 \AA & 615 \AA \\ 150,000 \times & 150,000 \times \\ \text { Under } & \text { Under } \\ 1180 & 1030\end{array}$

Sample Area \#2

Before
Correction

$4.6 \times 10^{16} \# / \mathrm{cm}^{3}$

$84.0 \AA$

$89.6 \AA$

$1.73 \%$

$22.0 \AA$

81.4

0.35

$415 \AA$

$150,000 \times$

Over

1300

After
Correction

$3.8 \times 10^{16} \# / \mathrm{cm}^{3}$ $83.0 \AA$

$88.5 \AA$

$1.38 \AA$

$21.8 \AA$

$80.2 \AA$

0.39

$415 \AA$

$150,000 \times$

Over

1080 


\section{8 UNIVERSITY OF WISCONSIN}

The same procedure of microscopy analysis and void size measurement as described previously (see Appendix A.3) was applied to examine this specimen at the University of Wisconsin. The results are shown below.

$\begin{array}{ll}\text { Average void size } & 85 \pm 4 \AA \\ \text { Void density } & 6.4 \pm 1.6 \times 10^{16} \text { voids } / \mathrm{cm}^{3} \\ \text { Void volume fraction } & 2.6 \pm 0.5 \%\end{array}$





\section{OFFSITE}

A. A. Churn

ERDA Chicago Patent Group

9800 S. Cass Avenue

Argonne, IL 60439

J. W. Beal

EROA Division of Magnetic

Fusion Energy

Washington, DC 20545

S. 0. Dean

ERDA Division of Magnetic

Fusion Energy

Washington, DC 20545

E. E. Kintner

ERDA Oivision of Magnetic Fusion Energy

Washington, DC 20545

J. M. Nitiliams

ERDA Division of Magnetic Fusion Enercy

Washington, DC 20545

R. Kostoff

ERDA Division of Magnetic

Fusion Energy

washington, DC 20545

J. N. Grace

ERDA Division of Magnetic Fusion Energy

Washington, DC 20545

J. Baublitz

ERDA Division of Magnetic Fusion Energy

Washington, DC 20545

3 F. E. Coffman

EROA Division of Magnetic Fusion Energy

Washington, DC 20545

J. F. Decker

ERDA Division of Magnetic Fusion Energy

Washington, DC 20545

3 K. M. Zwilsky

EROA Division of Magnetic

Fusion Energy

washington, DC 20545

Dr. Pnilip M. Stone

ERDA Applied Plasma Physics

Program

Nashington, OC 20545

G. W. Kuswa

ERDA Division of Laser

Fusion

Washington, DC 20545
6 E. Braunschweig

EROA Division of Laser Fusion

Washington, DC 20545

R. Blaunstein

ERDA Division of Biomedical and Environmental Research

Washington, DC 20545

H. M. Busey

ERDA Divison of MiTitary

Application

Washington, DC 20545

M. A. Bell

ERDA Division of Safety

Standards and Compliance

washington, DC 20325

27 EROA Technical Information Center

M. S. Kaminsky

Argonne Nationa?

Laboratory

9700 S. Cass Avenue

Argonne, IL 60439

V. A. Maroni

Argonne National

Laboratory

9700 S. Cass Avenue

Argonne, IL 60439

P. M. Persiani

Argonne National

Laboratory

9700 S. Cass Avenue

Argonne, IL 60439

M. Petrick

Engineering and Technology Division

Argonne Nationa Laboratory

9700 S. Cass Avenue

Argonne, IL 60439

W. E. Parkins, Manager

Atomics Internationa?

Component Engineering and Technolocy Division

North American Rockwel

P.0. Box 309

Canoga Park, CA 91304

D. Gurinsky

Brookhaven National

Laboratory

ERDA Brookhaven Area Office

Upton, NY 11973

H. J. Kouts

Brookhaven Nationa?

Laboratory

ERDA Brookhaven Area Office

Upton, NY 71973
S. Pearistein

Brookhaven National

Laboratory

ERDA Brookhaven Area uffice

Upton, NY Tig73

J. R. Powell

Brookhaven National

Laboratory

ERDA Brookhaven Area

Office

Upton, NY 11973

A. J. Impink, Jr

Carnegie Mellon University

Pittsburgh, PA 15213

R. A. Gross

Plasma Research Laboratory

236 SW Mudd $81 \mathrm{dg}$.

Columbia University

New York, NY 10027

W. C. Gough

Electric Power Research Institute

3412 Hillview Ave.

Palo Alto, CA 94304

G. R. Hopkins

Gulf General Atomic

P.0. Box 1111

San Diego, CA 92112

Zeinab Sabri

Iowa State University

26] Sweeney Hal1

Vuclear Engineering

Department

Ames, IA 50010

R. Borg

Lawrence Livermore

Laboratory

P.0. Box 808

Livermore, CA 94550

T. K. Fow ter

Lawrence Livermore

Laboratory

P.0. Box 808

Livermore, CA 94550

R. Moir

Lawrence Liverimore

Laboratory

P.0. Box 808

Livermore, CA 94550

A. Carl Haussman

Lawrence Livermore

Laboratory

P. $0.80 \times 808$

Livermore, CA 94550 
J. Hovingh

Lawrence Livermore

Laboratory

P.0. Box 808

Livermore, CA 94550

R. F. Post

Lawrence Livermore

Laboratory

P.O. Box 808

Livermore, CA 94550

C. J. Taylor

Lawrence Livermore

Laboratory

P.O. Box 808

Livermore, CA 94550

J. Maniscalco

Lawrence Livermore

Laboratory

P.0. Box 808

Livermore, CA 94550

W. Meier

Lawrence Livermore

Laboratory

P.0. Box 808

Livermore, CA 94550

R. Werner

Oak Ridge Nationa 7

Laboratory

P.0. Box X

Oak Ridge, TN 37830

L. L. Wood

Lawrence Livermore

Laboratory

P.0. Box 808

Livermore, CA 94550

W. Bauer

Division Supervisor of Physical Research

Sandia Labs Livermore

Livermore, CA 94550

L. Booth

Los Alamos Scientific

Laboratory

CTN Research

P.0. Box 1663

Los Alamos, NM 87544

D. J. Dudziak

Los Alamos Scientific

Laboratory

CTN Research

P.0. Box 1663

Los Alamos, NM 87544

D. B. Henderson

Los Alamos Scientific Laboratory

CTN Research

P.0. Box 1663

Los Alamos, NM 87544
E. L. Kemp

Los Alamos Scientific Laboratory

CTN Research

P.O. Box 1663

Los Alamos, NM 87544

F. L. Ribe

Los Alamos Scientific Laboratory

CTN Research

P.O. Box 1663

Los Alamos, NM 87544

L. Stewart

Los Alamos Scientific Laboratory

CTN Research

P.0. Box 1663

Los Alamos, NM 87544

K. Thomassen

Los Alamos Scientific Laboratory

CTN Research

P.0. Box 1663

Los Alamos, NM 87544

0. K. Harling

Massachusetts Institute

of Technology

Cambridge, MA 02139

Bruno Coppi

Department of Physics

Massachusetts Institute of Technology

Cambridge, MA 02139

L. Lidsky

Department of Nuclear Engineering

Massachusetts Institute of Technology

Cambridge, MA 02139

N. Rasinussen

Department of Nuclear Engineering

Massachusetts Institute of Technology

Cambridge, MA 02139

David Rose

Massachusetts institute of Technology

Cambridge, MA 02139

R. E. Stickney

Mechanical Engineering

Massachusetts Institute of Technology

Cambridge, MA 02139

J. J. Reinmann

NASA - Lewis Research Center

2100 Bookpark Rd.

$\mathrm{Clevel}$ and, $\mathrm{OH} \quad 44135$
Vincent Arp

National Bureau of Standards

Cryogenics Division

Boulder, CO 80302

J. F. Clarke

Oak Ridge National

Laboratory

P.0. Box $Y$

Oak Ridge, TN 37830

A. P. Fraas

Oak Ridge National

Laboratory

P.0. Box Y

Oak Ridge, TN 37830

J. Rand McNally, Jr.

Oak Ridge National

Laboratory

P.0. Box $y$

Oak Ridge, TN 37830

D. Steiner

Oak Ridge National

Laboratory

P.0. Box $Y$

Dak Ridge, TN 37830

J. Scott

Oak Ridge National

Laboratory

P.0. Box X

Dak Ridge, TN 37830

J. Banford

Physics International

2700 Merced St.

San Leandro, CA 94577

R. A. Huse

Public Service Electric

and Gas Compant

80 Park Place

Newark, NJ 07101

M. Gottlieb

Princeton University, PPPL

P.0. Box 457

Princeton, NJ 08540

R. G. Mills

Princeton University

P. 0. Box 451

Princeton, NJ 08540

E. C. Tanner

Princeton Univeristy

P.0. 30x 451

Princeton, NJ 08540

H. Perkins

Department of Chemistry

Princeton University

Princeton, NJ 06540 
R. E. Gold

303 Sayre $\mathrm{Ha} 11$

Forrestal Campus

P.0. Box 451

Princeton, NJ 06540

M. Kristiansen

Texas Tech. University

Lubbock, TX 79409

A. F. Haught

United Aircraft Research

Laboratory

United Aircraft Corporation

East Hartford, CT 06108

L. Levine

U.S. Naval Research

Laboratory

Washington, DC 20390

C. Z. Serpan, Jr.

U.S. Naval Research

Laboratory

Washington, DC 20390

Francis Chen

University of California

Electronics Research

Laboratory

College of Engineering

Berkeley, CA 94720

A. J. Lichtenberg

University of California

Electronics Research

Laboratory

College of Engineering

Berkeley, CA 94720

Dave Okrent

U.C.L.A.

Los Angeles, CA 90024

C. D. Hendricks

University of Illinois

Nuclear Engineering

Laboratory

Urbana, IL 61801

G. H. Miley

University of Illinois

Nuclear Engineering Laboratory

Urbana, IL 61801

Terry Kammash

University of Michigan

Nuclear Engineering

Department

Ann Arbor, MI 48105

Dean Abrahamson

University of Minnesota

School of Public Affairs

Social Science

Building/309

Minneapolis, MN 55455
W. G. Davey

University of Texas

Department of Physics

Austin, TX 78712

E. Linn Draper, Jr.

University of Texas

Department of Physics

Austin, TX 78712

W. E. Drummond

University of Texas

Department of Physics

Austin, TX 78712

Abraham Hertzberg

University of Washington

Aerospace Research

Laboratory

316 Guggenheim

Seattle, WA 98105

A. L. Babb

University of Washington

Nuclear Enoineering

Department

Seattle, WA 98105

R. Conn

University of Wisconsin

Nuclear Engineering

Department

Madison, WI 53706

G. L. Kulcinski

University of Wisconsin

Nuclear Engineering

Department

Madison, WI 53706

C. W. Maynard

University of Wisconsin

Nuclear Engineering

Department

Madison, WI 53706

D. Lichtman

Department of Physics

University of Wisconsin

Milwaukee, WI 53201

E. E. Donaidson

Washington State University

Department of Physics

Pullman, WA 99163

D. D. Mahlum

Division of Biomedical and Environmental Research Washington, DC 20545

J. V. Vanston

Engineering Science Building

University of Texas

Austin, $T X 78712$
S. Nichols

Engineering Science

Building

University of Texas

Austin, TX 78712

Leslie S. Ramsey

450 North 5 th Street

Indiana, PA 15701

E. Beckner

Sandia Laboratories

P.0. Box 5800

A1buquerque, NM 87115

J. Clayton

kMS Fusion, Inc.

P.0. Box 1567

Ann Arbor, MI 48106

A. Taylor

Argonne National

Laboratory

Argonne, IL 60939

F. W. Wiffen

Oak Ridge National Laboratory

Oak Ridģe, TN 37830

J. Bentley

Oak Ridge National

Laboratory

Oak Ridge, TN 37830

J. Moteff

University of Cincinnati

Cinncinnati, $\mathrm{OH} 4522$

David Kramer

Atomics International

8900 DeSoto Ave.

Canoga Park, CA 91304

D. W. Keefer

$E C$ and $G$

Idaho Falls, ID 83401

F. 'N. Smidt

Naval Research

Laboratory

washington, DC 20390

K. C. Russeil

Massachusetts Institute of Technology

Cambridge, MA 02139

Peter Wilkes

University of Wisconsin Madison, WI 53706

A. L. Bement

Massachusetts Institute of Technology

Cambridge, MA 02139 
ONSITE

ERDA Richland Operations Office

W. A. Burns

Hanford Eng ineering

Development Labs

D. G. Doran

H. H. Yoshkawa

Battelle-Northwest

D. T. Aase

G. S. Allison

T. W. Ambrose

D. G. Atteridge

D. A. Baker

J. L. Bates

M. A. Bayne

E. R. Bradley

10 J. L. Brimhall

R. L. Brodzinski

R. J. Brouns

L. R. Bunnel1

L. L. Burger

S. H. Bush

N. E. Carter

T. D. Chikalla

R. G. Clark

T. L. Criswel1

S. D. Dahigren

M. T. Dana

D. E. Deonigi

R. L. Dillon
D. A. Dingee

P. J. Dionne

B. H. Duane

$R$. L. Engel

J. W. Finnigan

J. C. Fox

J. J. Fuguay

J. E. Garnier

R. D. Gastil

B. F. Gore

J. N. Hartley

A. J. Haverfield

U. P. Jenquin

A. B. Johnson, Jr.

$R$. H. Jones

T. J. Kabele

W. S. Kelly

H. E. Kissinger

D. A. Kottwitz

N. Laegried

B. R. Leonard, Jr.

D. L. Lessor

H. B. Liemohn

R. C. Liikala

M. A. Mckinnon

$R$. F. Maness

R. P. Marshall

E. S. Murphy

R. D. Nelson

D. F. Newman

R. E. Nightingale

D. E. Olesen

L. T. Pederson

R. T. Perry

D. R. Pratt
L. A. Rancitelli

J. F. Remark

D. S. Renné

R. E. Rhoads

W. O. Richmond

W. F. Sandusky

L. C. Schmid

N. M. Sherer

E. P. Simonen

R. I. Smith

J. K. Soldat

C. W. Stewart

K. B. Stewart

R. W. Stewart

J. A. Strand

D. L. Styris

A. M. Sutey

V. L. Teofilo

G. L. Tingey

M. T. Thomas

R. C. Thompson

L. H. Toburen

T. J. Trapp

R. Wang

R. E. Westerman

L. D. Williams

J. R. Young

M. G. Zimmerman

Technical Publications (BH)

5 Technical Information

10 Economics Library 